\title{
ANALYTICAL MASTER PLAN FOR THE ANALYSIS OF THE DATA FROM THE ELECTRIC UTILITY RATE DEMONSTRATION PROJECTS
}

Volume I

Prepared for

U.S. Department of Energy

Office of Utility Systems

June 1978 


\section{DISCLAIMER}

This report was prepared as an account of work sponsored by an agency of the United States Government. Neither the United States Government nor any agency Thereof, nor any of their employees, makes any warranty, express or implied, or assumes any legal liability or responsibility for the accuracy, completeness, or usefulness of any information, apparatus, product, or process disclosed, or represents that its use would not infringe privately owned rights. Reference herein to any specific commercial product, process, or service by trade name, trademark, manufacturer, or otherwise does not necessarily constitute or imply its endorsement, recommendation, or favoring by the United States Government or any agency thereof. The views and opinions of authors expressed herein do not necessarily state or reflect those of the United States Government or any agency thereof. 


\section{DISCLAIMER}

Portions of this document may be illegible in electronic image products. Images are produced from the best available original document. 


$$
\text { ACO1-77RG08684 }
$$

\title{
Analytical Master Plan for the Analysis of the Data from the Electric Utility Rate Demonstration Projects
}

\author{
Volume I
}

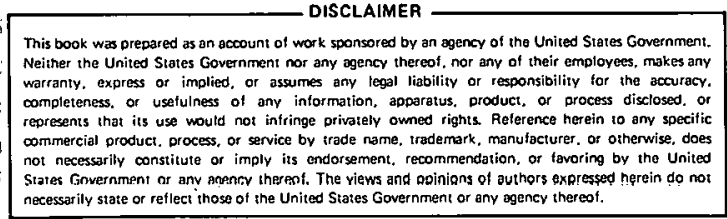

Prepared for

U.S. Department of Energy

Office of Utility Systems 
THIS PAGE

\section{WAS INTENTIONALLY LEFT BLANK}




\section{ACKNOWLEDGMENTS}

This report was prepared by the Research Triangle Institute (RTI), Research Triangle Park, North Carolina, pursuant to Contract No. CR-0480220-00 with the U.S. Department of Energy (DOE). The statements, findings, conclusions, and recommendations presented in this report do not necessarily reflect the views of the Department of Energy.

This report was prepared under the direction of Allen K. Miedema, Manager of the Institute's Economics Department. Other staff members who assisted in the preparation of this report included: Tayler H. Bingham, Christopher Burns, Andrew Clayton, Jerome A. 01 son, Steve Williams, and S. B. White.

In addition, consulting support was provided by Wallace E. Hendricks, University of Illinois, Daniel H. Hill, University of Michigan, Adrienne MCElwain, Duke University, and A. Ronald Gallant, North Carolina State University:

In the preparation of this report the authors were aided by participants of a working conference held at RTI on January 16-17, 1978. Our appreciation is extended to several outside participants in that conference: Jan Acton, Steve Braithwait, Brian Joiner, Roger Koenker, Michael Proctor, and Michael Sherman.

Finally, Steven Mintz (DOE project officer), Craig Johnson, Scott Atkinson, and David Hatcher of DOE provided valuable support and suggestions for which we also extend our appreciation. 


\section{THIS PAGE \\ WAS INTENTIONALLY \\ LEFT BLANK}




\section{TABLE OF CONTENTS}

Volume I

Chapter

Page

1 INTRODUCTION AND SUMMARY ........................... 1

1.1 Background .................. 1

1.2 Objectives .................... 2

1.3 Summary .................. 2

2 ANALYTICAL APPROACH .................. 5

2.1 Analytical objectives............. 5

2.2 Analytical Techniques............. 6

2.2.1 Descriptive Analyses.......... 7

2.2.2 Comparative Analyses.......... 12

2.2.3 Response Surface Analyses .......... 16

2.2.3.1 Standard Taylor's Series Approach . . 19

2.2.3.2 Neoclassical Demand Approaches . . 37

2.3 Analytical Problems .............. 42

2.3.1 Population Inference Problems ........ 42

2.3.2 Data Limitations............. 48

2.3.3 Experimental Design Constraints . . . . . 52

3 PROJECT-SPECIFIC ANALYSIS PLANS . . . . . . . . 57

3.1 Summary and Introduction ............ . . 57

3.1.1 Summary ................ 57

3.1.2 Introduction ............ 63

3.1.2.1 Overview of Specific Projects . . . 63

3.1.2.2 Format of Individual Project

Summaries ......... 72

3.2 Arizona ..................... 72

3.2.1 Description .............. . . 72

3.2.2 Proposed Analysis ........... . . 73

3.3 Arkansas ....................... 75

3.3.1 Description ............ . . 75

3.3.2 Proposed Analysis ............ 76

3.4 California .................... 78

3.4.1 Description ............... 78

3.4.1.1 Southern California Edison (SCE) . . 78

3.4.1.2 San Diego Gas and Electric (SDG\&E) . 81

3.4.2 Proposed Analysis ............ 82

3.4.2.1 Southern California Edison (SCE) . . 82

3.4.2.2 San Diego Gas and Electric (SDG\&E) - 83

3.5 Connecticut ............... 83

3.5.1 Description ............ 83

3.5.2 Proposed Analysis .......... 85

3.6 Los Angeles . . . . . . . . . . . . 85

3.6.1 Description .............. 85

3.6.2 Proposed Analysis ............ 87 
TABLE OF CONTENTS (Continued)

Chapter $\quad$ Page

3.7 New Jersey ................. . . 89

3.7.1 Description ................ 89

3.7.2 Proposed Analysis............ 90

3.8 North Carolina............... . . 92

3.8.1 Description .............. 92

3.8.2 Proposed Analysis ............. 93

3.9 Ohio..................... . . . . 95

3.9.1 Description ............... 95

3.9.2 Proposed Analysis............ . . 96

3.10 Oklahoma . . . . . . . . . . . . . 96

J.10.1 Description .............. . . 96

3.10.2 Proposed Analysis . . . . . . . . . . 97

3.11 Puerto Rico ................... . . 99

3.11.1 Description ................ 99

3.11.2 Proposed Analysis ............ 100

3.12 Rhode Island . . . . . . . . . . . . . 100

3.12.1 Description .............. 100

3.12.2 : Proposed Analysis . . ......... 102

3.13 Washington ................. 102

3.13.1 Description .............. 102

3.13.2 Proposed Analysis . . . . . . . . . . 103

3.14 Wisconsin . . . . . . . . . . . . . . 104

3.14.1 Description ............... 104

3.14.2 Proposed Analysis ............ 105

3.15 Michigan, New York, and Vermont .......... 106

3.15.1 Description .............. 106

3.15.2 Prnpọsed Analysis . . . . . . . . . 108

4 PŔOJECT-POOLED ANALYSIS PLANS . . . . . . . . . . 109

5 ORGANIZATION AND MANAGEMENT PLANS . . . . . . . . . 115

5.1 Project Management ................. 115

5.2 Data Handling Procedures ............. 117

5.3 Project Schedule and Budget . . . . . . . . . 119

BIBLIOGRAPHY . . . . . . . . . . . . 125

ADDENDUM: ECONOMETRIC MODELS OF ELECTRICITY--AN OUTLINE • • • • • 129 


\section{TABLE OF CONTENTS}

\section{Volume II}

APPENDIX

Page

A: ARIZONA PROJECT SYNOPSIS .............. A-1

B: ARKANSAS PROJECT SYNOPSIS .................. B-1

C: CALIFORNIA PROJECT SYNOPSIS ............... . c-1

D: CONNECTICUT PROJECT SYNOPSIS ............ . . D-1

E: LOS ANGELES PROJECT SYNOPSIS ............. . E-1

F: NEW JERSEY PROJECT SYNOPSIS . . . . . . . . . . F-1

G: NORTH CAROLINA PROJECT SYNOPSIS . . . . . . . . G-1

H: OHIO PROJECT SYNOPSIS ......................

I: OKLAHOMA PROJECT SYNOPSIS . . . . . . . . . . . I-1

J: PUERTO RICO PROJECT SYNOPSIS . . . . . . . . . . . . J-1

$\mathrm{K}$ : RHODE ISLAND PROJECT SYNOPSIS ................. . . .

L: WASHINGTON PROJECT SYNOPSIS . . . . . . . . . . . L L-1

M: WISCONSIN PROJECT SYNOPSIS ............. M-1

$\mathrm{N}$ : MICHIGAN, NEW YORK, AND VERMONT PROJECT SYNOPSES ..... $\mathrm{N}-1$ 
THIS PAGE

\section{WAS INTENTIONALLY \\ LEFT BLANK}




\section{LIST OF FIGURES}

Figure

Page

2-1 Daily rate profile - Rate A . . . . . . . . . 17

2-2 Daily rate profile - Rate B.............. 26

2-3 Independently priced rating periods (IRPs): for combined rate analyses .............. 26

2-4 Strategy for making inferences . . . . . . . 49

4-1 Criteria for project-pooled analyses . . . . . . . 111

5-1 Project organization structure . . . . . . . . 116 


\section{THIS PAGE \\ WAS INTENTIONALLY \\ LEFT BLANK}




\section{LIST OF TABLES}

$\underline{\text { Table }}$

2-1 Proposed set of average daily load curves ........ 9

2-2 List of variables to be estimated (by treatment) . . . 11

2-3 Variables to be analyzed in comparative analyses

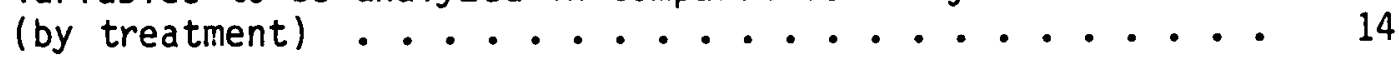

2-4 Treatment comparison in a finite population--example ... 15

3-1 Type of analysis by project--an overview ....... 58

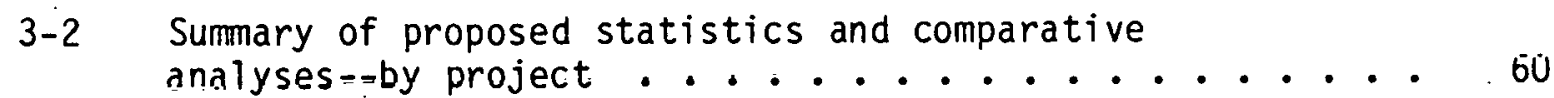

3-3. Summary of suggested response surface analyses ..... 61

3-4 Key to experimental electricity rate codes ...... 64

3-5 Summary of time-of-use experimental electricity rates . . 65

3-6 Summary of incentives and revenue neutralization .... 69

3-7 Summary of sample design characteristics ....... 71

3-8 Sunmary of Arizona experimental rates . . . . . . 74

3-9. Summary of Arkansas experimental rates ........ 77

3-10 Summary of California (SCE) experimental rates ..... 80

3-11 Summary of California (SDG\&E) experimental rates . . . 84

3-12 Summary of Los Angeles experimental rates ....... 88

3-13 Surmary of New Jersey experimental rates ....... 91

3-14 Summary of North Carolina (CP\&L) experimental rates ... 94

3-15 Summary of Oklahoma experimental rates ........ 98

3-16 Summary of Puerto Rico experimental rates . . . . . . 101

3-17 Summary of Wisconsin experimental rates . . . . . . 107

S-1 Sumary of relevant characteristics of projects
eligible for pooled analysis ................... 113

5-1 Electric utility rate demonstration data file ..... 118

5-2 Project reporting schedule ........... 122

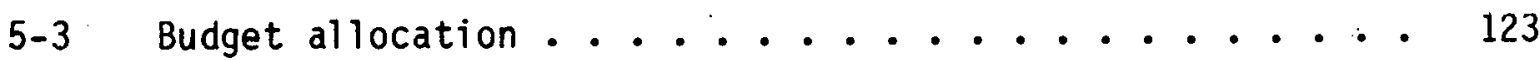




\section{THIS PAGE}

\section{WAS INTENTIONALLY \\ LEFT BLANK}


Chapter 1: INTRODUCTION AND SUMMARY

\subsection{Background}

The Federal Energy Administration (now the U.S. Department of Energy), in cooperation with state public utility commissions and participating utilities, has initiated 16 .electric utility rate demonstration projects (seven in FY75 and nine more in FY76). Funding for the projects was provided by the FEA, participating utilities, and state governments. The primary purpose of these projects was to evaluate experimentally the effects of time-of-use pricing of electricity for residential customers. The time-of-use rate most frequently employed was a time-of-day (TOD) rate.

TOD rates for electricity offer the opportunity to more closely align electricity' costs and prices than do non-time-differentiated rates. Hence, they would provide customers with price signals that more accurately reflect the costs to the utility of electric power. They can be regarded as a form of indirect load management since TO0 rates induce customers to alter their temporal pattern of electricity consumption.*

The method employed by the states to evaluate TOD rates was to select a subset of the residential population, place these people on TOD rates, and with special meters, monitor their temporal use of electricity. As might be expected, with the varying objectives of the states, available resources, and background in load management studies, a variety of approaches were employed, and a variety of data generated by the

*Direct load management includes a variety of interruptible service arrangements where the utility or customer cycles/customer loads on an automatic or as-needed bas is. 
projects. Also, the received and expected analyses of the data vary considerably among the projects due to the differing interests of the states, available resources, and the composition of the project teams.

In the fall of 1977, the DOE contracted with Research Triangle Institute (RTI) to provide a comprehensive, standardized analys is of the data from the DOE electric utility residential rate demonstration projects. This report is being submitted in accordance with the terms of that contract.

\subsection{Objectives}

Ihere are three purposes of this Analytıcal Master $\mu$ ian (AMY), as set out in the contract: 1) "to ensure the data. derived from the FEA projects and from related sources are subjected to econometric and statistical analys is that is both rigorous and as highly sophisticated as the state of the art will permit; 2) to ensure that the results of the analys is are organized and displayed in a manner useful to utility and regulatory decision-makers; and 3 ) to ensure that the analytical effort is conducted on a timely and professional basis."

This report identifies the alternative analytical approaches, project specific analyses, project-pooled analyses and organization and management plan for completing the study. Synopses of all the demonstration projects are presented in the appendixes which are bound separately in Volume II.

\subsection{Summary}

The objectives of the project-specific and project-pooled analyses outlined in this Analytical Master Plan are: 1) to determine the load shape responses of the residential class of electricity customers subjected, in the DOE sponsored experiments, to specific (generally, 
time-of-day) electric rates and 2) to determine the implications of those responses on electric system loads within the experimental service areas.

Three basic analytical techniques are suggested: descriptive, comparative, and response surface analyses. Descriptive analyses will consist of both graphical and tabular displays of estimated statistics for both test and control groups of 40 or more households observed while subjected to specific rates. The graphical displays will be several alternative average daily load curves associated with test and control group customers for alternative averaging periods within selected months. The tabular displays will consist of weighted average estimates of several (more than 20) load curve statistics for appropriate experimental groups. None of the descriptive analyses will involve inferential comparisons. By contrast, the comparative analyses will include tests for significant differences between test and control group statistics that characterize their load curves. These two types of analyses are particularly.important for synthesizing the enormous volume of data generated by the DOE projects.

The last type of proposed analys is involves the estimation of response surfaces--basically functional relationships between daily electricity price profiles and the resulting average daily residential load curves. Our suggested standard response surface model is a second-order Taylor's series expansion of a general time-of-day electricity demand function. Operationally, the independent variables in this model include all feasible time-of-day price terms, all appropriate covariates, and all second order combinations of those variables. The model is proposed for application to both individual rate regressions and combined rate regressions within the specific projects. Generally, the response variables will be KWH consumption during the daily rating periods of interest. We will also 
consider response surface models based more formally on the neoclassical theory of demand.

The reliability of the proposed analyses will be hampered by deficiencies in the sample designs, the experimental designs, and in the data associated with the DOE projects. Awareness of the unique problems within each study is essential to proper interpretations of the analys is that applies to each.

For each DOE project, we have identified (chapter 3) the minimum set of analyses we plan to conduct. However, we will expand this set to the extent permitted by available resources. For most of the projects, all three types of analyses will be conducted. However, the five studies that involve only a single time-of-day rate will be subjected to descriptive and comparative analyses only. Also, three other studies will be analyzed with only response surface techniques, either because standard two- or three-dial meters were used or because a small number of households were assigned to particular time-of-day rates.

It is suggested that recommendations concerning the feasibility of pooling data from the DOE projects be delayed until some fundamental questions involved in the project-specific analyses have been answered. Initially we suggest that those projects without experimental time-of-day rates, those without hourly data in the DOE data system, and those with a single experimental rate be excluded from consideration for pooling. This leaves eight studies (including two studies within the California project) that are candidates for pooling. Among those, further consideration of pooling will have to address analytical problems associated with disparities between geographic and climatic conditions, between experimental procedures, between experimental rate test periods, and between the experimental rate forms. 


\section{Chapter 2: ANALYTICAL APPROACH}

\subsection{Analytical Objectives}

Electric utilities and regulatory commissions considering time-of-day rates are primarily concerned about the effects of those rates on the load curve shape of individual electric utilities. Accordingly, the purpose of the suggested analyses is to learn more about those load curve shape effects--through further statistical and econometric studies of the data.

Specifically, the objectives of the proposed project-specific and project-pooled analyses are to determine the load shape responses of the residential class of electricity customers subjected experimentally to specific (generally, time-of-day) rates and to determine the implications of those responses on electric system loads within the experimental services areas. The overriding technical problem in achieving this objective is to determine how the entire locus of a continuous variable, $\mathrm{KW}$, will change through customer reaction to a new set of conditions (generally an alternative rate application) as compared with present conditions.

By the very nature of the experimental rates used in the DOE experiments, two major generic types of analyses are appropriate. If inferences are limited (either because of the experimental design or the particular analytical objective) to the particular rate or set of rates (treatments) actually applied in the experiment, then comparative analyses (analys is of variance or covariance) are appropriate. On the other hand, if the experimental design enables inferences about rates that were not specifically applied to customers in the experiment, so-called response 
surface analyses are appropriate. In either case when enough observations are available for a particular rate (or rates) to provide minimal statistical reliability, it will also be useful, as a "first-cut", to provide simple (non-inferential) displays of various load-characterizing, descriptive statistics. Section 2.2 further details these three analytical techniques--descriptive, comparative, and response surface analyses--in subsections 2.2.1-2.2.3, respectively.

The reliahility of the proposed analyses will be hampered by deficiencies in the sample, in the data, and in the experimental designs of each study. Section 2.3 discusses the anticipated analytical problems associated with these three deflclencles in subsections 2.3.1-2.3.3, respectively.

\subsection{Analytical Techniques}

The fundamental framework for the analys is of electric rate effects involves five basic steps. First, a set of response or dependent variables (such as KW or KWH within speciflc time periuds) must be identified to describe load shape changes. Second, a theory must be developed to relate these response variables to a set of independent variables. Third, this theory must ultimately lead to a general mathematical model that relates the response variables to the independent variables, including hypothesized restrictions on relationships among the effects of the latter. Fourth, alternative statistical or econometric models must be postulated for relating the dependent and independent variables operationally. And, finally, model parameter estimates must be developed and evaluated to quantify the relationships among the model variables.

The first level of analysis is to examine graphical and tabular displays of average estimates of the dependent variables identified in 
the first of the above five steps. Those estimates would be computed and displayed separately for each rate application (given an adequate number of observations) and for the existing (control) rate, without making inferential comparisons. These analyses are suggested in section 2.2.1. The second level of analysis postulates a fairly simple theory and correspondingly simple mathematical and statistical models of relationships between the dependent and independent variables under treatment and control, e.g., a straightforward analysis of variance model. These analyses are detailed and proposed in section 2.2.2. The third level of analysis is designed to provide valid predictions of customer responses for rate applications not actually included in the experiment. Correspondingly, it relies to a greater extent on the robustness of the theory and on the mathematical and statistical models that operationally specify those theories. Section 2.2 .3 details our suggested approach to the estimation of these models.

\subsubsection{Descriptive Analyses}

The volume of data generated in the rate demonstration projects is enormous. For instance, within one year an individual participant will generate almost 9000 hourly usage observations. Most of the projects have several hundred participants and many are multi-year studies. In view of this large number of data points, we feel that the initial analysis should summarize the data in a form that can be readily understood. Therefore we propose to estimate a large number of sumary statistics covering the variables of major interest. In some cases the sample results will be inflated to represent a finite population whereas, in other cases, unweighted sample data will be utilized. These descriptive 
statistics, which will be displayed either in graphical or in tabular form, are described in detail in the remainder of this section.

Estimates of Statistics for Graphical Display. A graphical presentation of the data serves two important, yet distinct, purposes. First, it will serve as a visual aid in providing to end-users and decision makers an overall "feel" for major findings in the investigation. Second, it provides information useful in identifying other areas or additional variables which deserve an in-depth analysis.

During a two-day, DOE-sponsored conference in Washington, D.C. in Vecember $19 / /$, members of the RTI project staff met with regulatury arld utility representatives: and discussed which variables are of major interest and which types of graphical presentations would be useful to them as end-users of the data from the demonstration projects. It was evident from these discussions that a series of (average) daily load curves, encompassing a number of averaging periods, would be beneficial. Therefore, we propose to construct for each project, data permitting, the set of average daily load curves shown in table 2-1.

The proposed set of load curves will be constructed for at least six calendar months per year covering those seasons pertinent to the particular utility. An exception is load curve 6 which will be developed for a minimum of two months. In each month, load curves for the control and treatment groups will be developed for the peak day of the control group. In addition, for the peak day of each treatment group, load curves for that treatment and control will be developed. The days for these selected load curves are determined by the hours of the month in which the sample means (weighted) for the control and each treatment reach a maximum value. The load curves of table 2-1 will be restricted to the control group and 
to those experimental rates with initial sample sizes greater than 40 . Projects involving a single experimental rate and control are exempt from this restriction. Consideration of precision in estimating a load curve along with time and funding constraints, led to the sample size cut-off point of 40 . In establishing this limit for development of load curves and for making comparisons among time-of-day rates and control, we recognize that some relationships and comparisons important to the utility and regulatory agency may not be examined. However, we feel these issues can be appropriately dealt with by the individual project staff as part of their own analyses.

Estimates of Statistics for Tabular Display. Information exhibited in load curves, i.e., hourly usage per customer averaged over some specified set of days, can be further condensed into summary statistics that describe meaningful characteristics of the curve and are useful to regulators and utility managers. The minimum set of variables that we propose to estimat'e for each project (in addition to load curves) is shown

Table 2-1. Proposed set of average daily load curves*

1. Day of monthiy system peak

2. Weekend days during month

3. Weekdays during month

4. All days during month

5. All days during month in which the observed daily system peak was greater than $X \%$ of the observed annual system peak $(X=80 \%, 90 \%, 95 \%)$

6. Day of monthly class peak

*Load curves 1-5 in this table will be developed for 6 (or more) months. Load curve 6 will be developed for 2 (or more) months. 
in table 2-2.*. Twenty-three variables are listed. Different estimation techniques must be employed since some of the variables can be constructed directly by aggregating data from individual customers (variables 1-15, for example), whereas others are ratio variables (16-18).

Variables 1-18 will be estimated (along with their standard durations) for at least six calendar months per year. Since all of these variables relate directly to two load curves (day of monthly systen peak and all days during month) the same calendar months will be used. ${ }^{\dagger}$ Variables 19-23 will be estimated for a minimum of two calendar months corresponding to those months for which load curve 6 is estimated. Variances associated with these estimates will not be provided for reasons given in section 2.2.2. The reason for the reduction in the number of months is that each hour must be analyzed separately in order to find the one-hour period in which the class peak occurs. For those projects where unweighted data are used, variables 21 and 22 will not be estimated since a meaningful population will probably not have been defined. Otherwise, variables 21 and 22 can be estimated for a population exposed to an experimental rate by constructing the estimated system load for the particular treatment. Such an estimated system load can be determined, in a crude way, by adding a constant times the difference between average residential usage under experimental and existing rates to the existing

*This does not preclude the analys is of other variables which have been suggested--for example, the average KWH per customer during first (last) hour of peak period on the day of observed peak in calendar month and over all days in the calendar month.

+Variables 1-6 and 7-12 are identical except that the first group is averaged over the day of observed system peak and the second over all days of the month. 
Table 2-2. List of variables to be estimated (by treatment)

1. Average KWH per customer during peak period on day of observed system peak in calendar month $i$

2. Average KWH per customer during intermediate period (if applicable) on day of observed system peak in calendar month $i$

3. Average KWH per customer during base period on day of observed system peak in calendar month $i$

4. Average KWH per customer during 1-hr. preceding peak period(s) on day of observed system peak in calendar month $i$

5. Average KWH per customer during 1-hr. following peak period(s) on day of observed system peak in calendar month $i$

6. Average KWH per customer on day of observed system peak in calendar month $i$

7. Average KWH per customer per day during peak period for ith calendar month

8. Average KWH per customer per day during intermediate period. (if applicable) for ith calendar month

9. Average KWH per customer per day during base period for ith calendar month

10. Average KWH per customer per day during 1-hr. preceding peak period(s) for ith calendar month

11. Average KWH per customer per day during 1-hr. following peak period(s) for ith calendar month

12. Average KWH per customer per day during ith calendar month

13. Diversified demand (average per customer) at time of observed system peak in the ith calendar month

14. Noncoincident maximum demand (average per customer) for ith calendar month

15. KWH per customer averaged over all hours in the ith calendar month for which observed system load was greater than $\bar{x} \%$ of observed annual system peak

16. Proportion of total KWH in peak period on day of observed system peak in the ith calendar month $(\# 1 / \# 6)$

17. Proportion of total KWH in peak period for ith calendar month (\#7/\#12)

18. Class load factor for ith calendar month based on diversified demand at time of observed system peak (\#12/\#13 $\div$ 24)

19. Maximum diversified demand (per customer) for ith calendar month

20. Class coincidence factor for ith calendar month (\#19/\#14)

21. System peak for ith calendar month

22. System load factor for ith calendar month

23. Class load factor for ith calendar month based on maximum diversified demand $(\# 12 / \# 19 \div 24)$ 
system load. The constant is a product of the total (residential) population size and a factor which inflates the measured usage up to the generated KWH (i.e., prior to distribution and transmission losses). In general, variables 1-23 will be estimated for all projects having only one experimental rate and a control group. For projects with multiple experimental rates, all of the variables will be estimated for the control group and for all experimental rates with initial sample sizes greater than 40 . This is consistent with the sample size criterion for developing load curves.

\subsubsection{Comparative Analyses}

Up to this point, the discussion has been restricted to identifying a set of variables for which estimates will be provided for specific treatments (rates) within the various projects. The second level of analys is we propose to conduct is a comparative analysis. This involves making statistical comparisons of responses observed under one pricing scheme with those observed under another. In this regard, we want to determine, for some population of customers, if the level of response for a particular variable of interest depends upon the treatment or rate being applied.

Our planned approach in determining whether a response under one rate differs significantly from that under another is based on the concept that there exists a definable population to which inferences from samples are to be made. This implies that weights must be used to expand the sample results up to that of a finite population. If a meaningful population cannot be defined or if weights are not available, then unweighted sample data will be analyzed. The problem then is to make valid inferences to some population larger than the sample itself. 
After identifying the population to which inferences are to be drawn, the second step involves specifying the population variables to be estimated. This is done in table 2-3 which differs from table 2-2 only in that variables 19-23 have been excluded. For those variables there is an analytical problem that prohibits the estimation of variances which are needed in testing hypotheses. This problem occurs because each of these estimates can vary in two dimensions--from customer-to-customer and across time (hour-to-hour). Procedures for obtaining the variance of such an estimate are not available.

The third step is to estimate, for each treatment of interest, the population means (i.e., variables 1-18) and their associated variances. These estimates, coupled with distributional assumptions, can then be used in making tests of hypotheses concerning the true population parameters. Table 2-4 provides an illustrative example (perhaps over-simplified) of how two treatments $\left(t_{1}\right.$ and $\left.t_{2}\right)$ may be compared for a finite population. Using variables 1-18, comparisons between responses under the control and under the time-of-day rates will be made for all projects having only one experimental rate. For projects with multiple experimental rates, similar comparisons will be made on those experimental rates with sample sizes greater than 40 . Other comparisons that will be considered, resources permitting, include: effect of level of information given to study participants (Edmond, Oklahoma); effect of a time lag in making incentive payments (Los Angeles); and effects of availability of interlocking devices (North Carolina, CP\&L).

Control versus time-of-day comparisons on each of the variables listed in table 2.3* will be carried out in at least six calendar months

\footnotetext{
*See footnote on page 10.
} 
Table 2-3. Variables to be analyzed in comparative analys is (by treatment)

1. Average KWH per customer during peak period on day of observed system peak in calendar month $i$

2. Average $\mathrm{KWH}$ per customer during intermediate period (if applicable) on day of observed system peak in calendar month $i$

3. Average KWH per customer during base period on day of observed system peak in calendar month $i$

4. Average KWH per customer during 1-hr. preceding peak period(s) on day of observed system peak in calendar month $i$

5. Average KWH per customer during 1-hr. following peak period(s) on day of observed system peak in calendar month $i$

6. Average $\mathrm{KWH}$ per customer on day of observed system peak in calendar month $i$

7. Average KWH per customer per day durlng peak jeriod for ith calendar month

8. Average KWH per customer per day during intermediate period (if applicable) for ith calendar month

9. Average KWH per customer per day during base period for ith calendar month

10. Average KWH per customer per day during 1-hr. preceding peak period(s) for ith calendar month

11. Average KWH per customer per day during 1-hr. following peak period(s) for ith calendar month.

12. Average KWH per customer per day during ith calendar month

13. Diversified demand (average per customer) at time of observed system peak in the ith calendar month

14. Noncoincident maximum demand (average per customer) for ith calendar month

15. KWH per customer averaged over all hours in the ith calendar month for which observed system load was greater than $\bar{x} \%$ of observed annual system peak

16. Proportion of total KWH in peak period on day of observed system peak in the ith calendar month $(\# 1 / \# 6)$

17. Proportion of total KWH in peak period for ith calendar month (\#7/\#12)

18. Class load factor for ith calendar month based on diversified demand at time of observed system peak $(\# 12 / \# 13 \div 24)$ 
Table 2-4. Treatment comparison in a finite population - example




per year. (same six months for which load curves are constructed). It should be noted that these are tests of hypotheses and that a given comparison may show a difference that is statistically significant (e.g. difference cannot be attributed to chance alone), but from a practical or engineering standpoint this difference may not be "meaningful". Normally this situation arises when large sample sizes are used which is not the case for most of the demonstration projects.

For the most part, comparative analyses will not utilize covariates. There may, however, be some projects where the stratification employed in the sample design would suggest that the use of covariates would be beneficial in reducing the experimental error. For these cases, a covariance analys is will be considered.

In sections 2.2 .1 and 2.2 .2 , the scope of the analyses has been stated in terms of the minimum that can be provided within the budget constraint. Several alternatives are available if funding permits additional analyses. Some of these alternatives (1isted in order of our priority) are to:

a) increase the number of calendar months for existing load curves,

b) increase the number of calendar months for existing comparative analyses,

c) construct other types of load curves, and

d) conduct tests of hypotheses with additional variables.

\subsubsection{Response Surface Analyses}

Response surface analys is is required whenever one wants to draw inferences to rates that were not specifically applied to customers in the experiment. Obviously, to make any inference beyond those specific rates used in the experiment, one must: 
a) clearly define that set or family of rates to which inferences are to be made, and

b) precisely define the model that will be assumed to apply to this family.

The concept of a rate family can be illustrated quite simply. Consider, for example, a time-of-day rate involving two daily rating periods, e.g., like those shown in figure 2-1. Assume, for discussion purposes, that the monthly customer charge and fuel adjustment charges can be ignored. Then any such rate could be completely specified by four variables: the peak period price, $P_{2}$; the base period price $P_{1}$; the hour, $T_{1}$, at which the base period begins; and the length $L_{1}$, of the off-peak period. Clearly one could experimentally vary $P_{1}$ and $P_{2}$ while holding $T_{1}$ and $L_{1}$ constant (at 1700 and 2100 , respectively, in the example of figure 2-1) and thereby obtain response surface or price elasticity estimates for this particular rate family--conditional on the constant values of $T_{1}$ and $L_{1}$.

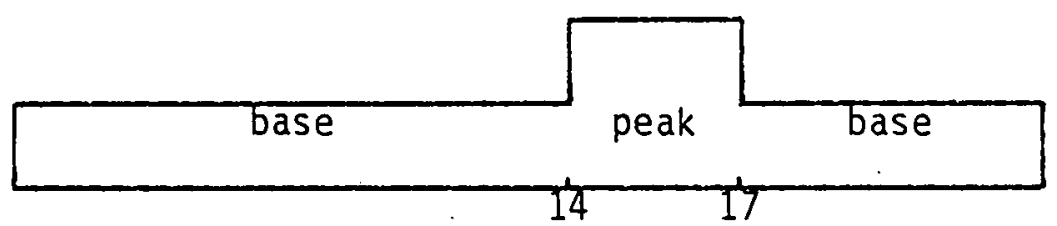

Figure 2-1. Daily rate profile - Rate A

Consider another rate family identical in all respects but one to the preceding family. Specifically, suppose that a demand charge, $H$, is applied during the peak period. With the addition of this single variable a new rate family has been defined. Any member of this new family is specified by values of five variables: $P_{1}, P_{2}, T_{1}, L_{1}$, and $H$. The first rate family described above is obviously a subset of the second when $H=0$. But suppose $H$ assumes some positive value. Then, once again, $P_{1}$ and $P_{2}$ can be 
varied experimentally to estimate own- and cross-price elasticities--but now these estimates are conditional for the new rate family.

It is obvious that rate families can be extremely complex, since a tremendous number of factors $c$ an be varied; these factors include the following:

- number and length of all distinct seasonal rating periods,

- starting date of at least one seasonal rating period,

- number and length of all distinct daily rating periods within each distinct seasonal rating period,

- starting time of at least one daily rating period within each seasonal rating period,

- energy (KWH) prices or charges within each of the distinct daily rating periods within each seasonal rating period,

- demand (KW) prices or charges within each of the distinct daily rating periods within each seasonal rating period,

- duration of the period over which demand charges are ratcheted for all unique demand charges, both by daily and seasonal rating periods,

- fuel adjustment charges applied within each unique daily and seasonal rating period, and

- billing period (usually monthiy) facilities charge.

Under traditional declining block rates, other variables must be added to the preceding list to define fully any such rate schedule. For example, it would be necessary to add:

- billing period electricity consumption (KWH),

- the KWH consumption levels at each of the points of discontinuity in the declining block price schedule, and

- the energy charges that apply within each of the blocks of the price schedule.

Even other variables would have to be added to define fully such complex rates as temperature-sensitive time-differentiated rates, interruptible rates, rates that incorporate price concessions for ripple control 
cycling of major appliances, etc. Yet most time-differentiated and declining block rates can probably be fully specified by defining specific values for the variables or factors within the entire set of rates as defined by the combination of the two preceding lists.

In the following subsections, we describe the particular approaches that are suggested for response surface analysis. The first subsection summarizes anticipated applications of our standard proposed model: an unrestricted, second order Taylor's series approximation to generally specified electricity demand functions by time-of-day.* First, the model is defined and applications to the analyses of single rate families--so-called individual rate regressions--are described. Then, applications of the model to "extended rate families"--so-called combined rate regressions--are described. A menu of alternative response variables are then presented along with our suggested standard selections. Finally, the choice of independent variables is discussed. The second subsection briefly describes potential applications of more restrictive response surface models that are more formally based on the neoclassical theory of demand.

\subsubsection{Standard Taylor's Series Approach.}

The Model. If one postulates a general theory that a customer's demand for electricity during time intervals within the day is a function of time-of-day prices, weather, and customer characteristics, one of the

*The technical reader is referred to the addendum for a detailed rationalization of our suggested approach. The bibliography contains many valuable references to the relevant literature on demand analys is. More complete bibliographies can be found in any of the several books and monographs on applied demand analysis, e.g. Deaton (1975) or Bridge (1971). 
most straightforward statistical response surface models of that relationship is a low order polynomial function of those variables. Referring back to the fundamental analytical framework outlined in the introduction to section 2.2, one can justify this approach as a minimally restrictive transition from a general economic theory to an estimable response surface model. Specifically, where the array of time-of-day prices, weather, and customer characteristics are all subsumed in a vector, $Z, *$ the theory states that electricity consumption, $Y$, during the specified time interval, is a general function of $Z$ or that $Y=f(Z) .^{+}$This general function can, like any other, be approximated in a small neighborhood by Taylor's series expansion of the function in that neighborhood. Since, as we will describe more fully below, even a second order Taylor's series approximation generally demands very rich experimental price variation to be fully estimable, our suggested standard response surface model hypothesizes that all third and higher order (remainder) effects are incorporated in the error term. Thus, the proposed standard model is (where all variables may be either linear or logarithmic transformations)

* See the section below on independent variables for a more detailed discussion of the choice of these independent variables.

tEconomic theory, specifically utility maximization under an income constraint, defines these general electricity demand functions. The general solutions to the first-order conditions for utility maximization state that the demand for each good in the consumer's market basket, e.g., demand for electricity by time-of-day, is a general function of all exogenous variables including prices and income. When the demand behavior being modelled represents community (residential class) behavior, additional (exogenous) variables must be added to distinguish shifters of the utility functions. Thus, the inclusion of exogenous variables such as the number of children and housing characteristics is also appropriate. Except for a very simple utility function like the exponential function, explicit solutions, i.e., explicit functional forms, are not obtainable from these first order conditions. Nonetheless, solutions exist in principle and can be stated generally as $Y=f(Z)$. 


$$
Y_{i}=\beta_{0}+\sum_{k=1}^{k} \beta_{k} Z_{i k}+\sum_{k=1}^{k} \sum_{\ell \geq k}^{k} \beta_{k \ell} Z_{i k} Z_{i \ell}+e_{i}, \quad l=1 \ldots N
$$

where $N=$ the number of customers in the study,

$K=$ the total number of variables thought to affect $Y$, including electricity prices in each rating period and all. appropriate covariates,

$Y_{i}=$ an observation for the ith customer on a given response variable, e.g., a monthly average of a customer's peak, intermediate, or base period KWH, or KWH for a particular hour of the day,

$Z_{i k}=$ an observation for the ith customer on the kth variable thought to affect $Y$ (the $\overline{s e}$ variables include prices, income, number of children, square footage, etc.)*,

$\beta=$ a set of parameters to be estimated, and

$e_{i}=$ an error term.

Estimation of (2-1) by ordinary least squares (OLS) will give unbiased and consistent estimates of the parameters provided $e_{j}$ is not correlated with any $z_{i-k}$. The efficiency of $(2-1)$ may be improved by an appropriate generalized least squares (GLS) scheme if the disturbances are not independent and identically distributed for all i. If two alternative dependent variables are simply averages over two different sets of days, it may be useful to use a seemingly unrelated regression approach. However, if the right-hand-side (RHS) of (2-1) is identical for ali $Y_{i}$ to be fitted, then, of course, this particular GLS scheme provides no gain in efficiency. Accordingly, unless different subsets of

*See footnote on page 20.

Hunder the assumption that the sample represents a random sample from an infinite population for which the parameters apply. Otherwise, the parameters will depend on the sample design, a property which is clearly undesirable. 
parameters are assumed a priori to be zero for different $Y_{i}$, GLS need not be performed.

If regressions with dependent variables that are monthly averages provide inefficient estimates, the efficiency may be improved by fitting appropriately specified models of daily consumption. In this case, the GLS procedure would include an autocorrelation scheme as well as a seemingly-unrelated regression scheme. The inclusion of weather variables may also improve the precision of the estimates.

What the simple approach of equation (2-1) lacks in theoretical elegance, it makes up for in simplicity of understanding and estimation. We feel that it is possible to apply this pragmatic approach in every study where any kind of response surface estimation is feasible.

Individual Rate Regressions: To illustrate the meaning and implications of the sets of analyses referred to as individual and combined rate regressions the model of $(2-1)$ is restated for convenience in a form that emphasizes the price variables as independent variables:*

$$
Y_{i}=a+\sum_{k=1}^{n} b_{k} P_{k i}+\sum_{k=1}^{n} c_{k} P_{k i}^{2}+\sum_{k=1}^{n} \sum_{j>k} d_{k j} P_{k i} P_{j i}+\sum g_{j} x_{j}+e_{i}
$$

where $Y_{i}$

$$
\begin{array}{ll}
P_{k} & =\text { price per } K W H \text { during the } k \underline{t h} \text { daily time interval, } \\
x_{j} & =\text { non-price independent variables, } \\
a_{,} b_{k}, c_{k}, d_{k j}, g_{j} & =\text { regression parameters, and } \\
e_{i} & =\text { error term. }
\end{array}
$$

* See the section below on the choice of independent variables, $x_{j}$, other than prices that will enter the regressions of (2-2). 
The parameters to be estimated in this model include the intercept, $a$, the coefficients, $b_{k}$, on the first order terms, the coefficients, $c_{k}$ and $d_{k j}$, on the second order terms and the $g_{j}$ coefficients on other indepencent variables. Excluding the $g_{j}$, these parameters total $1+2 n+$ $n(n-1) / 2$. Whether all of these parameters can be estimated or whether some truncated form of (2-2) must be estimated, depends entirely upon the number and configuration of rate variations that have been applied for each rate type in each experiment. This notion can be simply illustrated as follows.

Suppose that an experiment was designed to have a single peak period from 1400 to 1700 with all other hours defined as the base period as in figure 2-1. Suppose further that two such rates are applied, e.g., that $N_{1}$ customers receive a peak/base rate pair of 6 cents/2 cents and that $N_{2}$ customers receive a rate pair of 7 cents $/ 1$ cent. Now, since $n=2, a$ total--excluding the $\mathrm{g}_{\mathrm{j}}$--of 6 parameters ( 5 price plus the mean) are required to define the full model of (2-2), i.e., to estimate the model

$$
Y_{i}=a+b_{1} p_{1 i}+b_{2} P_{2 i}+c_{1} P_{1 i}^{2}+c_{2} P_{2 i}^{2}+d P_{1 i} P_{2 i}+\Sigma g_{j} X_{j}+e_{i}
$$

Unfortunately, (2-3) is non-estimable with data from the hypothetical experiment. Although there are $N=N_{1}+N_{2}$ observations there will be only two linearly independent rows in the design matrix-- $N_{1}$ of the customers will be on the $6 / 2$ rate combination and $N_{2}$ will be on the $7 / 1$ combination. Therefore, to estimate responsiveness to price within the context of this model, one is forced to accept a highly restrictive specification since the number of parameters to be estimated cannot exceed the number of unique rates that were applied. For example, one might choose to estimate truncated first order models of the form 


$$
Y_{k i}=a+b_{k} p_{k i}+\Sigma g_{k} X_{j}+e_{i} \text { for } k=1,2 \text {, }
$$

if the response variables of interest were, e.g., average KWH consumed during the two intervals over which the two prices are defined. Such models would, of course, arbitrarily restrict cross-elasticities to be zero and, further, would completely ignore second order effects (the non-linear (quadratics) effects of own-prices and the interactive effects of prices).

If the experiment were expanded to include a third rate combination, say a $6 / 1$ combination, the mudel to be estimated could be enriched to a full first order Taylor's series approximation, i.e.,

$$
Y_{k i}=a+b_{1} p_{1 i}+b_{2} p_{2 i}+\Sigma g_{j} x_{j}+e_{i} \text { for } k=1,2 \text {, }
$$

that would enable the estimation of cross elasticities. It should be noted that independent variation in base and peak period prices is desired, as opposed to simultaneous variation. Choice of a 5.5/2.5 price combination as the third rate, for example, would not permit estimation of the above model.

Extending this logic, it is obvious that with six or more unique rate combinations the full second order model of $(2-3)$ can usually be est imated and, in general, given $1+2 n+n(n-1) / 2$ rate combinations, the full second order model of (2-2) can usually be estimated.

If the application of (2-2) or, more generally, (2-1) is restricted to a particular subset of a rate family where, e.g., in the case of the rates of figure 2-1 the starting time and length of the base period are 
fixed, we refer to the associated regressions as individual rate regressions. If a particular experiment includes flat rates and if other factors associated with the rates, e.g., facilities charges, etc., are identical, we regard data from customers on these flats as valid elements of the data set for estimating the response surface for any TOD rate. These data are admissible because the flat rate is only a special member of every particular rate family in which electricity prices are defined by time of day.

Combined Rate Regressions. Virtually the same logic that permits the inclusion of data from customers on a flat rate in the analys is of a particular subset of a rate family suggests a second major option for estimating response surface models of the type described by (2-1). It is the capability of defining a more general or expanded rate family within which two or more narrowly defined TOD rates within a particular study can be regarded as special cases. In combining the data from these rates new partitions of the day are created and, if effective, the number of unique rate combinations is increased. This then allows the estimation of richer response surface models, i.e., models with a larger number of estimable price effects coefficients. This combined rate regression concept can be illustrated as follows.

Suppose the experiment described above has only five rate combinations of the type shown in figure $2-1$ and that it also has five combinations of the type shown in figure 2-2 in which the peak period begins at 1200 instead of 1400 . When the data from customers on these two rates are combined, we will generally observe three instead of two partitions of the day during which the price vectors are linearly independent. Specifically, if $a$ and $c$ are the $5 \times 1$ vectors of base 


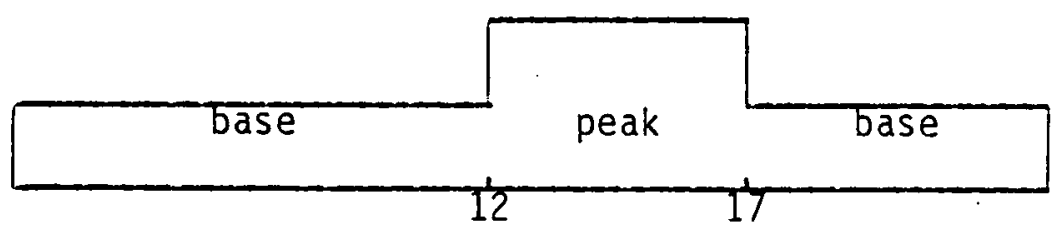

Figure 2-2. Daily rate profile - Rate B

period prices for the five rates of the type illustrated in figures 2-1 and $2-2$, respectively, then the three independently priced rating periods and the associated price vectors are shown in figure 2-3. The term "independently priced rating periods" (IRPs), of course, means that the three $10 \times 1$ price vectors shown in figure 2-3 are linearly independent.

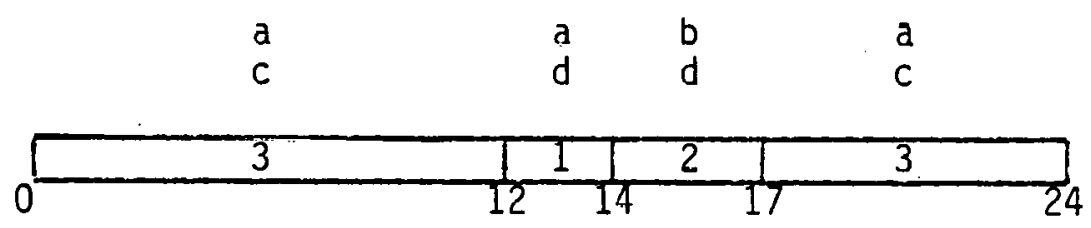

Figure 2-3. Independently priced rating periods (IRPs) for combined rate analyses.

In this combined analys is, the number of prices, n, now equals three, the number of IRPs-- $P_{1}$ is the price between 1200 and $1400 ; P_{2}$, between 1400 and 1700; and $P_{3}$, between $1 / 00$ and 1200. By combining the data associated with both of the two rate forms of figure $2-1$ and 2-2, the number of unique price rows in the three equations of the type given by 2-1 is increased to 10 . Consequently, the number of estimable parameters in (2-2) is generally equal to 10 . In other words, it is possible to construct a maximum of 10 linearly independent columns and rows in the design matrix. If those columns are chosen to be the vector of ones associated with the intercept, the three columns formed by the first order price terms, and the six columns formed by the second order price 
terms of $(2-2)$, then $a 11$ of the parameters (2-2) would normally be estimable.

One possible technique for testing the validity of this kind of combined rate analys is is to use indicator variables to distinguish the particular detailed rate from which each observation is drawn. These can then be used to shift the intercept of the regressions--and therefore provide a statistical test of model adequacy.

Three additional comments apply equally to both the individual and combined rate analysis. First, each unique flat rate in the experiment of interest adds another unique price row and, hence, increases by one the number of estimable price coefficients. Second, none of the coefficients on squared price terms--the $c_{k}$ in (2-2)--can be estimated if the associated price takes on only two values. Third, many of the IRPs in both the individual and combined rate regressions will be split (nonadjacent) periods. Für example, it is especially prevalent to observe two daily peak periods within the experimental rate structures. In these cases, it is clearly impossible to distinguish the effect of price variations within one of those split portions on electricity consumption in the other, i.e., cross-price effects are non-estimable because of the confounded experimental design. Yet it will be useful to examine KWH consumption in the split periods because, e.g., one can still distinguish the independent effects of variations in the base and intermediate period prices on consumption during those split portions.

Response variables. A particular electricity demand response variable ( $Y_{j}$ in equation $2-1$ ) can be viewed as the outcome of four simultaneous choices regarding:*

*A11 response variables must be based on KWH consumption over a minimum time interval of 15 minutes when standard recording meters are used. Actually the DOE data file will contain data for minimum time intervals of one hour. 
1) the algebraic form of the response variable,

2) the daily time interval over which the chosen variable is integrated,

3) the day(s) over which the chosen variables is totaled or averaged, and

4) whether the final response variable is a total or average variable.

Typically the algebratc form of the response variables is regarded as KWH or perhaps a logarithmic transformation of KWH. Generally, the response variable we propose to use will be of that form. However the list of possible variables includes:

1) KWH consumption,

2) KWH consumption shares,

3) electricity expenditures,

4) electricity expenditure shares, and

5) parameters of a cubic spline (or other smooth function) fitted to individual load curves.

Since variables 1-4 are more common, they are discussed first in the following paragraphs. Then we turn to variable 5 .

Variables 1-4 must be further defined in terms of the daily time interval over which they are integrated. For example, under the rate illustrated in figure 2-1 the peak and base periods would be two logical daily integrating periods, since the definition of unique rates during those periods implies special interest in the quantity of electricity consumed within them. In general, it will be of interest to examine variables for daily integrating periods that correspond to the independent 
rating periods (IRPs) as defined above. Also it will be useful to analyze separately those response variables that correspond to split portions of IRPs. Therefore we suggest that all IRPs and split portions of IRPS constitute the minimum set of daily integrating periods. Further, we wi 11 , at minimum, analyze variable 1, or a logarithmic transformation thereof, for these integrating periods.

Even when the algebraic form and the daily integrating periods are identified, it is still necessary to determine the day(s) over which that chosen variable is totalled or averaged before regressions are performed. For those studies where standard two- or three-dial meters are used, e.g., Arizona and Oklahoma, there is no choice other than averaging over the billing cycles, usually a month, during which data are collected. But in other studies that furnish hourly data, many other options are available: averages over a) the peak day in each month, b) weekdays, c) weekends, d) weekdays excluding holidays, e) weekends and holidays, f) 28-day months, g) calendar months, h) billing months, i) seasons, j) Mondays, Tuesdays, etc. within a 28-day month, calendar months, etc.

While all these options are interesting, their sheer volume implies the need for choice. We suggest a two-tiered analysis with respect to integrating periods. First, since the month and day of system peak are of particular interest to utilities and regulators, we propose, at minimum, to estimate response surfaces both for the single day of system peak and for the month (probably calendar month) of system peak. Since the experimental TOD rates account for all hours of the month within the full set of IRPS, we do not propose to distinguish weekdays and weekends for the analys is of monthly variables. 
Second, we propose to conduct seasonal analyses in which monthly demand systems are first estimated separately within each season (as distinguished by the electricity rates). Then the monthly cross sectional data will be pooled with the time series data within season to estimate a demand system in which price coefficients are restricted to be constant within seasons. Then the F-statistics from the pooled regression will be used with the sum of those from the component monthly regressions to test. the validity of the seasond mudel.

With respect to the last choice, there is no essential analytic difference between response variables that are averages and those that are tutals provided that identical days are represented within the set of response variables for all individuals in the experiment. Totals would appear to be advantageous in analyzing variables specific to IRPs in particular studies; specifically, in those studies where only base prices apply during weekends (and sometimes holidays) while not only base but also peak (and sometimes intermediate) prices apply during weekdays. Otherwise, e.g., average daily consumption within the base period during a 28-day month would be hard to interpret, since consumption within eight 24-hour periods ( 4 weekends) would be combined with consumption during the base periods for the 20 weekdays and (presumably) divided by 28. If daily averages are preferred, one alternative is to average over only non-holiday weekdays within the month and to ignore the weekend data. However, the estimation of a response surface model from such data implicitly assumes zero substitutability between electricity consumption during weekends and weekdays--a questionable assumption. Therefore, in those studies with rates of the type described 
above, i.e., base period weekends, we tentatively suggest the use of total variables over a 28-day month.*

Variable 5 offers another interesting option that we plan to investigate if adequate resources are available. It consists of the parameters of some smooth function of the observed individual load curves. The basic motivation for estimating such a function is that it allegedly involves little sacrifice of the fine detail of individual load curves while offering some computational economy through data reduction. If the cost of human and computational resources were a negligible factor, the advocates of this approach might argue that the best choice (number 2 above) of integrating periods for the chosen response surface variables would be those periods that are smallest among those for which data are available -- in the case of this study, the 24 hourly intervals. The purpose of fitting a smooth function to these 24 time series observations, also averaged over some appropriate period, would be to reduce the number of cross sectional regressions from 24 to whatever number of parameters is required to describe the smooth function. One such function, the cubic spline, has already been successfully applied to the data from the Connecticut experiment by Hendricks, Koenker, and Poirier (1977). The advantage of this approach is, of course, that the response surface model would predict an entire load curve shape rather than step functions associated with the IRP invervals. The disadvantages include: a) potentially substantial computational costs for the additional regressions and for obtaining

*This suggestion is subject to change because of complications that may arise in the seasonal analyses when the number of holidays differ among the 28-day months of interest. Perhaps some normalization scheme will be feasible, e.g., by some method, weighting non-holiday weekday totals up to 20-day equivalents and dropping weekday holiday data. 
confidence intervals about the predicted load curves and b) perhaps the arbitrariness of chosen parameterizations of the smooth function.

Independent Variables. The use of cross-sectional data to estimate demand functions requires the incorporation of variables, in addition to prices, to explain the cross-sectional variation in electricity demand. Thus, estimating demand equations using cross-sectional data implies demand as a function of prices, income, and other demographic, economic and climatic variables. These other independent variables can be incorporated in a wide variety of ways; a few of the more promising incorporations are discussed here.

The demand for elestririt.y is hasically a demand derived from usage of the household's stock of electrical appliances.* In general, the larger a household's stock of electrical appliances, the greater its demand for electricity, ceteris paribus. An index of electrical appliances can be constructed that will reflect the relative size of different households' stocks of electrical appliances. The appliances used by a household can be weighted by their wattage or by their approximate KWH usage per month. The index would then sum over these weighted values for all major appliances for a given household. The advantage of weighting by approximate KWH usage per month per appliance rather than by wattage per appliance is that appliances with high wattages (e.g., ranges) which are

*The relative prices of different fuels may have a significant influence on the stock of electrical appliances owned by a household. Due to the short-run nature of most of the experiments, the stock of appliances can be considered exogeneous, however. In other words, the stock of appliances was determined prior to implementation of time-of-day rates and in the short-run the time-of-day prices will not alter the stock of appliances.

tAn example of weighting by wattage can be found in Hendricks et al (1977). Although their data is aggregated over households, the concept remains the same. 
generally not turned on for a major part of the day would not receive a weight as great as an appliance with a similar wattage which might run for a major part of the day.*

Weather conditions also influence the consumption of electricity. A measure of one or more climatic variables could be incorporated directly into the demand equation. If the data are essentially aggregated over some period of time, such as a month, then an average of the weather variable over the month could be used. In this case, however, the question of cross-sectional variation in a variable arises, If the experimental region is a relatively small or homogeneous geographic area, an average over a month of a variable such as temperature will not vary much crosssectionally. Such a variable would thus lend little explanatory power to the equation being estimated. If the data are pooled cross-sectional, time-series data (numerous households are observed over a period of days), weather variables might be more significant. Since consuinition of electricity seems to depend not only on current temperature but on temperature on previous days as well, then some sort of distributed lag in temperature could be incorporated. Again, this is nonsensical if the data are aggregated and analyzed over a period of time such as a month.

Temperature and other climatic variables influence electricity consumption by influencing the use of weather-sensitive appliances such as air-conditioners and heaters. Thus, an alternative way of incorporating weather's influence is to construct a variable that interacts weather with

*It must be stressed that the approximate KWH usage per appliance weights are the same across households. In this way, the index remains exogeneous. Weighting by how much each individual family utilizes an appliance might introduce simultaneous equation bias due to incorporating a variable which might itself be influenced by time-of-day prices. The suggested weights are based on average usages of appliances and thus the weights do not vary cross-sectionally. 
weather's influence is to construct a variable that interacts weather with weather-sensitive appliances and household characteristics that determine the efficiency of such appliances. This type of variable would involve an attempt to calculate KWH requirements for heating (cooling) based on type of heating (cooling), area to be heated (cooled), design conditions (such as single family house, apartment, storm or insulated windows, insulation), and weather conditions. The construction of a variable of this sort requires an immense amount of information concerning each household in the experiment. Even if some of this type of information exists, there is no doubt much that is omitted (for example, the interaction between solar incidence and location and size of wirluws, or the existence of insulation in walls and attics) and much would have to be assumed during the construction of the variable (such as the degrees of temperature difference maintained between the inside of the house and the outside). The cost of constructing such a variable may well exceed its benefits. Any insignificance of the coefficient of such a variable in a regression equation may be due to the fact that the variable as constructed does not really capture the interaction of weather with weather-sensitive appliances rather than due to no significant influence of weather on electricity use.

A strategy of first employing relatively simple proxies for the interaction between weather and appliances and working toward more complicated proxies, if time and money permit, might prove more fruitful than immediate incorporation of variables constructed to capture some intricate interaction. One simple proxy incorporates the idea that weather will only influence electricity consumption of a household if that household owns weather-sensitive electrical appliances (e.g., air 
conditioners or electric heat). Thus a variable such as temperature (perhaps maximum, minimum, or average over the relevant period) multiplied by a dummy variable for owning electric weather-sensitive appliances could be constructed. Such a variable would more accurately reflect the influence of weather than would simply entering temperature, if those households without weather-sensitive appliances are not influenced by temperature:

If a simple proxy for the weather-appliance interaction such as discussed above were incorporated, one might also include an air conditioning or heating index constructed in a manner similar to the construction of the electrical appliance index. This index could be included separately or added to the electrical appliance index and would take into account relative sizes of electric heating or cooling capacities. If such an index were implicitly included in a more complex weather-appliance proxy, of course, there would be no need for incorporating it again.

The data collected on individual houschold's electrical appliances concerns large appliances such as ranges, refrigerators, washers, dryers, and freezers. Small appliances, from toasters to hairdryers and lights are not included in the construction of an electrical appliance index as previously discussed. The contribution of small appliances can be proxied by including such variables as size of house, number of rooms, or income (Lawrence and Braithwait, 1977).

Another very important influence on time-of-day consumption of electricity likely involves household composition and labor force participation. A household with two pre-school children and a woman who remains at home would likely have a different time-of-use pattern than a household with two adults working full-time outside the home. A dummy variable for all adults working outside the home during the "eight-to-five" hours could 
be incorporated. Alternatively, the number of people (or adults) at home during the day could be included. Inclusion of the number of children in the age group 0-6 years may prove to be significant as well.

The prices of alternative fuels (natural gas, oil) would influence electricity consumption through influencing the choices between types of appliances. This is basically a long-run consideration, however, and if the time-of-day rates apply only for a relatively short period of time, relative prices of alternative fuels would have little impact on the appliance stock and thus on electricity consumption.* In addition, in an experimental region, little cross-sectional variability in the prices of alternative fuels will generally be observed, potentially suggesting the exclusion of such variables in an analysis:

Theory would suggest that past usage should be of significance in explaining electricity consumption. ${ }^{+}$In stratified random sampling, this was often the basis for stratification so that incorporation of a variable measuring past levels of usage may take into account many stratification effects (or vice versa). However, past usage is itself a function of the independent variables already discussed. Inclusion of all these variables may lead to considerable multicollinearity problems. If one is interested only in price elasticities, demand could be expressed as a tunction of prices and past usage only, since past usage is essentially a portmanteau variable. If the influence of other independent variables is of interest, however, two approaches are feasible. First, if the portmanteau variable alone reduces the sum of squared errors more than all the specified

*Wenders and Taylor (1976) suggest that the long-run, with respect to appliance stocks, is 7 years, at a minimum.

${ }^{+}$By past usage we refer to usage in a time period prior to implementation of time-of-day rates. 
independent variables combined, it is possible to complete a two-stage regression in which the first stage regresses prior usage on the variables of interest. Second, if there is little difference in explanatory power, the independent variables should be included directly as separate variables: demand is expressed as a function of prices, income and other relevant exogeneous variables.

\subsubsection{Neoclassical Demand Approaches}

Many of the operational response surface models that are intrinsically linear and also based on the neoclassical theory of demand are very similar to the standard Taylor's series approach summarized in the previous section. However, these models have unique features that commend them for considerations. Therefore, we will consider applying them if resources permit.

One positive feature of the neoclassical theory is that it hypothesizes refutable propositions that suggest several restrictions on the parameters of multi-commodity demand systems (in this case, the commodities consist of electricity during several IRPs). Specifically, four fundamental, refutable propositions about demand behavior have been derived by economic theoreticians and are frequently incorporated as assumptions in postulating econometric demand models. The propositions are (Deaton, 1975, pp. 12-13):

1) Aggregation: the sum of an individual's expenditures equals total expenditure;

2) Homogeneity: a proportional change in income and all prices has no effect on purchased quantities or budget allocations;

3). Symmetry: the matrix of cross-price derivatives (used to estimate cross-price elasticities) must be symmetric; and

4) Negativity: the "substitution matrix" must be negative semidefinite. This implies, among other things, that income compensated price increases decrease the demand for, the goods involved. 
While these propositions may seem esoteric, they are essential elements in estimating elasticities. Often modellers build non-testable restrictions into their empirical models in accord with these four refutable propositions. This represents a fundamental misunderstanding of the role of economic theory in econometric analysis. One example is an untested homogeneity assumption that is pervasive in expenditure share models. Yet, as Deaton (1975, p. 237) points out: "In every case where it has been seriously tested, the homogeneity postulate has been rejected." Another example of model restrictions may apply within experimental situations involving extremely wide variation in experimental prices within rating periods. The inclusion of these wide price ranges may invalidate the assumption of a linear or loglinear model and lead to gross miscalculations of rate effects over the region of practical interest. Nonetheless, if the suggested restrictions are valid, they offer potential increases in the efficiency of the model estimation procedure.

A second positive feature of models based on neoclassical demand theory is that they yield parameter estimates that can be fairly easily translated into a set of price elasticities that are easy to interpret.

Infortunately, the derivation of an operational model based on the neoclassical theory requires an assumed functional foril (ur appruximation of the form) of a utility function. Actually, the estimable neoclassical models and associated restrictions are developed as though a single individual's behavior were being observed at equilibrium under the effective experimental prices. What we in fact estimate, however, is the average behavior of several individuals in transition from one price regime (existing rates) to another, a TOD rate. These divergencies suggest some caution about the application of untested propositions about electricity demand behavior (Clarkson, 1963; and Mishan, 1961). 
The remainder of this section briefly summarizes potential applications of two of the more attractive models based on neoclassical demand theory: the linear expenditure system and the translog system.

The Linear. Expenditure System. Given $M$ goods that the consumer may wish to buy, the assumption of a utility function of the form

$$
U=\sum_{i=1}^{M} a_{j} \log \left(a_{i}-b_{i}\right)
$$

implies a set of demand functions of the form

$$
q_{i}=b_{j}+\frac{a_{j}}{P_{i}}\left(Y-\sum_{k=1}^{M} P_{k} b_{k}\right)
$$

where $a_{i}$ and $b_{j}$ are parameters,

$q_{i}$ is quantity of the good $i$,

$Y$ is income, and

$P_{i}$ is the price of good $i$.

It can be shown (Deaton, 1975) that (2-4) is the only linear specification of demand functions that obeys the postulates of neoclassical theory. Bridge (1971) gives a detailed interpretation of this system and discusses estimation methods. We will not use (2-4) in the form shown because we are not in a position to analyze the consumer's behavior with respect to all goods, but only with respect to electricity. Hence the estimation of $(2-4)$, with all the implied restrictions on the estimation equations, is not of interest unless separability is imposed. We propose instead to follow Benus, Kmenta and Shapiro (1976) in simply taking the functional form of $(2-4)$ as a convenient starting point in specifying a demand system for a subset of the consumer's market bundle. Accordingly we reparameterize $(2-4)$ and get a function of the form 


$$
E_{i k}=a_{0}+a_{1} \gamma_{i}+\sum_{k=2}^{M+1} a_{k} P_{i k}+e_{i}, i=1, \ldots N
$$

where $P_{i k}=$ electricity prices faced by household $i$ in period $k$,

$Y_{i}=$ expenditures for household $i$, and

$E_{i k}=$ expenditure for electricity by household $i$ during period $k$.

If the demand equation for electricity is one of a system of demand equations for all $M$ goods, then $Y$ should be family expenditures for the $M$ goods. However, if the utility function being maximized is separable between electricity and all other goods, then $Y$ must be interpreted as total expenditure on electricity. The former interpretation implies that this modified linear expenditure system approach is just a special case of the Taylor's series approach of (2-1), where the response variable consists of expenditures and the second order terms are dropped.

If we assume the latter approach, potential difficulties arise in both interpretation and estimation. The $f$ act that $Y$ is endogenous means that that system is underidentified. Ordinary least squares estimates will be biased and inconsistent because $Y$ will be correlated with the error term. Two stage least squares and three stage least squares estimators will not exist because the system is underidentified. If an extra equation is added to explain variation in total expenditures on electricity, a second additional (identity) equation is also necessary to insure that electricity expenditures identically equal the sum of expenditures by time-of-day. This situation implies an overdetemination of the system unless one of the time-of-day equations is dropped. 
Lawrence and Braithwait (1977) have applied a version of the linear expenditure system to the data from Connecticut. The approach we suggest is essentially the same as their estimation of the reduced-form expenditure system equations.

The Translog System. The translog system of demand equations is based on transcendental logarithmic utility functions suggested by Christensen, Jorgenson, and Lau (1975). Under this approach a general utility function is approximated by a second order Taylor's series. Both a direct and an indirect specification of the utilily function are used. Then several manipulations are applied to these approximations to derive two alternative systems of nonlinear demand equations that comprise the system. Those based on the direct utility functions use quantities consumed as regressors while those based on the indirect functions use income (expenditure)-normalized prices; both specify budget (expenditure) shares as dependent vartables. The major advantage of the translog model is that it is completely general and facilitates tests of the postulates of neoclassical demand theory.

However, the fact that the basic translog models are nonlinear reportedly causes signficant computational problems with convergence in the estimation process. Regardless, the estimation of a large number of nonlinear systems is potentially tedious and costly.

An alternative is to impose the homotheticity assumption as Atkinson (1977) did. However the implications of this assumption with respect to estimated elasticity magnitudes is currently under debate and, therefore, its appropriateness is unclear. In any event, with the homotheticity assumption imposed, the translog system is a special case of the second order Taylor's series model when the dependent variables are budget (expenditure) shares. 


\subsection{Analytical Problems}

Three basic types of potential problems occur in the proposed analyses (section 2.2):

1) problems of inference to the desired customer population,

2) problems arising from the lack of (the most desirable type of) data, and

3) problems arising from the experimental design (the configuration of treatments and the techniques for assigning customers to treatments).

The extent to which these problems occur varies considerably over the demonstration projects; the discussion of the individual projects (chapter 3 and Volume II) will describe the major analytical problems which are inherent in each project. The purpose of the rollowing discussion is to point out the problems, indicate why they are problems, and indicate, where possible, what is required to overcome or circumvent the problems.

\subsubsection{Population Inference Problems}

The population of customers for which inferences are desired is either the entire class of residential customers in a utility's service area or some specific subgroup of this class (for which a time-of-day rate might be implemented by the utility). This population is clearly indicated as the desired population of inference in the Request for Proposal, and it is reflected in the proposed lists of (dependent) variables to be analyzed and reported (section 2.2). Load curves presented as part of the descriptive analyses, for example, would ideally represent an estimate of those that would occur if the entire class were exposed to particular rates.

To achieve valid statistical inferences to this population is, in a strict sense, virtually impossible, because the population is constantly changing. Target populations for most of the demonstration projects have 
been defined (at least, initially) as all households with an active residential account as of a specific time (namely, when the sample was drawn). This appears to be a reasonable modification of the desired population of inference. To obtain valid estimates for this target population requires that a probability sample of the target population be exposed to each experimental rate. Appropriate weighting of the observations from the sample members then provides one with estimates which are applicable to the target population.

Unfortunately, in most of the demonstration projects, a number of customers in the above-described target population have been systematically excluded from participation in the experiment. These exclusions are of two basic types. The first type of exclusion simply involves the removal of some accounts from the sampling frame; that is, some customers have a zero probability of being included in the experiment. Although this type of exclusion may reduce the meaningfulriess of results, since the implied target population may be less relevant, it does not otherwise cause inferential problems as long as one is willing to limit inferences to this reduced population and as long as the population counts of the eligible accounts are available (by stratum, if applicable). Relative to the entire class of residential customers, of course, the results may be biased. Typical examples of this type of exclusion are the following:

1) customers with a short (e.g., less than 12 months) billing history,

2) customers with an estimated bill in the past $X$ months,

3) accounts associated with seasonal dwellings*,

*These are considered as exclusions of the first type only if such information is available for all accounts. Otherwise, they are regarded as exclusions of the second type. It should also be noted that these may be legitimate exclusions if such customers would not be placed on a non-experimental time-of-day rate. 
4) customers with irregular monthly usage patterns,

5) customers with low annual usage or low usage in $X$ out of the past $Y$ months,

6) customers with credit problems,

7) accounts associated with multiple-family dwellings*, and

8) customers living in certain geographic areas within the service area*.

The second type of exclusion differs from the first type in that the t.nt.al number of eligible accounts in the resulting population is unknown when exclusions of the second type occur. Exclusions of the second type may be further subdivided according to whether exclusion occurs because of customer's actions and/or attitudes or because of other circumstances.

The latter include:

1) wiring incompatibility or meter inaccessibility, and

2) failure to locate or contact customer.

Customer actions/attitudes which may bias results include:

1) failure to be included because of numerous customer complaints,

2) failure to participate in experiments (including, in some cases, failure to volunteer as a participant) or cooperate in interviews, and

3) failure to be included because of certain interview responses (e.q., plans for moving).

One would like to achieve estimates which are valid for the universe --usually, the class of all residential customer accounts as of a specific time. Let

$\begin{aligned} N^{*}(h)= & \text { the number of such customers in the hth stratum } \\ & (h=1,2, \ldots, H),\end{aligned}$

$N(h)=$ the number of such customers in the hth stratum who are in the sampled population (i.e., in the sampling frame: those eligible after excTusions of the first type),

*See footnote on page 43. 


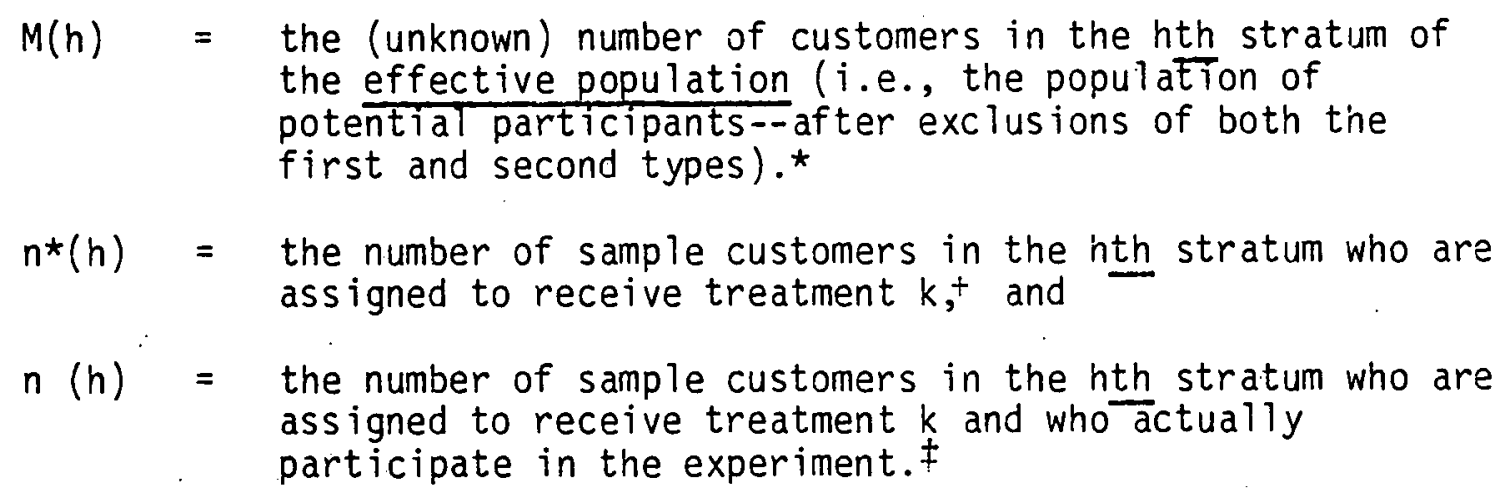

Valid statistical estimates can be made for the effective population: ** This requires that one estimate $M(h)$, the number of potential participants in the hth stratum. Under the previously indicated assumptions, such an estimate is given by

$$
\hat{M}(h)=\left[N(h) \sum_{k=1}^{K} n_{k}(h)\right] \int_{k=1}^{k} n_{k}^{*}(h),
$$

where $K$ denotes the total number of treatments involved in the experiment. Est imates of the means of a response variable $Y$ for the effective population (E) under the various, treatments are as follows:

*For discussion purposes, it is assumed that a customer's participation or non-participation does not depend on the treatment to which he/she has been assigned. Alterations to some of the subsequent formulae are necessary in those cases where this assumption appears unreasonable.

tCustomers within each stratum are assumed to be assigned to treatments at random.

ҒAlthough this quantity can change with time (e.g., due to movement of customers), it is treated as a constant in order to facilitate the discussion.

**This will generally require information on the sample and sampling frame which may not be routinely available in the Product User's Guides. 


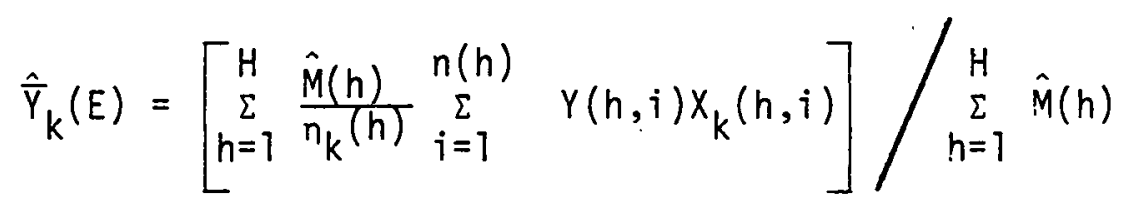

where $n(h)=$ the total number of sample participants in stratum $h$, $Y(h, i)=$ the response of the ith participant in stratum $h$,

and

1 if the ith sample participant of stratum $h$ is

$$
x_{k}(h, i)=\begin{aligned}
& \text { assigned to treatment } k \text {, and } \\
& 0 \text { otherwise. }
\end{aligned}
$$

Inferences to the samplad population, as opposed to the effective population, require that one assume that exclusions of the second type are unimportant--i.e., an assumption that the effective population represents a random sample from the sampled population (on a stratum-by-stratum basis). In a quantitative sense, one would like $M(h)$ to be large relative to $N(h)$; in a qualitative sense, one would like customers in the effective population to be similar to those in the sampled population but excluded from the effective population. If such assumptions appear reasonable, one may report estimates for the sampled population (S). Estimated means for each treatment would be obtained, for instance, as

$$
\hat{\bar{Y}}(S)=\sum_{h=1}^{H} \frac{N(h)}{n_{k}(h)} \sum_{i=1}^{n(h)} Y(h, i) X_{k}(h, i) / \sum_{h=1}^{H} N(h) .
$$

Statistically-valid inferences to the universe are, in a strict sense, not attainable unless the universe and sampled population coincide. If the number of exclusions is small and they are regarded as unimportant in terms of the types of customers excluded, one may wish to replace $N(h)$ with $N *(h)$ in formulae such as $(2-7)$. No claim of unbiasedness or indication of accuracy of the resulting estimates, however, can be made. 
All inferences--whether they be to the effective population, the sampled population, or the universe--are obviously conditional on the nature of the experiment--the duration of the experiment, the types of educational information that participants receive, the terms of customer participation (voluntary or mandatory, the use of incentives, etc.), etc. Such considerations are highly interrelated and judgments concerning the validity of inferences to a specific population can be only partially quantitative. For instance, consider an experiment involving voluntary participation in which the sampled population coincides with the universe (i.e., no type one exclusions). Assume further that there are no type two exclusions; in particular, assume that a.11 of the selected customers agree to participate in the experiment. Even though the effective population coincides with the universe, the inferences may be of limited value because customers' willingness to participate may have been based upon the fact that incentive payments were offered (direct paymerils), that the experimental rate involved extremely low prices relative to the existing rate (indirect payments), or that the duration of the experiment was extremely short.

The above-indicated strategy for making inferences is depicted in the flow chart in Figure 2-4.

The concept of drawing inferences to a finite population is a common practice in econometric modeling; usually, however, these inferences are non-statistical inferences. That is, it is assumed that one can specify a model which holds uniformly over all persons in the population. Of course, one can actually test such a model only with respect to the sample customers. Hence, it is important that all segments of the population be included in the sample, particularly if the coefficients on the price-related 
variables depend on customer characteristics (e.g., prior usage, income, dwelling size).* In some projects, the experimental and sampling designs are such that little justification can be made for conducting a weighted analysis which would expand inferences up to a given finite (effective) population, since this population may be virtually meaningless relative to the universe. In these cases, the response surface models would be fitted using only the sample participants. An attempt will be made, however, when summarizing these models over customers with different covariate values, to utilize weighted covariate values.

\subsubsection{Data Limitations}

The DOE data base consists of five main components rur each of the demonstration projects:

1) A machine-readable file of customer information, including customer identification information (stratum and treatment assignment codes, information for 1 inking customer data with other data files), historical usage information (on a billing month basis), customer survey data (from one or more interviews) on customer and dwelling characteristics.

2) A machine-readable file of weather information from weather stations in the geographical area of the project, generally on an hourly bas is.

3) Machine-readable system load data, on an hourly basis.

4) A machine-readable file of customers' KWH usages, usually on an hourly basis, but sometimes on a rate-specific, billing month bas is.

5) Hard-copy data (e.g., stratum and treatment specifications, alternate fuel prices) and documentation of sampling and experimental procedures.

The analyses proposed in section 2.2 involve using the first two types of data as independent variables. Although failure to have complete data records on these files may hinder the analyses, they should pose no

*In the linear model situation, this would usually be handled by including treatment-covariate interactions in the model. 


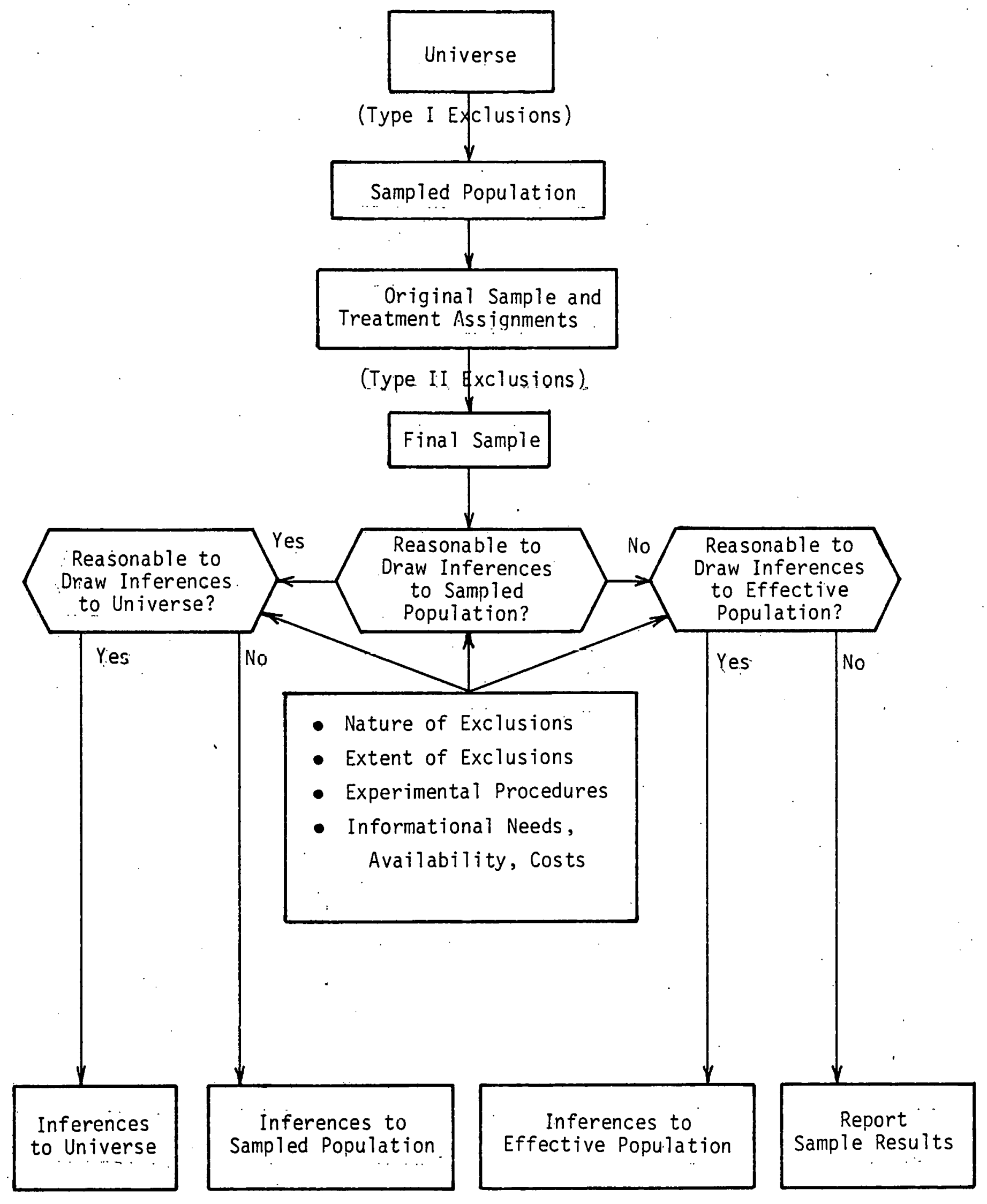

Figure 2-4. Strategy for making inferences 
major limitations otherwise. The third type of data should also pose few, if any, limitations on the analysis.

Potential analytical limitations associated with the remaining two data types arise from:

1) the use of two- or three-dial meters in some projects,

2) the inability to associate a particular customer at a particular time with a given billing month,

3) the lack of complete information on fuel adjustment charges,

4) the lack of complete information on sampling procedures and sampling weights, and

5) inconsistent missing-data criteria from project-to-project.

The use of two- or three-dial meters causes obvious analytical problems in that none of the proposed analys is (dependent) variables can be constructed when meters are read on a billing month basis. The construction of meaningful alternative variables is likely to require additional information. The use of dependent variables defined on a billing month bas is is considered undesirable, particularly when sample sizes per treatment are smal1. The use of experimental rates wilh different daily rating periods, in conjunction with the use of such metering, severely constrains some analyses. Since the construction of many meaningful dependent variables across all rates cannot be achieved, it may be necessary to conduct separate analyses by rating period.

Many of the proposed analyses will be restricted due to: the fact that the usage data file does not indicate the billing monthi from which a particular hourly KWH originated. This causes no problem for the comparative analyses if the daily rating periods remain constant throughout the experiment. Whenever daily rating periods change from season to season, it will not be possible to construct some of the analysis variables for 
those calendar months in which such changes occur. More serious constraints are imposed on those analyses which involve explicit use of price levels (section 2.2.3). First, if time-of-day prices change seasonally (even if rating periods remain constant), then response surface analyses (elasticity estimation) cannot be performed for the seasonal transition periods. Secondly, if fuel adjustment charges are present and are to be incorporated into the prices involved in the models, then additional information on both the magnitude of the fuel adjustment (by billing month) and the starting and ending time of each billing month (by customer) will be needed.

As indicated in the previous subsection, inferences would ideally be made to the universe of residential customers; in most instances, however, the assumptions necessary for inferences to this population are unrealistic and some smaller population of inference will be used. Extensive documentation on the sampling proccdures, including relevarl population sizes (by stratum) and sample sizes (by stratum and treatment) and detailed information on the number of exclusions (by type of exclusion, stratum and/ or stratum/treatment) will be required. It may be that the documentation furnished by many of the demonstration projects to DOE will be insufficient for constructing sampling weights appropriate for the determined population of inference. Direct contacts with the local projects will be required in such cases to obtain this information, if available.

Any technique for handling non-response or missing data* problems relies on assumptions (for example, that a customer's pattern of usage is

*The use of the terms non-response or missing data in this context refers both to item non-response (e.g., failure to respond to particular questionnaire items or failure to have complete usage data over some time interval) as well as unit non-response (i.e., lack of a data record). 
like that of customers with similar characteristics who receive the same treatment). Judging the reasonableness of such assumptions may require extensive information concerning why a particular portion of data is missing. What may be a valid hourly zero usage reading in one project, for instance, could be a valid missing value for another project; similarly, a customer's entire set of usage data over some time period (e.g., a billing month) may not be submitted by a project because of project-specific definitions and procedures regarding what constitutes "valid" data. Though these definitions and procedures may bè well docunlenled, reasons for zcros and missing data nn a specific customer bas is will generally be unavailable. Again, it is likely. that additional information will be needed from some projects in order to deal with these problems.

\subsubsection{Experimental Design Constraints}

Two basic types of experimental design constraints are evident in (some of) the demonstration projects. The first of these is closely iinked to the inferential problems discussed in section 2.3.1. The notion of evaluating the impact of time-of-day rates on a systemwide bas is implies that derived estimates be applicable to the system or the relevant subpopulation of the system (e.g., all residential customers). This, in our opinion, implies that there is a specific finite population for which inferences are desired; such inferences are desired, in the case of comparative analyses, for each treatment. In the case of response surface analyses, the points on the surface would, ideally, represent estimates of usage which would occur if the entire universe were exposed to the specific set of prices. In either case, a probability sample of the universe 
for each treatment or design point would be desired.* If the population is partitioned into strata, as is the case with most of the projects, this implies that every treatment should be represented in every stratum ${ }^{\dagger}$ (preferably, by several customers). Several of the project designs lack this feature. Two basic patterns occur in these cases. First, some strata may be completely excluded. This constitutes systematic (Type I) exclusions from the population and it is necessary to redefine the population for which inferences are to be made. The second type of pattern occurs when all strata are represented but they are not represented for each treatment. As previously indicated, this may or may not pose problems for the response surface analyses. For comparative analyses, treatment effects are confounded with population differences (e.g., the estimated monthly on-peak usage for treatment \#l is an estimate for one population of customers and the estimated monthly on-peak usage for treatment \#2 is an estimate for a different population). This problem can be treated in two basic ways. First, inferences may be confined to a smaller population consisting of those strata where all treatments involved in the particular comparison of interest are represented. The second alternative is to assume that modeling over the unsampled segments of the population is reasonable and can remove the population differences from the treatment effects.

*This restriction can be somewhat relaxed for the response surface analyses, in that the configuration of design points does not have to be the same for all strata; rather, the requirement is that the response surface be estimable for each stratum.

tThis does not preclude the use of different strata definitions for different treatments or the use of multistage sampling. If multistage sampling is employed (e.g., first units could be geographic areas, second stage units could be customers), then probability sampling at each stage would be desired. 
The second basic type of experimental design constraint is involved chiefly in the building and estimation of response surface models, although essentially the same problem sometimes occurs in the comparative analyses. In the latter case, the problem is generally referred to as confounding of treatment effects. Such cunfounding may occur, for instance, in a comparison of treatment and control groups. Differences between the groups, ideally, would reflect the effect of a particular time-of-day pricing scheme relative to the existing scheme. However, if the treatment group has been treated differently from the control group in other respects (e.g., a higher level of educational information may have been provided, or a larger incentive payment may have been used for the treatment group), then group differences may be attributed, at least partially, to these factors.

The problem of confounding is present, in a variety of forms, in virtually all of the projects where response surface analyses are indicated. Its effect is twofold: 1) to produce estimated regression coefficients with low precision,

2) to produce estimated regressinn coefficients (and, hence, price elasticity estimates) which are conditioned upon a number of as sumptions.

Lack of precision in the estimated coefficients arises from a poor configuration of design points relative to the proposed model. In many cases, this occurs because local projects were legally constrained. In other cases, the configuration may be poor simply because the model specification is not compatible with the model specification envisioned by the project at the design stage. The estimates are, in many cases, highly conditional because complete specification of rates in terms of independent variables 
is not made. In many cases, this occurs because specification of such complete models would be useless since they would be non-estimable. One common example of this occurs when seasonal time-of-day rates are involved. Usually it is necessary to assume that prices charged in the wintertime have no effect on the amount or patterns of summertime usage. In general, such assumptions cannot be avoided since most experiments involve nearly-saturated designs (i.e., the number of unique design points barely exceeds the number of (treatment-related) parameters to be estimated for each dependent variable). In this regard, it should also be noted that such a situation provides one with little capability for exploring alternative models and making comparisons among models. 


\section{THIS PAGE WAS INTENTIONALLY LEFT BLANK}


This chapter outlines the analyses that are planned for each of the projects for which final reports are required. Section 3.1 first summarizes the analysis plans and then introduces the remainder of the chapter with an overview of all the projects and general comments on the format of the project-specific presentations.

\subsection{Summary and Introduction}

\subsubsection{Summary}

Three basic types of analysis are planned: descriptive, comparative, and response surface analyses. Details on each of these approaches are provided in chapter 2. Generally those rates within projects which will be subjected to descriptive and comparative analyses have been identified as a.11..those for which 40 or more observations are available. This cut-off is suggested because of the serious deterioration in statistical reliability that is likely with fewer observations. For those projects with several rates that have 40 or more observations, multiple descriptive and comparative analyses will be completed.

Response surface (or elasticity) estimation is suggested for all those projects that have several time-of-day rate combinations rather than just a single experimental time-of-day rate. Table 3-1 summarizes the suggested types of proposed analyses by project.

In developing the project specific analysis plans, we have taken the approach of specifying a minimum set of analyses that will be conducted. In addition, sections 3.2-3.15 identify other analyses that may be completed if adequate resources remain. Generally two kinds of restrictions were imposed to develop the minimum set of analyses. First, the number of 
Table 3-1. Type of analys is by project--an overview

\begin{tabular}{|c|c|c|c|c|}
\hline \multirow[b]{2}{*}{ Project } & \multicolumn{4}{|c|}{ Comparative Analys is } \\
\hline & $\begin{array}{l}\text { Descriptive } \\
\text { statistics } \\
\text { (graphical) }\end{array}$ & $\begin{array}{c}\text { Single- } \\
\text { comparison } \\
\text { (treatment } \\
\text { vs. control) }\end{array}$ & $\begin{array}{l}\text { Multiple } \\
\text { comparisons } \\
\text { among treat- } \\
\text { ment \& control }\end{array}$ & $\begin{array}{c}\text { Response } \\
\text { surface } \\
\text { analys is } \\
\text { (elasticities) }\end{array}$ \\
\hline Arizona & & & & $x$ \\
\hline Arkansas & $x$ & & $x$ & $x^{1}$ \\
\hline California (SDG\&E) & $x$ & · & $x$ & $x$ \\
\hline California (SCE) & $x$ & & $x$ & $x$ \\
\hline Connecticut & $x$ & $x$ & & \\
\hline Los Ariyeles & $x$ & & $x$ & $x$ \\
\hline New Jersey & $x$ & & $x$ & $x^{1}$ \\
\hline N.C. (BREMC) & $x$ & $x$ & & \\
\hline N.C. $(C P \& L)$ & $x$ & & $x$ & $x$ \\
\hline Ohio & $x$ & $x$ & & \\
\hline Ok l ahoma & & & & $x$ \\
\hline Puerto Rico & & & & $x$ \\
\hline Rhode Island & $x$ & $x$ & & \\
\hline Washington & & $x$ & & \\
\hline Wiscons in & $x$ & & $x$ & $x$ \\
\hline
\end{tabular}

IDecision to estimate response surfaces is tentative. 
variables to be analyzed in the comparative analysis and the number of functional specifications to be estimated in the response surface analys is were restricted to those considered most meaningful for a first analys is. Second, restricted time aggregations have been suggested for all types of analyses. Generally it has been suggested that, at minimum, analyses be conducted for the month of winter and of summer peak as well as other high demand months surrounding those two months. Also separate analyses have been suggested for the day of summer and the day of winter system peak.

Accordingly, table 3-2 further details the suggested descriptive and comparative analyses. The upper portion identifies the variables that will be estimated and the subset of variables which will be utilized in testing hypotheses. The lower portion of the table indicates, by project, the number of treatments that will be involved in the analyses and whether weighted analyses are being considered. In cases that involve a large number of months and/or treatments, the individual monthly analyses will be included as appendix material and will be replaced by seasonal (3-4 month) summaries in the body of the project-specific reports.

In the analys is plans for the individual projects (sections 3.2-3.15), the parts dealing with descriptive statistics and comparative analys is will only reference table 3-2. Departures from the procedure outlined in table 3-2 for a particular project will, however, be discussed. Additional comparisons that will be considered, time and funds permitting, are also described.

Table 3-3 summarizes the response surface analyses that are suggested for the final response surface model that is selected (a single average response surface for each season may be estimated for alternative models). As indicated, both peak month analyses and seasonal analyses are planned.

The peak month analyses will be conducted and presented for only one or two months per year depending upon whether the rate forms in the associated 
Table 3-2. Summary of proposed descriptive statistics and comparative analyses - by project

\begin{tabular}{|c|c|c|}
\hline \multirow[b]{2}{*}{ Statisticl } & \multicolumn{2}{|c|}{ Frequency of: } \\
\hline & $\begin{array}{c}\text { Estimate } \\
\text { (months/year) } \\
\end{array}$ & $\begin{array}{c}\text { Control vs. treatment } \\
\text { comparison } \\
\text { (months/year) }\end{array}$ \\
\hline Variables $1-18$ & 6 & 6 \\
\hline $\begin{array}{l}\text { Variables } 19-23^{2} \text { and } \\
\text { load curve } 6\end{array}$ & 2 & 0 \\
\hline Load curves 1 - 5 & 6 & 0 \\
\hline Project & $\begin{array}{l}\text { Number of } \\
\text { experimental rates } \\
\text { to be compared } \\
\text { with control }\end{array}$ & $\begin{array}{l}\text { Method } \\
\text { of } \\
\text { analysis } 3 \\
\end{array}$ \\
\hline $\begin{array}{l}\text { Arizona } \\
\text { Arkansas } \\
\text { California (SCE) } \\
\text { California (SDG\&E) } \\
\text { Connecticut } \\
\text { Los Angeles } \\
\text { New Jersey } \\
\text { North Carolina (BREMC) } \\
\text { North Carolina (CP\&L) } \\
\text { Ohio } \\
\text { Uklahoma (tdmond) } \\
\text { Puerto Rico } \\
\text { Rhode Island } \\
\text { Washington (SCL) } \\
\text { Washington (PSPL) } \\
\text { Wisconsin } \\
\text { Michigan, New York, } \\
\text { Vermont }\end{array}$ & $\begin{array}{r}0 \\
3 \\
8 \\
3 \\
1 \\
5 \\
4 \\
1 \\
3 \\
1 \\
0 \\
0 \\
1 \\
1 \\
1 \\
11 \\
0\end{array}$ & $\begin{array}{l}- \\
W \\
W(?) \\
W(?) \\
W \\
W(?) \\
W(?) \\
W \\
W \\
U \\
- \\
- \\
W(?) \\
W(?) \\
W(?) \\
W \\
-\end{array}$ \\
\hline
\end{tabular}

1 See tables 2-1 and 2-2.

2 Variables 21 and 22 will not be estimated if unweighted sample data are analyzed.

$3 \mathrm{~W}=$ weighted analysis will be performed

$W(?)=$ weighted analys is will be performed if considered feasible and appropriate

$U \quad=$ unweighted analys is will be performed 
Table 3-3. Sumnary of suggested response surface analyses

\begin{tabular}{|c|c|c|c|c|c|c|c|c|c|c|c|c|c|}
\hline \multirow[b]{3}{*}{ Project } & \multicolumn{5}{|c|}{ Experimental Rate Characteristics } & \multicolumn{5}{|c|}{ Peak Month Analyses } & \multicolumn{3}{|c|}{ Seasonal Analyses } \\
\hline & \multirow{2}{*}{$\begin{array}{l}\text { Number } \\
\text { of rate } \\
\text { forms } 1\end{array}$} & \multirow{2}{*}{$\begin{array}{l}\text { Number } \\
\text { of IRPs } \\
\text { in each? }\end{array}$} & \multirow{2}{*}{$\begin{array}{l}\text { Number of } \\
\text { IRPs for } \\
\text { combined } \\
\text { analys is } 3\end{array}$} & \multirow{2}{*}{$\begin{array}{l}\text { Number of } \\
\text { rating } \\
\text { seasons }\end{array}$} & \multirow{2}{*}{$\begin{array}{l}\text { Number } \\
\text { of months } \\
\text { per season } 4\end{array}$} & \multicolumn{2}{|c|}{$\begin{array}{l}\text { Number of individual } \\
\text { rate regress ions } \\
\text { averaged over } 5\end{array}$} & \multicolumn{2}{|c|}{$\begin{array}{l}\text { Number of combined } \\
\text { rate regressions } \\
\text { averaged over }\end{array}$} & \multirow[b]{2}{*}{ Total } & \multicolumn{3}{|c|}{$\begin{array}{l}\text { Number of addit ional regress ions } \\
\text { per project year averaged over months. } \\
\text { Individual rate Conbined rate }\end{array}$} \\
\hline & & & & & & montho & peak day & montho & peak day & & regressions 10 & regressionsil & Total \\
\hline & $(\operatorname{Col} 1)$ & $(\mathrm{Col} 2)$ & $(\mathrm{Col} 3)$ & $(\mathrm{COl} 4)$ & $(\operatorname{Col} 5)$ & $(\operatorname{Col} 6)$ & $(\mathrm{Col} 7)$ & $(\operatorname{Col} 8)$ & $(\operatorname{Cot} 9)$ & $(\operatorname{Col} 10)$ & (Col 11) & $(\operatorname{Col} 12)$ & (Col 13) \\
\hline Arizona & 3 & 3 & n.a. & 1 & 12 & 9 & 0 & 0 & 0 & 9 & 54 & 0 & 54 \\
\hline Arkansas & 1 & 2 & n.a. & ? & $\begin{array}{l}5-5 \\
7-w\end{array}$ & 4 & 4 & 0 & 0 & 8 & 24 & 0 & 24 \\
\hline $\begin{array}{c}\text { Cal if ornia } \\
\text { (SDG\&E) }\end{array}$ & 1 & 3 & n.a. & 2 & $\begin{array}{l}5-5 \\
7-w\end{array}$ & 6 & 6 & 0 & 0 & 12 & 36 & 0 & 36 \\
\hline $\begin{array}{l}\text { Cal if ornia } \\
\text { (SCE) }\end{array}$ & 2 & 2 & 4 & 1 & 12 & 4 & 4 & 4 & 4 & 16 & 48 & 48 & 96 \\
\hline Los Angeles & $14 *$ & 2 & 5 & $1 * \star$ & 12 & 28 & 28 & 5 & 5 & 66 & 336 & 60 & 396 \\
\hline New Jersey & 1 & 2 & n.a. & 2 & $\begin{array}{l}5-5 \\
7-w\end{array}$ & 4 & 4 & 0 & 0 & 8 & 24 & 0 & 24 \\
\hline N.C. (CP\&L) & 1 & 3 & n.a. & 2 & $\begin{array}{l}5-5 \\
7-w\end{array}$ & 6 & 6 & 0 & 0 & 12 & 36 & 0 & 36 \\
\hline OKlahoma & 1 & 2 & n.a. & 2 & $\begin{array}{l}5-5 \\
7-w\end{array}$ & 4 & 0 & 0 & 0 & 4 & 24 & 0 & 24 \\
\hline Puerto Rico & 3 & 2 & 3 & 1 & 12 & 6 & 6 & 3 & 3 & 19 & 72 & 36 & 108 \\
\hline Wäscons in & 3 & 2 & $\begin{array}{l}4-s \\
5-w\end{array}$ & 2 & $\begin{array}{l}4-5 \\
8-w\end{array}$ & 12 & 12 & $\begin{array}{l}4-5 \\
5-w\end{array}$ & $\begin{array}{l}4-s \\
5-w\end{array}$ & 42 & 72 & $\begin{array}{l}16-5 \\
10 \mathrm{~N}\end{array}$ & 128 \\
\hline
\end{tabular}

1 The number of rate forms is regarded here as the number of unique arrangements of peak, intermediate, and base periods not including flat rates

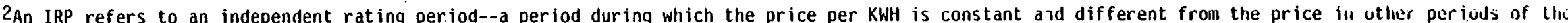

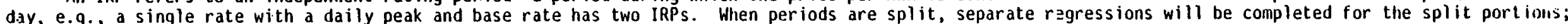
to avoid further complication those regressions are not listed on this table.

3The number of IRPs when all rate forms within the project are combined (see section 3.1.2.2 and the tables of section 3.2.2). n.a. denotes not applicable either because all customers face the same IRPs or because two- or three-dial meters were used.

4The number of sumner (s) and winter (w) months are separately identified.

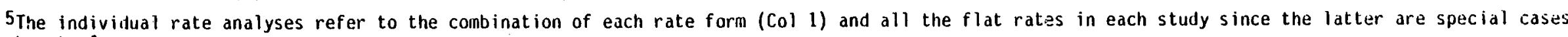
of each rate form.

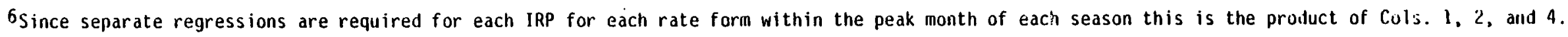

7 Except for those studies with metering constraints indicated by n.a. in Col. 3 this number is identical to the previous column.

8 This is identical to the number of IRPs for combined analysis--Cal. 3--if there is no metering constraint.

${ }^{9}$ Identical to previous column.

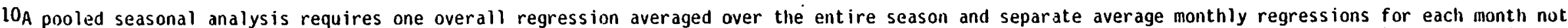

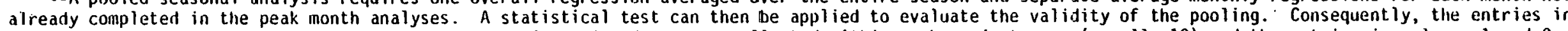

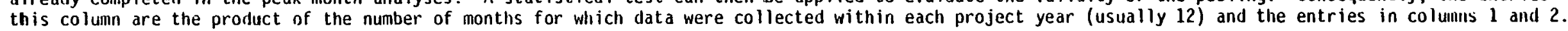

11 The appropriate nuruber of months times the entries of Col. 8--one regression for each month.

*There are seven rate forms and two approaches for weekend pricing (see section 3.6).

* Los Angeles has seasonal flat rates hut the time-of-day rates are identical in all seasons. 
project have incorporated one or two rating seasons. Within each peak month, demand systems will be estimated for both the average over the month and the peak day within the month. The demand systems will consist of separate equations for each of the daily rating periods plus additional equations for the split portions of rating periods (for ease of presentation these equations are not enumerated in table $3-3$ ).

Two general types of demand systems will be estimated in the peak month analyses in each study. First, demand systems will be estimated for each of the individual time-of-day rate forms where data from customers on appropriate flat rates in the project are included in the response-surface est imate --since flat rates are just speclal cases of all Line-uf-day rates. These are referred to as individual rate regressions. Second, demand systems will be estimated for combined rates within each project. These are referred to as combined rate regressions. This procedure is appropriate for only four of the projects.

Also seasonal analyses are suggested for both the individual rate and combined rate regressions. The purpose of these analyses is to determine whether seasonal demand systems are appropriate for explaining variations in monthly average consumption within appropriate rating periods. These analyses will require separate regressions for a 11 months of each year during which data were collected in each project as well as a fully restricted regression for all months combined within each rating season. A Chow test or the Mean-Square Error Criterion can then be used to test the validity of the restricted seasonal estimates.

The anticipated final response surface model to be used in these regressions is either a full or truncated version of a second-order Taylor series model, as appropriate. Other more restrictive models may be applied subject to resource availability. 


\subsubsection{Introduction}

This introduction first provides an overview of the characteristics of each project to be analyzed and then provides some general comments on the format of sections (3.2-3.15) that detail the suggested project-specific analyses.

\subsubsection{Overview of Specific Projects. This section summarizes} salient characteristics of the 13 DOE projects that RTI will analyze in detail.* Since our primary purpose is to determine the effects of time-ofuse residential electric rates on load curves, it is essential to understand the detailed characteristics of those rates. Summaries of those characteristics are given in tables 3-4 and 3-5. First, table 3-4 summarizes a three character code that is used in table 3-5 to identify the experimental rates used in each study. The first of the three characters is an alphabetic code that identifies the extent of energy price variations between various periods. The codes are assigned in an order of increasing complexity of the rates. For example, the code $A$ denotes the flat rate without any energy price variation within the year, B denotes a seasonal flat rate, and $H$ denotes the most complex time-of-day rate that has energy price variation between hours within days, between weekdays and both weekends and holidays within the week and between seasons within the year. The second character is a numeric code that indicates the number of rating periods within the day. The third character summarizes the periods during which any demand charges apply. For example, an E21 rate has energy price variations between a peak and a base period on weekdays and (usually) a flat rate on the weekend.

*Reports are not suggested for the New York and Michigan projects. The Vermont report will contain a summary of previous analyses. 
Table 3-4. Key to experimental electricity rate codes*

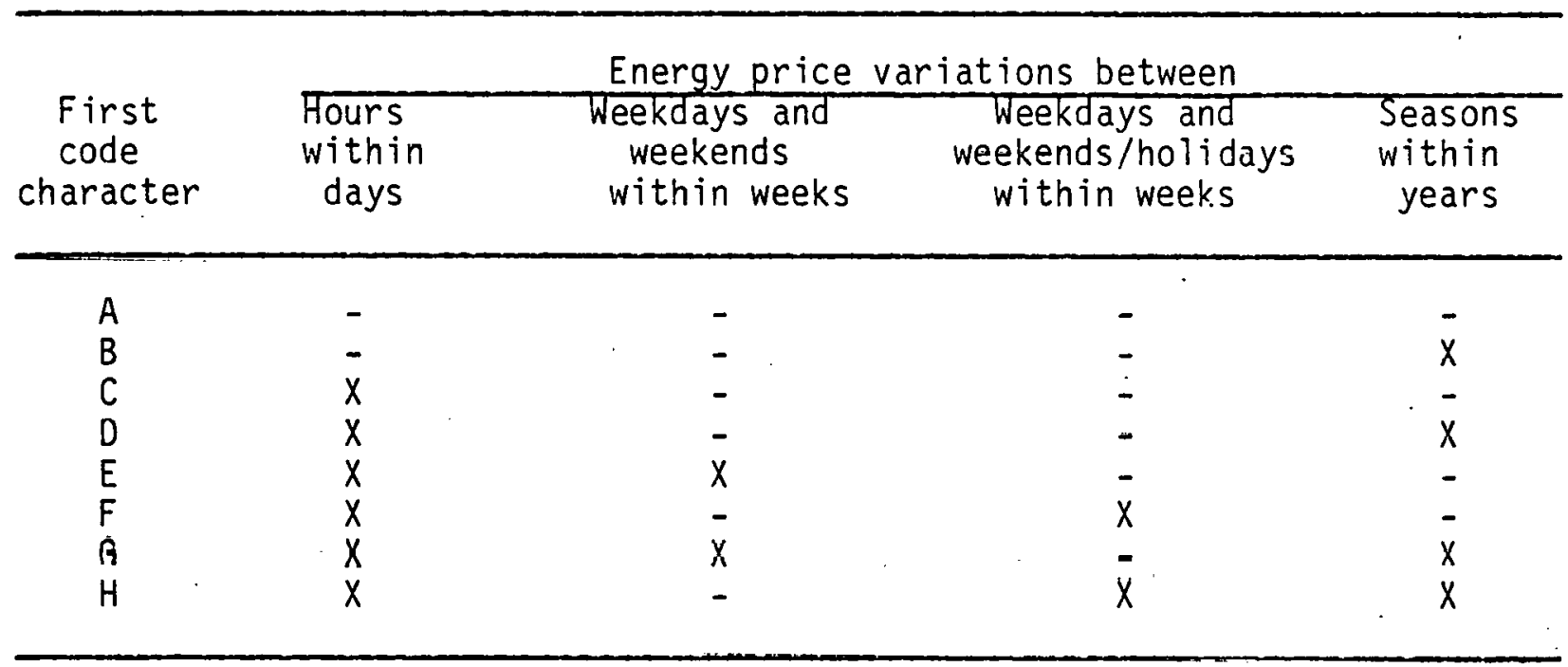

\begin{tabular}{cccc}
\multirow{2}{*}{$\begin{array}{c}\text { Second } \\
\text { code } \\
\text { character }\end{array}$} & \multicolumn{3}{c}{ Daily rating periods } \\
\cline { 2 - 4 } & Peak & Bntermediate & \\
\hline 1 & - & - & $x$ \\
3 & $x$ & - & $x$ \\
$x$ & $x$ & $x$
\end{tabular}

Third

code

character

Peak hours

Demand charge applies during

\section{character}

$3^{1}$

$\begin{array}{ll}\bar{x} & - \\ \bar{x} & \bar{x}\end{array}$

$x$

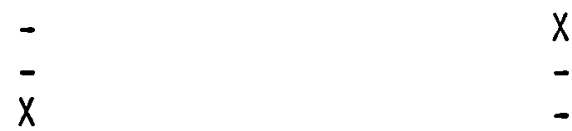

* The $X$ symbol denotes the presence and the - symbol the absence of the indicated characteristic.

t This code applies only for a rate with two demand charges. 
Table 3-5. Summary of time-of-use experimental electricity rates

\begin{tabular}{|c|c|c|c|c|c|c|c|c|c|c|c|c|}
\hline \multirow[t]{2}{*}{ Study } & \multirow[t]{2}{*}{$\begin{array}{l}\text { Rate } \\
\text { type }\end{array}$} & \multirow[t]{2}{*}{$\begin{array}{l}\text { Number } \\
\text { of rates }\end{array}$} & \multirow[t]{2}{*}{$\begin{array}{l}\text { Months } \\
\text { in } \\
\text { season }\end{array}$} & \multicolumn{3}{|c|}{$\begin{array}{l}\text { Combined length } \\
\text { of weekday } \\
\text { rating periods }\end{array}$} & \multicolumn{2}{|c|}{$\begin{array}{l}\text { Length of weekend } \\
\text { (and holiday, if } \\
\text { applicable) rating } \\
\text { periods }\end{array}$} & \multirow[t]{2}{*}{$\begin{array}{l}\text { Customer } \\
\text { charge } \\
(\$ / \text { month })\end{array}$} & \multirow[t]{2}{*}{$\begin{array}{l}\text { Number } \\
\text { of } \\
\text { customers }^{a}\end{array}$} & \multicolumn{2}{|c|}{ Participation } \\
\hline & & & & $P$ & I & $B$ & $P \quad I$ & $B$ & & & & \\
\hline Arizona & $\begin{array}{l}\text { C31 } \\
\text { C31 } \\
\text { C31 }\end{array}$ & $\begin{array}{r}16 \\
6 \\
6\end{array}$ & $\begin{array}{l}\text { A } 11 \\
\text { A } 11 \\
\text { A } 11\end{array}$ & $\begin{array}{l}3 \\
5 \\
8\end{array}$ & $\begin{array}{c}10 \star \\
8 \star \\
5\end{array}$ & $\begin{array}{l}11 \\
11 \\
11\end{array}$ & 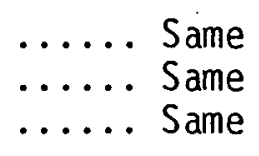 & $\begin{array}{l}\cdots \cdots \\
\ldots \ldots \\
\cdots \cdots\end{array}$ & & $\begin{array}{l}(67) \\
(20) \\
(26)\end{array}$ & $\dot{v}$ & yes \\
\hline Arkansas & $\begin{array}{l}\mathrm{D} 21 \\
\mathrm{~B} 11\end{array}$ & $\begin{array}{l}1 \\
2\end{array}$ & $\begin{array}{c}6-10 \\
11-5 \\
\text { A } 11\end{array}$ & $\begin{array}{l}8 \\
8 \\
-\end{array}$ & $\begin{array}{l}- \\
-\end{array}$ & $\begin{array}{l}16 \\
16 \\
24\end{array}$ & $\begin{array}{c}\ldots . . \\
\ldots . .\end{array}$ & $\begin{array}{l}\cdots \cdots \\
\cdots \cdots \\
\cdots \cdots\end{array}$ & $\begin{array}{l}3.00 \\
3.00 \\
3.00\end{array}$ & $\begin{array}{c}101 \\
82(856)\end{array}$ & $M$ & $\begin{array}{l}\text { no } \\
\text { no }\end{array}$ \\
\hline $\begin{array}{l}\text { California } \\
\text { (SDG\&E) }\end{array}$ & $\begin{array}{l}\text { H31 } \\
\text { A11 }\end{array}$ & $\begin{array}{l}4 \\
1\end{array}$ & $\begin{array}{c}6-10 \\
11-5 \\
\text { A } 11\end{array}$ & $\begin{array}{l}8 \\
4 \\
-\end{array}$ & $\begin{array}{l}4 \\
8 \\
-\end{array}$ & $\begin{array}{l}12 \\
12 \\
24\end{array}$ & $\begin{array}{cc}- & - \\
- & - \\
\ldots . & \text { Same }\end{array}$ & $\begin{array}{c}24 \\
24 \\
\ldots \ldots\end{array}$ & $\begin{array}{l}1.86 \\
1.86 \\
1.86\end{array}$ & $\begin{array}{l}203 \\
\cdot 52\end{array}$ & i & $\begin{array}{r}\text { no } \\
. \\
.\end{array}$ \\
\hline $\begin{array}{l}\text { California } \\
\text { (SCE) }\end{array}$ & $E 21$ & $8^{C}$ & A11 & 10 & - & 14 & - & 24 & 2.40 & 460 & $M$ & yes \\
\hline Connecticut & $\mathrm{H} 31$ & 1 & $\begin{array}{l}5.5-10.5 \\
10.5-5.5\end{array}$ & $\begin{array}{l}4^{\star} \\
4^{\star}\end{array}$ & $\begin{array}{l}9 * \\
9 *\end{array}$ & $\begin{array}{l}11 \\
11\end{array}$ & $\begin{array}{l}13 \\
13\end{array}$ & $\begin{array}{l}11 \\
11\end{array}$ & $\begin{array}{l}2.00 \\
2.00\end{array}$ & 200 & V & yes \\
\hline Los Angeles & $\begin{array}{l}C 21^{d, e} \\
C 21^{d} \\
C 21^{d} \\
C 21^{d} \\
E 21^{d, e} \\
E 21^{d} \\
E 21^{d} \\
E 21^{d} \\
B 11^{d}\end{array}$ & $\begin{array}{r}11 \\
1 \\
2 \\
3 \\
11 \\
1 \\
2 \\
3 \\
6\end{array}$ & $\begin{array}{l}A 11 \\
A 11 \\
A 11 \\
A 11 \\
A 11 \\
A 11 \\
A 11 \\
A 11 \\
6-9 \\
10-5\end{array}$ & $\begin{array}{r}3 \\
6 \\
9 \\
12 \\
3 \\
6 \\
9 \\
12 \\
- \\
-\end{array}$ & $\begin{array}{l}- \\
- \\
- \\
- \\
- \\
- \\
- \\
-\end{array}$ & $\begin{array}{l}21 \\
18 \\
15 \\
12 \\
21 \\
18 \\
15 \\
12 \\
24 \\
24\end{array}$ & $\begin{array}{cc}\ldots . . & \text { Same } \\
\ldots \ldots & \text { Same } \\
\ldots \ldots & \text { Same } \\
\ldots \ldots & \text { Same } \\
- & - \\
- & - \\
\ldots & - \\
\ldots & - \\
\ldots . . . & \text { Same } \\
\ldots & \text { Same }\end{array}$ & $\begin{array}{r}\ldots \ldots \\
\ldots \ldots \\
\ldots \ldots \\
\ldots \ldots \\
24 \\
24 \\
24 \\
\quad 24 \\
\ldots \ldots \\
\ldots \ldots\end{array}$ & $\begin{array}{l}\dot{ } \\
\dot{.} \\
\dot{b} \\
\dot{.} \\
\dot{.} \\
\dot{.} \\
\dot{.}\end{array}$ & $\begin{array}{c}270 \\
20 \\
70 \\
130 \\
270 \\
20 \\
70 \\
130 \\
164(656)\end{array}$ & $\begin{array}{l}\dot{.} \\
\dot{.} \\
\dot{V} \\
\dot{.} \\
\dot{.} \\
\dot{.}\end{array}$ & $\begin{array}{c}\cdot \\
\dot{ } \\
\text { yes } \\
. \\
\dot{ } \\
. \\
.\end{array}$ \\
\hline
\end{tabular}


Table-3-5. (Continued)

\begin{tabular}{|c|c|c|c|c|c|c|c|c|c|c|c|c|c|}
\hline Study & $\begin{array}{l}\text { Rate } \\
\text { type }\end{array}$ & $\begin{array}{l}\text { Number } \\
\text { of rates }\end{array}$ & $\begin{array}{l}\text { Monthis } \\
\text { in } \\
\text { seascn }\end{array}$ & \multicolumn{3}{|c|}{$\begin{array}{l}\text { Combined. length } \\
\text { of weekiday } \\
\text { rating periods } \\
\end{array}$} & \multicolumn{3}{|c|}{$\begin{array}{l}\text { Length of weekend } \\
\text { (and holiday, if } \\
\text { applicable) rating } \\
\text { periods }\end{array}$} & $\begin{array}{l}\text { Customer } \\
\text { charge } \\
(\$ / \text { month })\end{array}$ & $\begin{array}{l}\text { Number } \\
\text { of } \\
\text { customers }\end{array}$ & \multicolumn{2}{|c|}{ Participation } \\
\hline New Jersey & G21 & 4 & $\begin{array}{l}6-10 \\
11-5\end{array}$ & $\begin{array}{l}12 \\
12\end{array}$ & - & $\begin{array}{l}12 \\
12\end{array}$ & - & - & $\begin{array}{l}24 \\
24\end{array}$ & $\begin{array}{l}7.00 \\
7.00\end{array}$ & 850 & k & no \\
\hline NC (CP\&L) & $\begin{array}{l}\text { G31 } \\
\text { G32f } \\
\text { G22f }\end{array}$ & $\begin{array}{l}9 \\
1 \\
1\end{array}$ & $\begin{array}{c}6-10 \\
11-5 \\
6-10 \\
11-5 \\
5-6 \\
7-10 \\
11-4\end{array}$ & $\begin{array}{c}10 \\
8^{\star} \\
10 \\
8^{\star} \\
12 \\
12 \\
12^{\star}\end{array}$ & $\begin{array}{l}6 \pm \\
8 * \\
6+ \\
8 * \\
- \\
- \\
-\end{array}$ & $\begin{array}{c}8 \\
8 \\
8 \\
8 \\
12 \\
12 \\
12^{\star}\end{array}$ & $\begin{array}{l}- \\
- \\
- \\
- \\
- \\
-\end{array}$ & $\begin{array}{l}16 \\
16 \\
16 \\
16 \\
- \\
- \\
-\end{array}$ & $\begin{array}{r}8 \\
8 \\
8 \\
8 \\
24 \\
24 \\
24\end{array}$ & $\begin{array}{c}\operatorname{Var} \text { iable } \\
3.80-6.30 \\
5.95 \\
6.00\end{array}$ & $\begin{array}{l}278 \\
118 \\
118\end{array}$ & $\begin{array}{l}\dot{\cdot} \\
\dot{M} \\
\dot{\dot{M}}\end{array}$ & $\begin{array}{r}\dot{ } \\
\dot{ } \\
\text { no } \\
. \\
.\end{array}$ \\
\hline NC (BREMC) & D31 & 1 & $\begin{array}{c}11-4 \\
5-10\end{array}$ & $\begin{array}{l}8 * \\
-\end{array}$ & $\begin{array}{c}8^{\star} \\
16\end{array}$ & $\begin{array}{r}8 \\
16\end{array}$ & & $\begin{array}{l}\text { Same } \\
\text { Same }\end{array}$ & & 6.10 & 100 & . & . \\
\hline Ohio & $\mathrm{H} 21$ & 1 & $\begin{array}{l}6.5-9.5 \\
9.5-11.5 \\
11.5-2.5 \\
2.5-6.5\end{array}$ & $\begin{array}{l}6 \\
6 \\
6 \\
6\end{array}$ & $\begin{array}{l}- \\
- \\
-\end{array}$ & $\begin{array}{l}18 \\
18 \\
18 \\
18\end{array}$ & $\begin{array}{l}- \\
- \\
-\end{array}$ & $\begin{array}{l}- \\
- \\
-\end{array}$ & $\begin{array}{l}24 \\
24 \\
24 \\
24\end{array}$ & 6.00 & 100 & V & no \\
\hline Okl ahoma & $\begin{array}{l}\text { D21 } \\
\text { B11 } \\
\text { A11 }\end{array}$ & $\begin{array}{l}6 \\
4 \\
2\end{array}$ & $\begin{array}{r}5-9 \\
10-4 \\
5-9 \\
10-4 \\
5-c \\
10-4\end{array}$ & $\begin{array}{l}9 \\
9 \\
- \\
- \\
- \\
-\end{array}$ & $\begin{array}{l}- \\
- \\
- \\
- \\
-\end{array}$ & $\begin{array}{l}15 \\
15 \\
24 \\
24 \\
24 \\
24\end{array}$ & & $\begin{array}{l}\text { Same } \\
\text { Same } \\
\text { Same } \\
\text { Same } \\
\text { Same } \\
\text { Same }\end{array}$ & & $\begin{array}{l}6.00 \\
6.00\end{array}$ & $\begin{array}{c}30(270) \\
(150)^{9} \\
(60)^{9}\end{array}$ & $\begin{array}{l}\dot{M} \\
\dot{M} \\
\dot{.}\end{array}$ & $\begin{array}{c}\dot{ } \\
\text { yes } \\
\dot{\cdot} \\
\dot{\cdot}\end{array}$ \\
\hline Puerto Rico & $\begin{array}{l}F 21^{h} \\
F 21\end{array}$ & $\begin{array}{r}15 \\
7\end{array}$ & $\begin{array}{l}\text { A } 11 \\
\text { A11 }\end{array}$ & $\begin{array}{r}6 \\
12\end{array}$ & - & $\begin{array}{l}18 \\
12\end{array}$ & - & - & $\begin{array}{l}24 \\
24\end{array}$ & $\begin{array}{l}b \\
b\end{array}$ & $\begin{array}{l}187 \\
163\end{array}$ & $\begin{array}{l}\text { V } \\
V\end{array}$ & $\begin{array}{l}\text { yes } \\
\text { yes }\end{array}$ \\
\hline
\end{tabular}


Table 3-5. (Continued)

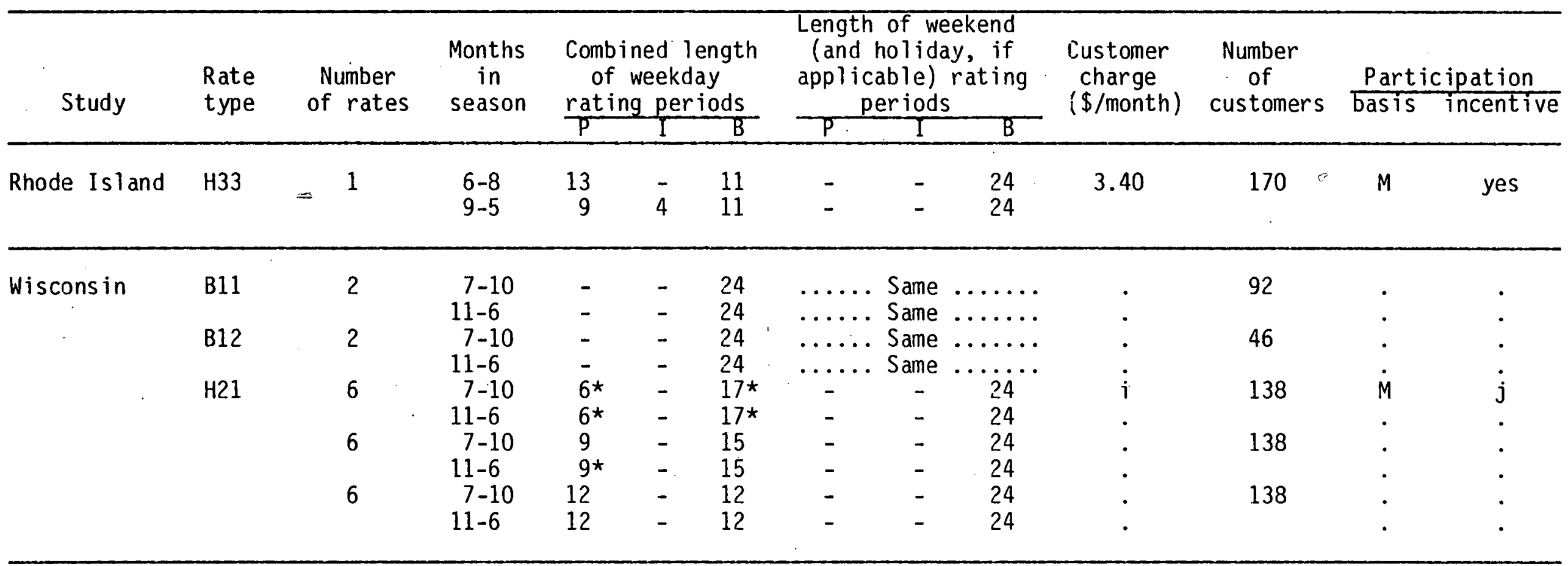

Total of two non-adjacent periods.

+ Total of three non-adjacent periods.

a Parenthesized numbers denote monthly observations from one-, two-, or three-dial meters. All other observations are for 15-minute, 30-minute, or 1-hour intervals.

b There is no explicit customer charge; implicitly the charge is incorporated into the participation incentive.

c Four of these rates have peak hours from 10-20; and the other four, from 12-22.

d Half of the customers on each of these rates receive quarterly participation payments; the other half receive those payments at the end of the experiment.

e Three of these rates have peak hours from 9-12; two, from 12-15; three, from 15-18; and three, from 18-21.

$f$ Thirty-two (32) of the customers on this rate have demand controllers; 36 do not.

$g$ Sixty $(60)$ households have two-dial meters; the rest have standard one-dial meters.

$h$ Seven of these rates have peak hours from 10-16; and the other 8, from 16-22.

i One-half (urban) rates have a customer charge of $\$ 4.94 / \mathrm{mo}$; and the other half (rural) have $\$ 8.99 / \mathrm{mo}$.

j Company notifies customer with bills that are $\$ 5.00$ or $15 \%$ over what bill would have been under existing rate.

$k$ Voluntary completion of a mail questionnaire not mentioning experimentation defined a presample for mandatory application of rates. A change to strict mandatory participation is under consideration.

1 Currently voluntary but mandatory participation is under consideration; rates to be effective September, 1978. 
Table 3-5 reports the number of each rate type within projects, the months included in each season for which the rates apply, the combined lengths of rating periods (asterisks denote combinations of non-adjacent rating periods), customer charges, number of participants, whether the rates are voluntary or mandatory, and whether there is a participation incentive. The entries in this table underscore the enormous variety of rates within the DOE experiments.

Table 3-6 further characterizes the inducements or adjustments associated with experimental rates. Specifically, the table summarizes incentives and revenue neutralizers applied within the experimental setting. A revenue neutralizer is defined as some form of direct payment, bill adjustment, or rate design adjustment that causes an "expected bill" under the applicable time-of-day rate to be the same as that under the control (existing residential) rate. Usually the "expected bill" is defined under the so-called zero elasticity assumption. In particular the revenue that would be generated under the experimental rate is computed as if the "representative customer" would remain totally unresponsive to timeof-day rates; then this expected revenue is reduced by direct payments, by bill adjustments, or by an adjustment of the energy or demand charges to levels that would yield the same revenue as the same customer would have generated on the control rate (under the same assumptions). The "representative customer" is usually the average customer in the residential class and the adjustments are usually applied to yield identical total annual bills under the experimental and control rates. However in several studies, the "representative customers" are the average customers within usage strata of the residential class and different adjustments are applied to yield identical total annual bills under the experimental and control 
Table 3-6. Summary of incentives and revenue neutralizers

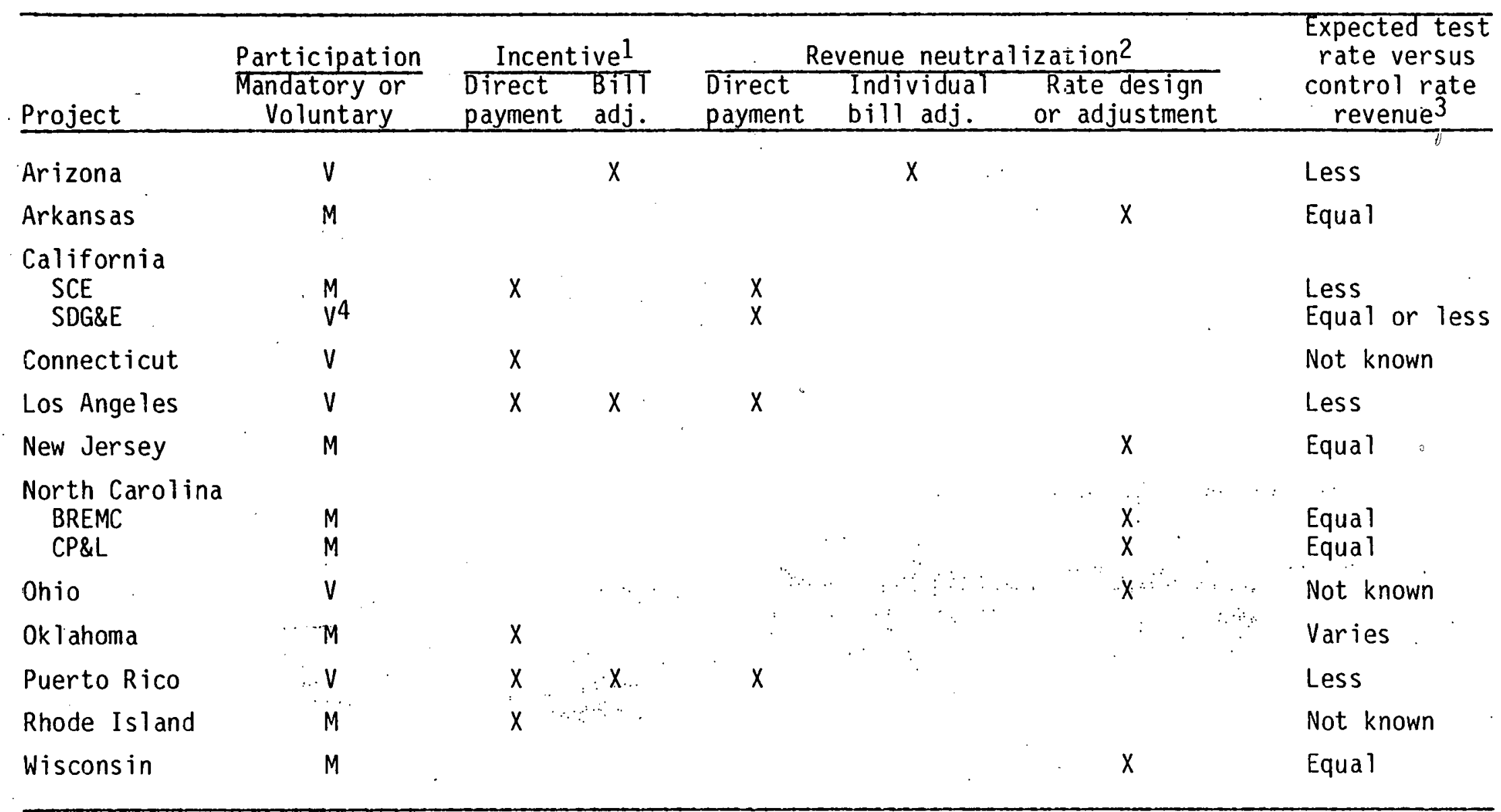

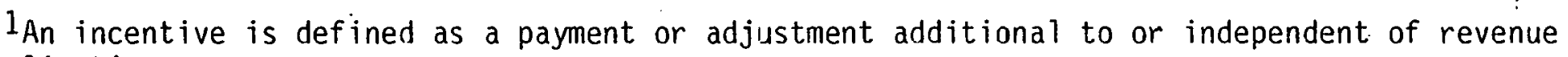
neutralization.

2 Revenue neutrality is defined as equality between annual test rate revenue and control rate revenue for the same usage, excluding incentives. Depending upon the project design, the basis for comparison may be individual, stratum, or class usage measurements or esimates for some period prior to the test period.

3 Expected test rate revenue net of incentives, versus control rate revenue, based on the prior usage measure employed by each project.

4 Mandatory participation is under consideration. 
rates. Also, in one study (Arizona) every participant constitutes his own "representative customer" through a guarantee that his bill in each month would be 80 percent of his bill for the same month of the previous year if his total monthly consumption within each of three daily rating periods were identical to those of the previous year. This was feasible because baseline data were collected for a full year prior to the application of the experimental rates.

Finally, table 3-7 summarizes the characteristics nf the sample dẹsign in each of these studics (detailed documentation is avallable in the third section of the project specific appendixes). The table distinguishes two general types of sample exs.lusions. Typs I exclusions are those that apparently occurred prior to the selection of the sample. (These exclusions were enumerated under the assumption that the target populaton or universe was the entire class of residential customers served by the participating utility within the regulatory jurisdiction where the study is being conducted.) Type II exclusions are those that occurred after sample selection, but before any data were collected. Clearly all the customer 3 omitted because of either type I or type II exclusions had no chance of being included in the studies. Therefore, strictly speaking, none of the experimental results apply to those customers. Any attempts to draw inferences for the excluded portion of the population therefore have to be regarded as more or less educated guesses depending on the extent of related analyses of matching characteristics of those excluded and those included. Such matching analyses will be helpful in identifying potential sources of bias involved in extending the sample results to various customer populations and, therefore, in establishing a reasonable population of inference. 
Table 3-7. Summary of sample design characteristics $\underline{1}$

\begin{tabular}{|c|c|c|}
\hline Project & $\begin{array}{l}\text { Presample } \\
\text { exclusions } \\
\text { (type I) }\end{array}$ & $\begin{array}{l}\text { Post-sample } \\
\text { exclusions } \\
\text { (type II) }\end{array}$ \\
\hline Arizona & $B, E$ & $B, D$ \\
\hline $\begin{array}{l}\text { Arkansas } \\
\text { Califfornia }\end{array}$ & $B$ & $C, F, G, H$ \\
\hline $\begin{array}{l}\text { California } \\
\text { (SDG\&E) }\end{array}$ & B & $A, C, F, G, H$ \\
\hline Connecticut & $L$ & $A, D, K$ \\
\hline Los Angeles & $B, M$ & $A, D, M$ \\
\hline New Jersey & $B, K, N$ & $A$ \\
\hline $\begin{array}{l}\text { North Carolina } \\
\text { (CP\&L) }\end{array}$ & - & $F, J, K$ \\
\hline $\begin{array}{l}\text { North Carolina } \\
\text { (BREMC) }\end{array}$ & - & D \\
\hline Ohio & $E, I, N, 0$ & A \\
\hline Ok T ahoma. & - & $C, P, Q$ \\
\hline Puerto Rico & $B, L, R$ & $A, S$ \\
\hline Rhode Is land & - & $C, D$ \\
\hline Wiscons in & $C, I$ & $T$ \\
\hline
\end{tabular}

Codes:

A. Refusal

B. Geographic areas or rates specific to geographic areas

C. Moving plans

D. Incompatible wiring or meters

E. Recent movers (short history)

F. Meter inaccessibility

G. Meter visible from street

H. Not at home

I. Low KWH usage

J. "Active" accounts that are actually inactive for most of study period

K. Seasonal

L. Bad credit

M. Finite selection model

N. Special rates not specific to a geographic area, e.g., controlled water heating rate

0 . Company employees

P. Trailer homes

Q. Low income

R. Public housing

S. Customer shifts between usage strata over time (erratic usage)

T. Renters 
3.1.2.2 Format of Individual Project Sumaries. The remaining sections of chapter 3 (sections 3.2-3.15) provide:

a) a brief desctiption of each demonstration project, including a summary of the overall study design and of the sample design (Appendixes $A-N$ in Volume II provide further details on these topics); and

b) the proposed descriptive, comparative and response surface analyses, including additional analyses that will be considered if resources permit.

For those projects where response surface analyses are indicated, tables are provided which summarize the information that is necessary to evaluate the potential effectiveness of combining rate forms within each project. Specifically, the top part of each table "stacks" the daily rate profiles that correspond to figures 2-1 and 2-2 for each of the rate forms used in each project (not including rates that incorporate a demand charge) and the associated number of applications (unique combinations) of rates of those forms as well as the associated periods during which the rates are effective. The bottom part of each table identifies the independent periods for analys is that correspond to figure 2-3. Also shown are the resulting number of unique rates and, hence, the number of estimable parameters in a combined rate analys is model of the type given in $(2-1)$.

\subsection{Arizona}

\subsubsection{Description}

The Arizona experiment involved a total of 28 experimental rates which were in effect for about six months during the summer of 1976. These TOD rates fall into three major categories which differ in terms of the lengths of the on-peak and shoulder periods. Three-dial meters were used to give, on a billing month basis, the total KWH usage in the peak, shoulder, and 
base periods. Participation was voluntary in this experiment; indirect incentive payments (through bill adjustments) were used.

In the Arizona Demonstration Project, residential customers from the Phoenix and Yuma metropolitan areas were sampled. These two areas are the regions responsible for the summer peaking of electric usage and contain 70 percent of the residential customers of the Arizona Public Service Company. Separate simple random presamples of 414 Phoenix customers and 210 Yuma customers were drawn from the accounting records lists for these two areas. From the initial Phoenix presample, 18 percent of thc customers were rejected because they had billing histories of less than one year and 41 percent were rejected because of inaccessible service entrances or because of insufficient space to accommodate the TOD meter. Similar results were obtained for Yuma. A total of 183 customers from Phoenix and Yuma were assigned to the experimental rate with 172 ultimately being assigned to 36 experimental groups and 11 to the control group. The control group was largely composed of customers who refused to accept an experimental rate.

\subsubsection{Proposed Analys is}

Descriptive Statistics and Comparative Analysis. The standard analys is as outlined in table 3-2 will not be made for Arizona because of the small sample sizes used in the study.

Response Surface Analysis. Table 3-8 graphically summarizes the Arizona rates. Three systems of regressions will be performed corresponding to the three groups of customers that faced the three different time-of-day rate forms. Each system will include single regressions on average monthly consumption (billing month) for peak, intermediate, and base periods (a total of nine regressions per month). Response surfaces will be estimated for each group, with linear price terms, linear price interaction terms, and 
Table 3-8. Summary of Arizona experimental rates

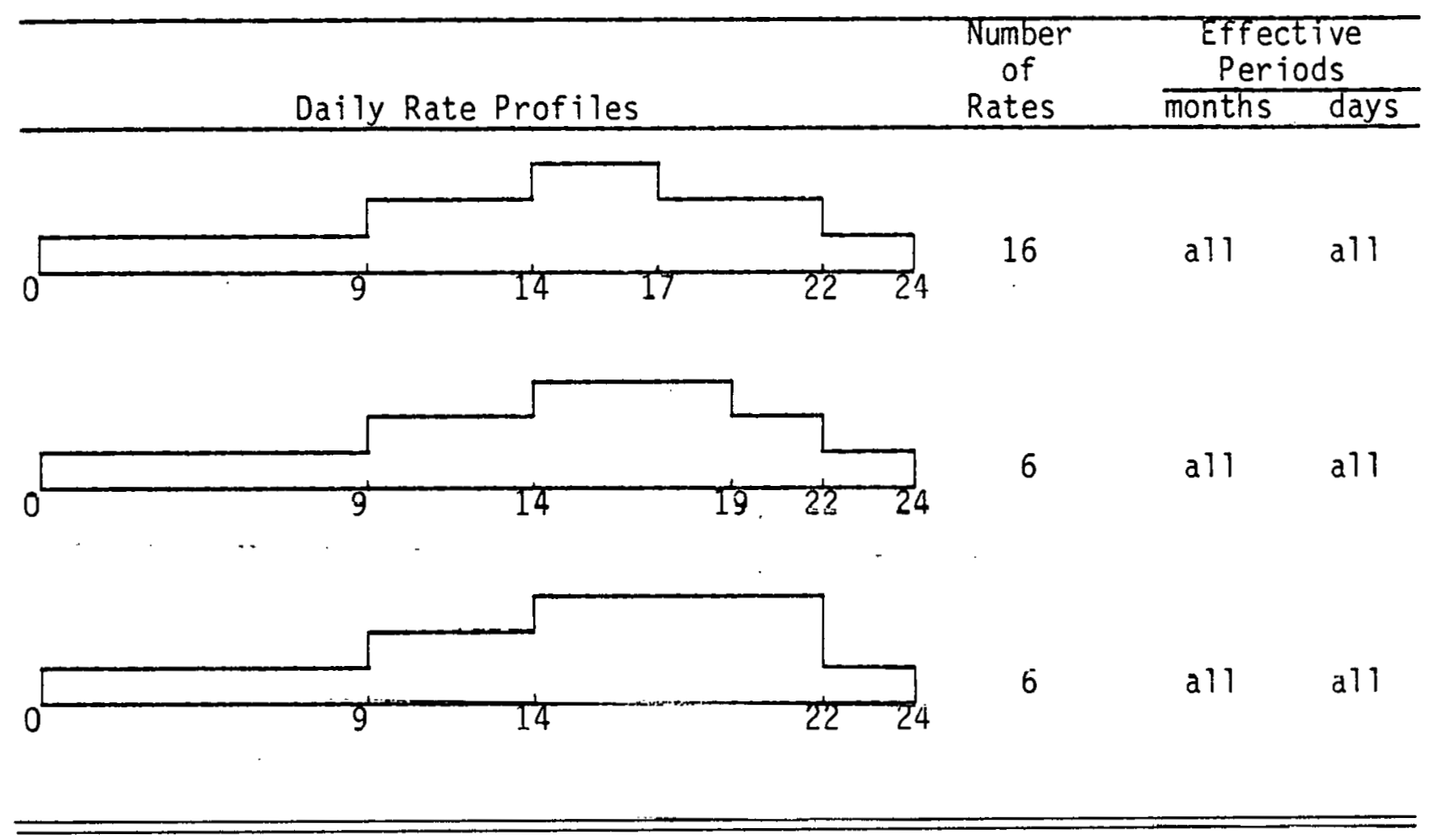

Independent Rating Periods for Combined Rate Analys is

\begin{tabular}{|l|l|l|l|l|l|l|l|}
\hline 1 & 2 & 3 & 4 & 5 & 1 & all \\
\hline 9 & & 34 & 17 & 19 & 22 & 24
\end{tabular}


squared price terms being included in that order, subject to rank limitations of the price matrix. Thus, in the first group, where there are 16 unique rows, all nine price terms may be included. In the other two groups. where there were only six unique rows of prices, the regression can include only two of the linear interaction terms in addition to the three linear price terms. Also, as summarized in table 3-3, a seasonal analys is will be attempted. The limited number of observations--67 customers in group 1,20 in group 2, and 26 in group 3--will likely affect this analys is. This suggested approach is distinguished from that of Taylor (1977) in that second order effects will be estimated and seasonal analyses will be completed.

The use of three-dial meters also prevents any possibility of pooling the data from three groups into one group comprised of five time periods. Therefore the five independent rating periods (IRPs) identified in the lower portion of table 3-8 cannot be analyzed separately.

\subsection{Arkansas}

\subsubsection{Description}

The Arkansas demonstration project, a one-year experiment completed in February, 1977, involved three experimental rates and a control group. About 1400 customers were involved in the experiment. One-hour recorders were used on 129 control-group customers, on 101 customers who received a seasonal time-of-day rate, and on 41 customers on each of two flat seasonal rates. All remaining experimental participants were on flat rates and were metered with standard one-dial meters. Participation was mandatory.

The project was conducted by Arkansas Power and Light Company, a summer-peaking utility. Two cities, Hamburg and Wynne, were chosen from 22 cities with 1,000 to 2,500 service units. The two cities were selected as 
having electric usage patterns representative of the average AP\&L usage pattern. The residential customers in Hamburg and Wynne were stratified by ten levels of average monthly KWH consumption in 1974. The sample sizes from each stratum were determined by a Neyman optimal allocation procedure and a simple random sample was drawn from each stratum within each city. Hamburg residents were assigned to one of the three experimental rates and Wynne residents to one of the three control rates. The treatments were:

E1 - Hamburg residents on time of day rates,

E2 - Hamburg residents on seasonal flat rate \#1,

E3 - Hamburg residents on seasonal flat rate \#2,

C1 - Wynne controls on time of day metering,

C2 - Wynne regular controls, and

C3 - Wynne blind controls.

Participation in the experiment was mandatory. Those residents of Hamburg not selected for inclusion in the sample were assigned rate E3. Similarly all Wynne households not selected for the sample of control customers were arbitrarily assigned to one of the control groups.

\subsubsection{Proposed Analysis}

Descriptive Statistics and Comparative Analysis. The standard analys is as outlined in table $3-2$ will be conducted. Since inferences are considered limited to the cities of Hamburg and Wynne, system variables (21 and 23 in table 2-2) will not be estimated.

Response Surface Analyses. Table 3-9 graphically summarizes the rates in the Arkansas experiment. Since the flat rates are special cases of the time-of-day rate, only individual rate regressions will be performed. Single regressions on average monthly consumption and day of system peak consumption for peak and base periods (a total of four regressions per month) will describe al1 appropriate response surfaces. There are three linearly independent rows in the design matrix (one TOD rate and two flats). Thus, only two price parameters may be estimated--there can be no price interaction 
Table 3-9. Summary of Arkansas experimental rates

\begin{tabular}{lllll}
\hline & Number \\
Daily Rate Profiles & $\begin{array}{c}\text { Effective } \\
\text { Periods } \\
\text { Rates }\end{array}$ & \begin{tabular}{c} 
months days \\
\hline
\end{tabular} \\
\hline
\end{tabular}


terms in the regression. In the winter months, the price spread between the peak and base price is only six percent, so that the likelihood of discerning a strong time-of-day effect, even if one exists, is quite small. The number of customers that will be included in the regressions is 183 .

\subsection{California}

\subsubsection{Description}

\subsubsection{Southern California Edison (SCE). Eight non-seasonal}

time-of-day rates with two daily rating periods during weekdays are being tested in the SCE study along with a control group. The rating periods are constant in length but vary with regard to starting time. Participation in the study is mandatory; however, incentive payments are provided. Four hundred twenty customers have been assigned to the eight experimental rates and are being monitored with 15-minute recorders.

The target population for SCE consists of its $2,814,000$ residential customers. Initially, a modified Conlisk-Watts model was used to obtain a sample allocation to price and income cells. This allocation was used subject to the constraint that each customer subgroup must be represented in the experiment by at least two customers. The realistic objective of this constraint was to facilitate model verification.

All customers in the target population had a known positive probability of being selected for the experiment. The sampling design yields an "optimum" stratified random sample although, as noted above, optimum here is not the traditional Neyman allocation. The stratification consisted of three geographic areas and five levels of KWH usage or 15 strata.

Sample selection and treatment-to-customer assignments were both a random (stochastic) process; that is, the use of a Conlisk-Watts type technique was not used to select customers or assign treatments. 
The following categories of sampled customers were rejected:

- not at home,

- meter inaccessibility,

- meter visible from street, and

- moving plans.

Hopefully, these exclusions are relatively small categories and possibly not substantially unique, although excluding the "not at home" and "moving plans" categories may result in serious biases if they are large groups. With these caveats in mind, we expect that defensible analyses can be conducted for approximately 80 percent of the target population and that the results can be extended to the target population through the use of several. "missing observation" techniques, or under reasonable assumptions about rejected categories.

The optimum allocation mentioned above resulted ultimately in 93 percent of the experimental sample being allocated to two of the 15 strata. In fact, most of the treatiments are measured in only two strata. As a result, weighted analys is should be used to compare the control and rates $A / 9: 1$ and B/9:1 but may not be particularly useful for response surface analyses.

The response surface analys is is suggested for the high-usage (average of 741-2400 KWH/month) customers. Both individual rate regressions and combined rate regressions are suggested (see table 3-3). Two regressions for average monthly consumption and day-of-system-peak consumption for the peak and base periods (4 regressions per month) will comprise the appropriate. individual rate regressions for each of the two rate forms shown in table 3-10. Since only four unique price rows are defined for each individual rate regression, only the mean, two linear price terms, and the on-peak/off-peak price interaction coefficients will be estimated. For the combined rate regressions, eight unique rows will be available (see table 3-10) so the 
Table 3-10. Summary of California (SCE) experimental rates

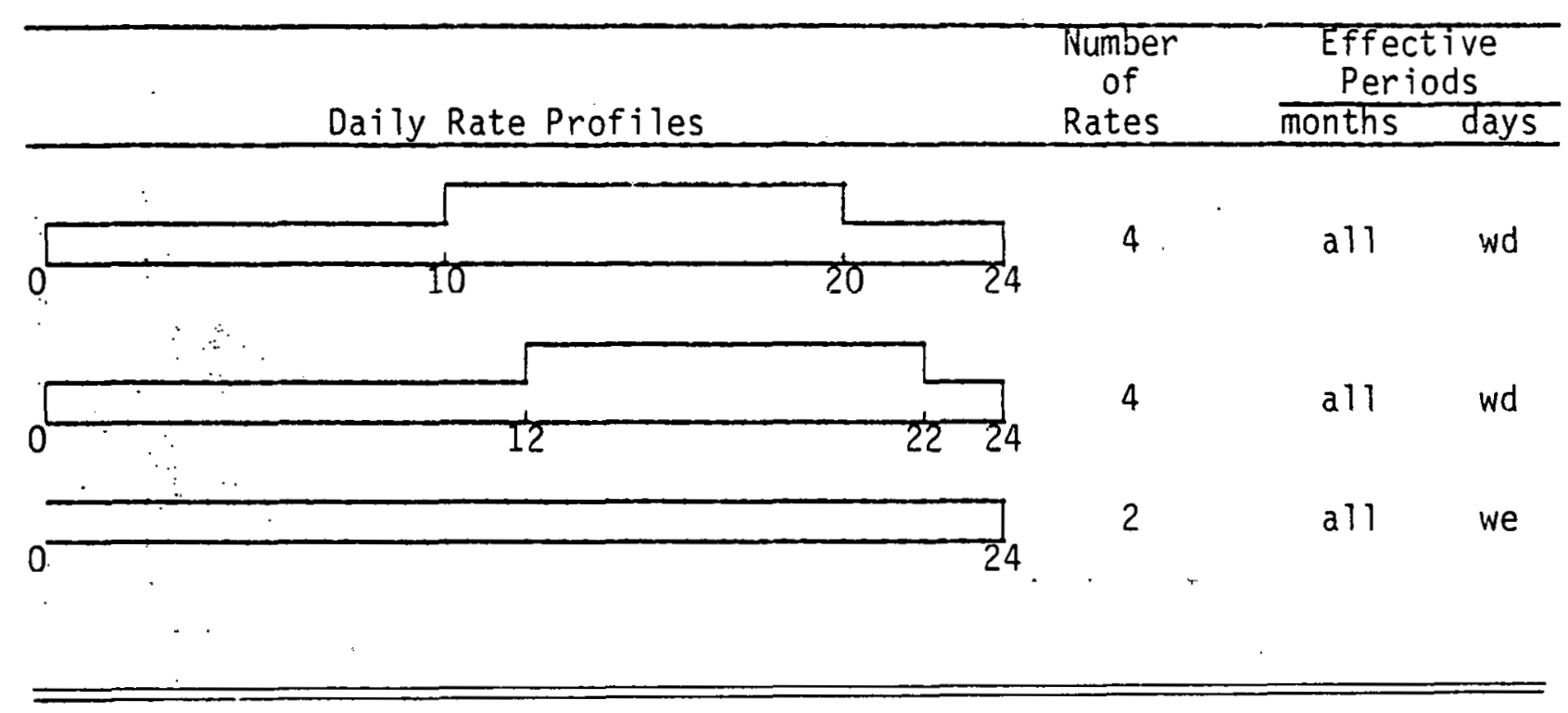

Independent Rating Periods for Combined Rate Analys is

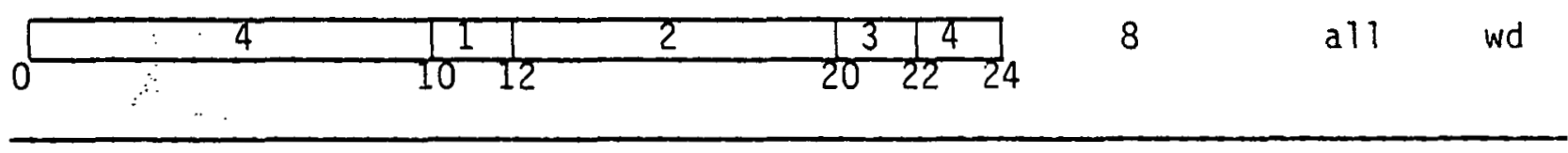


coefficients on the linear price terms and on three interactions can be est imated.

3.4.1.2 San Diego Gas and Electric (SDG\&E). The SDG\&E study involves one flat rate, four seasonal time-of-day rates with two rating periods, and the existing (control) rate. Currently, participation is voluntary; however, mandatory participation is still under consideration. There are no incentive payments. The five experimental rates involve a total of 255 customers who will be monitored with 15 -minute recorders.

The target population for the SDG\&E consists of its $1,090,000$ residential customers, which approximately comprise the population of San Diego County. SDG\&E chose, however, to limit their investigation to two substations, El Cajon with 10,500 residential customers and Murray with 20,000 residential customers. As SDG\&E points out, this limits valid inferences to these two substations or approximately three percent of the target population. The researchers, however, consider San Diego County to be a pertinent level of inference and present numerous demographic comparisons to investigate the feasibility of the extension. Unfortunately, even a perfect demographic alignment cannot ensure that the sample is representative for the dependent variables of interest.

With respect to the two substations, a stratified random sample was selected. A modified Conlisk-Watts allocation was used to allocate the sample of customers to the rates. Five KWH usage categories in the two substations comprised the five strata used (assuming that the two substations were not.sampled independently). Sample rejections include those with moving plans, incompatible meters, meters visible from the street, not at home when the interviewer visited, and refusals, because the SOG\&E is a voluntary experiment. 
Strictly defensible inferences can be produced for only a very small proportion of the total service area (one to two percent of the service area). This population consists basically of those in the two substation areas that are willing to participate and that are most accessible. If . this is a meaningful population, weighted analys is should be used, otherwise weighted analys is might be considered marginal--see Appendix $C$. The weighted analyses would account for the sample design, including unequal selection probabilities. Other forms of weighting might be considered for the SDG\&E experiment, such as the use of weighting to more nearly align the sample with some target population on the bas is of their respective demographics.

\subsubsection{Proposed Analyses}

\subsubsection{Southern California Edison (SCE)}

Descriptive Statistics and Comparative Analysis. The standard analys is as outlined in table 3-2 will be conducted for this utility.

Response Surface Analyses. Table 3-10 graphically summarizes the SCE rates. Individual rate regressions and seasonal analyses are suggested for each of the two rate forms. Two regressions each on average monthly consumption and day-of-system-peak consumption during peak and base periods (a total of eight regressions per month) will describe all appropriate response surfaces--see table 3-3. Each regression will include 210 customers. There are four unique rows for each of the individual rate regressions, so two linear terms and one second order term are potentially estimable in addition to the intercept. Since the base price takes on only two values, a squared term for the base period price is not estimable. Further, since there is little difference in the two base prices, the estimate of the linear term coefficient for the base period will be quite imprecise. 
Combined rate regressions on the SCE data may be based on four independent rating periods (table $3-10$ ). The pooled design matrix will contain eight unique rows, so that, in addition to the four linear terms, three second order terms may be included.

\subsubsection{San Diego Gas and Electric Company (SDG\&E)}

Descriptive Statistics and Comparative Analys is. The standard analysis as outlined in table $3-2$ will be conducted for this utility.

Response Surface Analyses. Table 3-11 graphically summarizes. the SDG\&E rates. Since there is only one TOD rate furm, only individual rate regressions will be performed. Single, monthly regressions on average monthiy consumption and day-of-system-peak consumption during peak, intermediate, and base periods (a total of sixiregressions per month) will describe all appropriate response surfaces for each season--see table 3-3. There are five unique rows in the design matrix (including the flat) so that, in addition to the three linear terms and the intercept, one second order term may be included in the regression. The number of customers included in the regressions is 255 .

\subsection{Connecticut}

\subsubsection{Description}

- The Connecticut demonstration project involved a single experimental rate--a seasonal time-of-day rate with three daily rating periods during weekdays and two daily rating periods on weekends. Two hundred customers received this rate for one year (October 1975-0ctober 1976); a control group of 200 customers was also monitored with 15-minute KWH recorders during this year. The experimental group was monitored during a one-year baseline phase. Volunteers were secured through the use of a participation payment. 
Table 3-11. Summary of California (SDG\&E) experimental rates

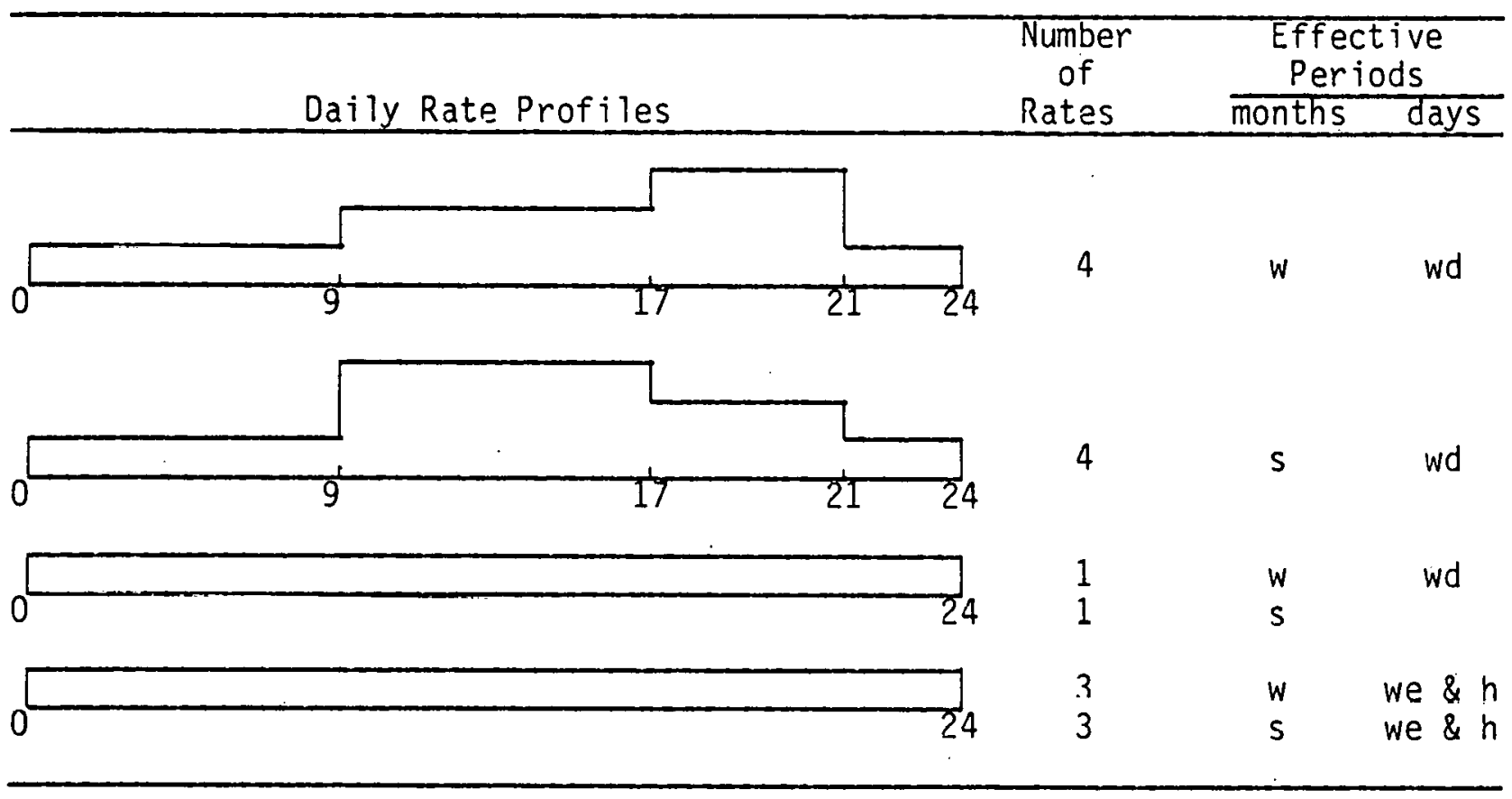


The Connecticut Demonstration Project surveyed residential customers of the Connecticut Light and Power Company (CL\&P). Farm customers, customers with less than 12 months billing history, and customers that had some bills estimated during the 12-month period were excluded from the sample. These exclusions comprised 37 percent of the customers served by CL\&P. The remaining customers were stratified into five KWH usage groups. Within each stratum, simple random sampling was employed to obtain 50 customers to participate in a residential load test study. Approximately one year later, these customers were asked to participate in the peak load pricing study. This was done in order to utilize the one-year history of consumption as baseline information. In addition, simple random sampling was employed within each stratum to obtain 40 customers to serve as a separate control group. The control sample was selected at the start of the peak load pricing study. It is unclear whether the control sample was selected from the same sampling frame as the expcrimental group.

\subsubsection{Proposed Analysis}

Descriptive Statistics and Comparative Analysis. The standard analys is as outlined in table 3-2 will be conducted.

In addition to comparing responses under the experimental rate with those under the control, the Connecticut study is also amenable to "before/ after" type comparisons for the experimental group. These will be considered to the extent that time and funds permit.

Response Surface Analyses. Since a single TOD rate was involved, elasticities will not be estimated.

\subsection{Los Angeles}

\subsubsection{Description}

The Los Angeles experiment involves 40 experimental rates plus a control (existing) rate. The experimental rates span a wide range of rating 
periods: 34 are time-of-day rates; two are flat rates; and four are flat seasonal rates. One half of the time-of-day rates are applicáble throughout the week, whereas the other half apply only to weekdays with the off-peak price in effect for all weekend hours. A total of 1,344 customers will be monitored by 15-minute recorders. Participation in the study is voluntary and incentive payments are being made--at varying time intervals.

The Los Angeles Demonstration Project surveyed the 940,000 residential customers of the Los Angeles Department of Water and Power (DWP). The sample design was based on designated census tracts and meter readers' books matchied to those census tracts. The census tracts were stratified and selected for their representativeness of the respective slrata and for the prescncc of a well-defined weather zone. If any part of the territory covered by the read book fell in the selected census tract, the entire listing of the read book was considered part of the tract. A list of customers was compiled from the resulting collection of read books matched to selected census tracts and used as the sampling frame. The frame was compiled in read book order so that all customers listed in a particular read book were adjacent on the frame. A systematic presample of customer records was then taken. Customers with fewer than 12 months in their billing histories, customers residing in mobile homes, or customers on the tariff available to property tax exempt customers were excluded from the sample. In the third stage of selection, the sample was stratified by KWH usage and climate zone and sampled using stratified random sampling.

A finite selection model (FSM) was used in the final stage of sample selection and in the treatment assignment. Sample rejections at these stages included refusals, not-at-home for interview, incompatible wiring, and employees of participating organizations. 


\subsubsection{Proposed Analysis}

Descriptive Statistics and Comparative Analysis. The standard analys is as outlined in table 3-2 will be conducted.

In addition to the treatment versus control comparisons, several analysis-of-variance models can be employed for analys is of the Los Angeles data, if time and funds permit. Effects of seasonal flat rates, of weekend-weekday differentiated and non-differentiated rates, and of two methods of paying participants can be investigated through such analyses. Alternative rate structures can also be examined; for instance, 22 of the TOD rates have a 21-hour off-peak period (weekdays) in which the price per

KWH is 2 cents. These twenty-two rates crossed with the two methods of making participation payments yields 44 treatments (factor-leve) combinations) as shown below:

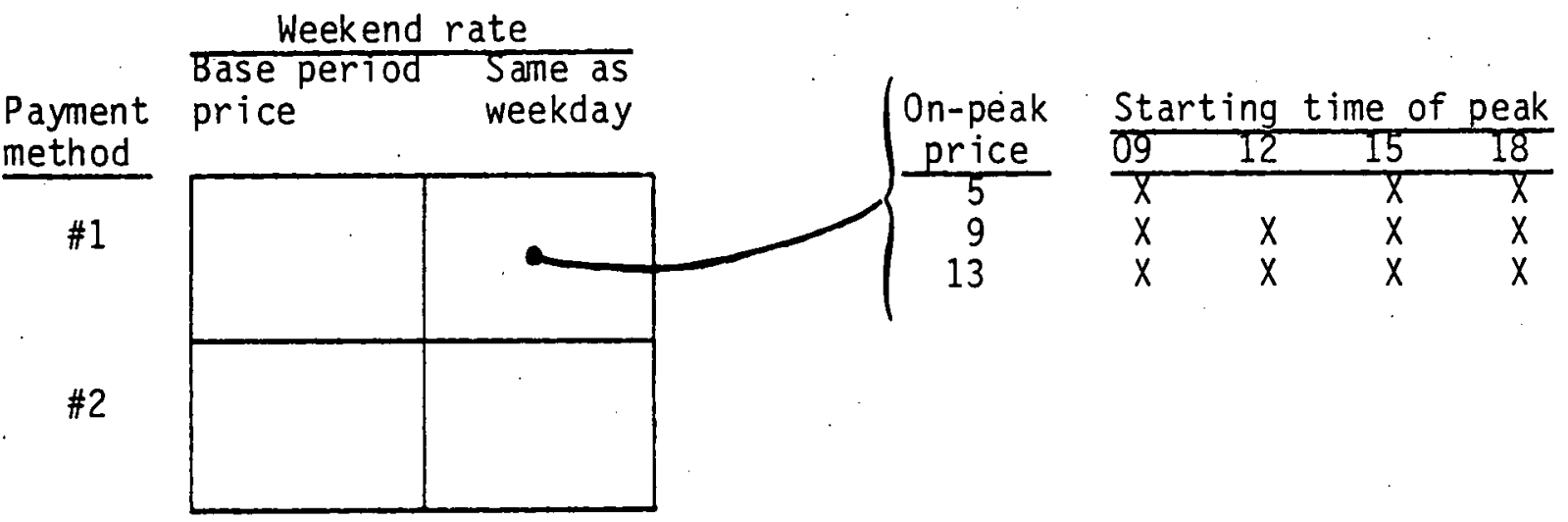

An analysis of variance involving the four factors indicated above would permit a number of effects--in particular, interaction effects--to be examined. Such analyses would be quite useful as a starting point for building realistic response surface models.

Response Surface Analyses. Table 3-12 depicts the rates in the Los Angeles experiment. Since there are fourteen different rate forms (seven 
Table 3-12. Summary of Los Angeles experimental rates*

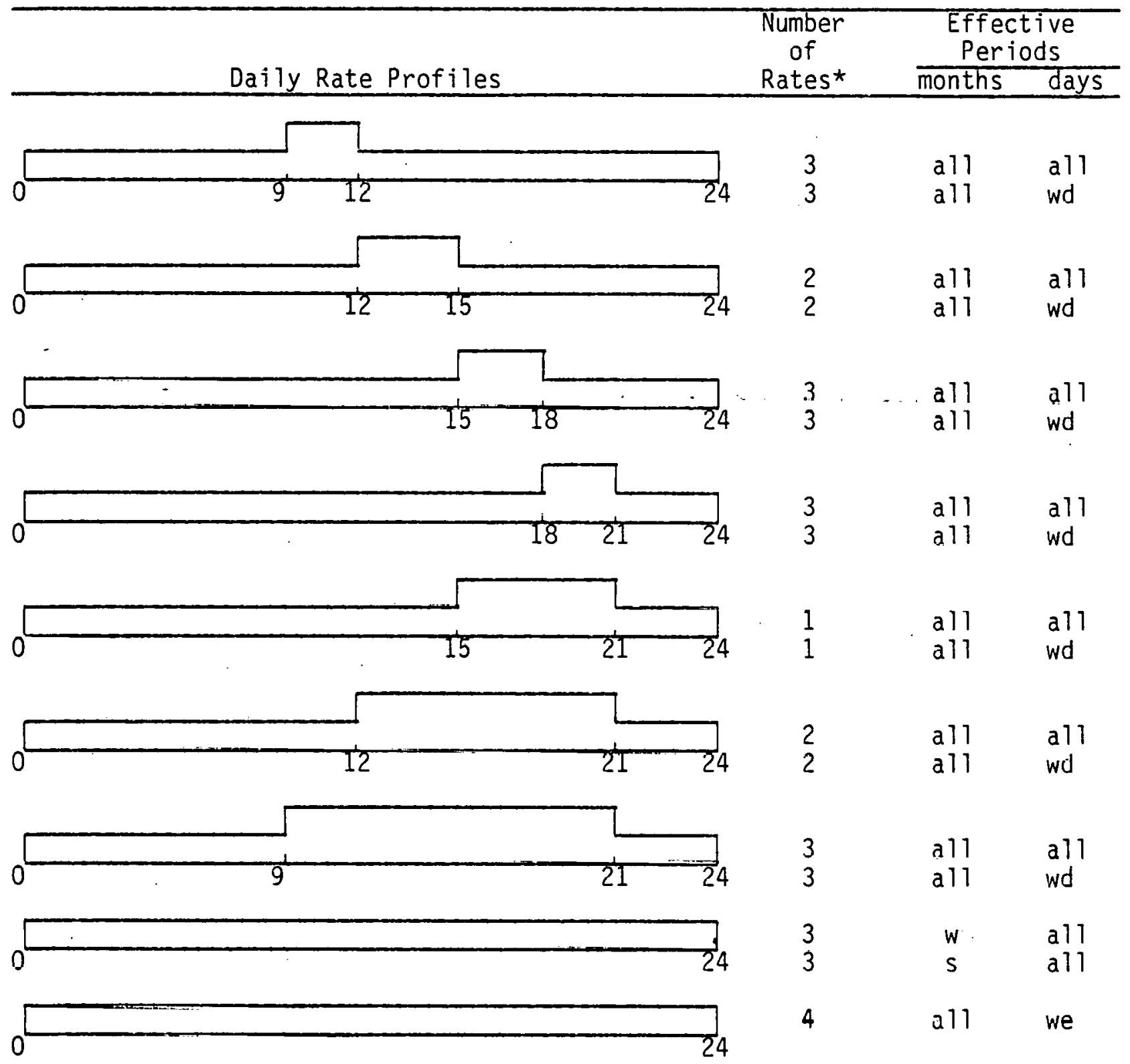

Independent Rating Periods for Combined Rate Analysis

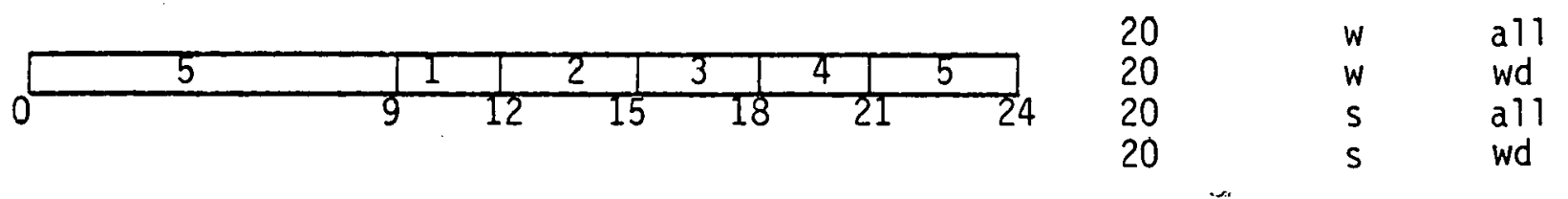


weekday time-of-day rate forms combined with two weekend rate forms), fourteen individual rate regressions are suggested for each of the two rating periods. These will be completed for average monthly consumption and for the day-of-system-peak consumption during peak and base periods (a tota) of 56 regressions per month--14 times two IRPs times two averaging periods-are needed to describe all appropriate response surfaces for individual rate regressions)(see table 3-3). Also, five combined rate regressions will be

performed for each averaging period. These will correspond to the five IRPS identified in the lower portion of table 3-12.

Typically, a regression will include 164 observations of individuals on the three flat rates and from 20 to 130 individuals on the time-of-day rates being investigated. The number of estimable second order terms will vary from one (in the 15-21 time period) to three in most of the other periods.

For purposes of combined rate analyses, the seven separate rate structures define five IRPs (see the lower portion of lable 3-12). There are twenty unique rows in the design matrix so that, in addition to the five linear price terms and the intercept, as many as fourteen of the fifteen second order terms may be included. A seasonal (in this case, annual) analys is will also be completed.

\subsection{New Jersey}

\subsubsection{Description}

Four seasonal time-of-day rates with peak/off-peak energy charges for weekdays and a single price for weekends are being evaluated. Eight hundred fifty customers will be placed on the experimental rates and 150 on the exisiting rate to serve as a control. Participation is mandatory and there will be no incentive payments. The method of selecting customers has not yet been finalized. Usage will be monitored during 15-minute intervals. 
The project deals with residential customers of the Jersey Central Power and Light Company. Controlled water heating customers, who represent 8 percent of Jersey Central's residential customers, were excluded from the sample. The experiment will be confined to customers served by six of the 272 substations in the Jersey Central service area. The six substations were chosen in a non-probability manner so that there was one substation in each of the six geographical subdivisions of the service area and so that the customers of the chosen substations would be predominantly residential. The 10,000 customers served by these six substations were surveyed by mail during January, 1977. Jersey Central proposes to exclude from the sample the customers who did not return the questionnaire and those who failed to answer the income questions or expressed an intention of moving. Seasonal customers will also be excluded at this stage. The net sampled population will be the remaining customers or approximately 35 percent of those who were sent questionnaires. The current plans call for stratification of this "net sampled population" into 81 strata based upon service category, income, family size, and appliance index. A stratified random sample of 1000 will then be selected and assigned to experimental rates and control.

\subsubsection{Proposed Analysis}

Descriptive Statistics and Comparative Analysis. The standard analysis as outlined in table 3-2 will be conducted.

Response Surface Analyses. Table 3-13 depicts the New Jersey rates. The customers in the sample were divided into two categories depending upon whether they had previously been classified as total electric or had previously had uncontrolled water heating service. Thus, two systems of regressions will be performed. Both groups of customers will be tested on two peak period prices against. a single base period price. A flat rate was 
Table 3-13. Summary of New Jersey experimental rates

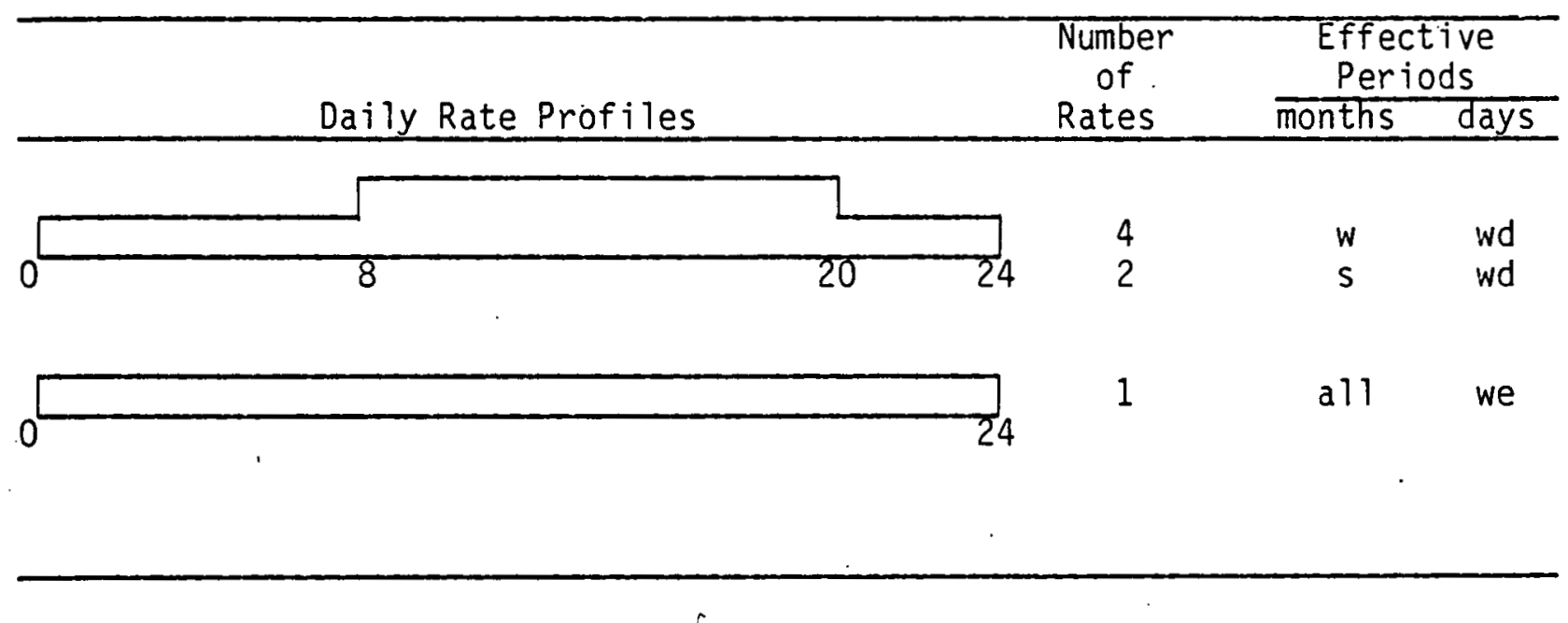


given to additional customers in one of the groups. For each group, single regressions on average monthly consumption and day-of-system-peak consumption for the peak and base periods (a total of eight regressions per month) will be performed. In the case where a flat rate will be available to create a third unique row of prices, linear terms for peak and base period prices can be included on the regression. In the case where there was no flat rate, there will be only two unique rows, thus making it possible to estimate only one of the two linear price terms. This must be the on-peak price because there is no variation in the off-peak prices.

\subsection{North Carolina}

\subsubsection{Description}

The North Carolina experiment involves two utilities--Blue Ridge Electric Membership Corporation (BREMC) and Carolina Power and Light Company (CP\&L).

The BREMC study involves one seasonal time-of-day rate with three rating periods plus a control (existing) rate. A total of 200 customers (100 on each rate) are being monitored with 15-minute recording meters. Participation is mandatory and there are no direct incentive payments given to the participants.

The CP\&L study involves a control group and eleven seasonal time-of-day rates--nine with three rating periods with no demand charge, one with three rating periods and a demand charge, and one with two rating periods and a demand charge. The study involves a total of 600 customers who are being monitored with 15-minute recording meters. Participation is mandatory and there are no direct incentive payments given to the participants.

The sampled population for the BREMC study is all residential customers with an active account as of April, 1977. The sampled population for the CP\&L study is all North Carolina residential customers with an active account as of April 1977, with the exception of seasonal customers. Those populations 
number 33,730 for BREMC and 472,667 for CP\&L. The sampled populations were stratified according to location and prior level of electricity consumption. For the CP\&L study, strata were formed based upon two geographic locations, four summer-usage and four winter-usage levels. Stratified random sampling was used to select approximately 19 customers from each stratum. The sampled households were then assigned to experimental rates at random so that at least three households per major stratum were assigned to each rate (the eight summer-usage/geographic area strata are termed major strata). For the BREMC study, stratification was based upon two geographic locations, four levels of winter usage, and four levels of summer usage. A stratified random sample was used to select six customers from each stratum. The sampled households from each stratum were then assigned to the experimental rates at random so that three households in each stratum were assigned to each rate.

\subsubsection{Proposed Analysis}

Descriptive Statistics and Comparative Analysis. The standard analysis as outlined in table 3-2 will be conducted. for both CP\&L and BREMC.

Response Surface Analyses. Table 3-14 depicts the experimental CP\&L rates. Since all customers on rates amenable to response surface analysis face the same rate forms within season, no combined rate regressions will be completed. Single regressions of average monthly consumption and day-ofsystem-peak consumption for peak, intermediate, and base periods (a total of six regressions for each month analyzed) will describe all appropriate response surfaces. There are ten unique rows in the design matrix for the surmer season since the existing (control) rate is flat during the summer. The three linear response terms in the regression may be augmented by five second order terms in the summer regressions. For the winter regressions, only four second order terms may be included because one unique price row, 
Table 3-14. Summary of North Carolina (CP\&L) experimental rates*

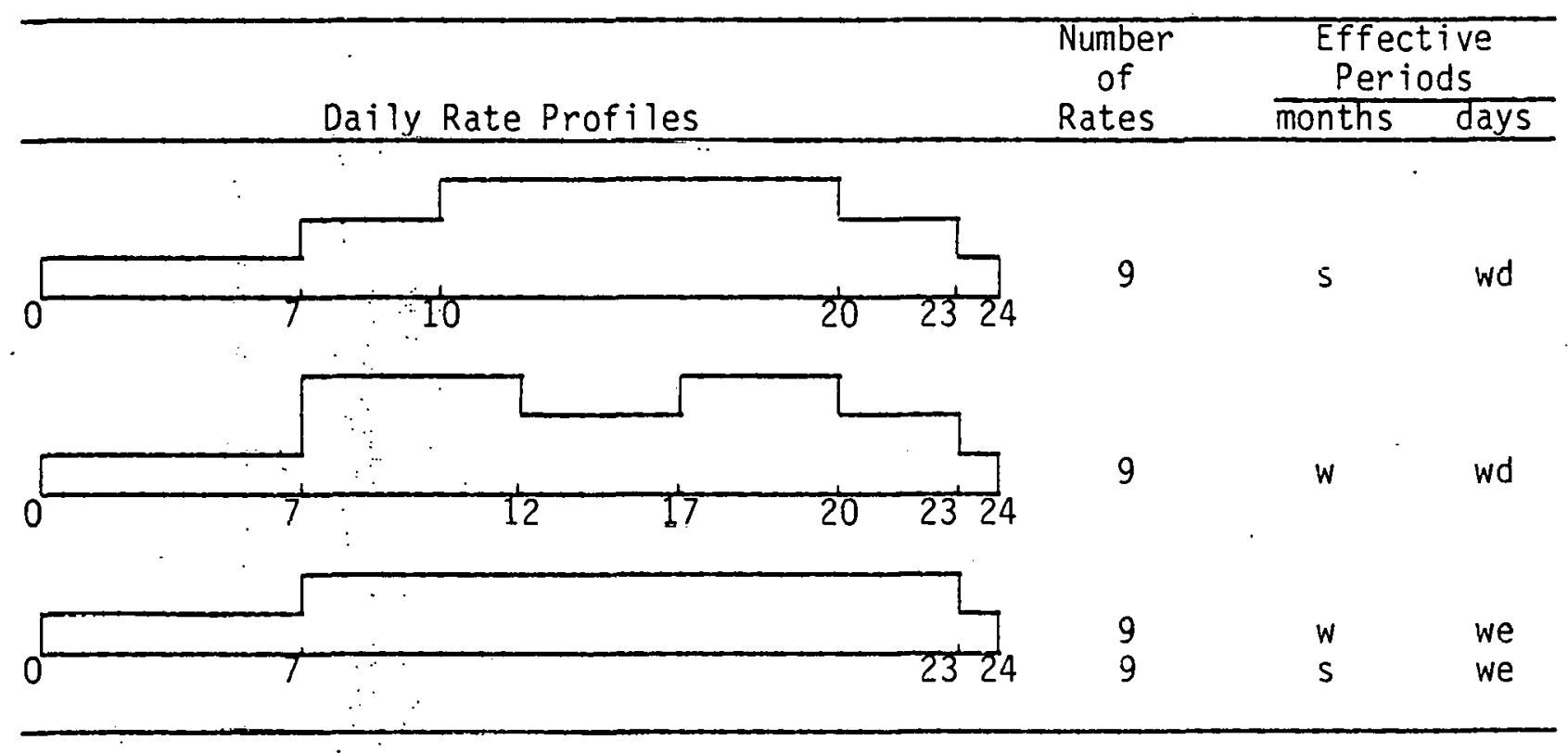

*Excludes rates with demand charges. 
the flat, must be dropped from the design since a declining block rate is in effect for those months. The summer regression will include 364 customers; the winter regression will include 278 .

Since the BREMC study involves a single rate, no elasticities will be estimated.

\subsection{Ohio}

\subsubsection{Description}

A single seasonal time-of-day rate was applied to 100 customers of Dayton Power and Light Company (DPL) who volunteered to participate in the study. These customers, along with 100 customers on the existing rate, were monitored via $30-$ minute $\mathrm{KWH}$ recorders. The experimental rate was in effect for about 18 months (ending in November, 1977).

Approximately 42 percent of the DPE customers were excluded prior to sampling. These included customers without a 12-month billing history, bulk metered residences, company employees, and residents on frozen rates.

Customers in the sampled population were ordered for systematic sampling on the basis of total annual usage. For the selection of the control group, 100 strata were formed with an equal number of customers in each stratum. All customers were included regardless of annual usage. For the selection of the experimental group, 100 strata were again formed with an equal number of customers in each stratum; but customers with an average annual usage below $6000 \mathrm{KWH}$ were excluded. The stratum boundaries for the experimental and control groups are not the same because of this exclusion. An initial sample of six customers per stratum was selected from the experimental and control strata. A total of 551 customers were contacted in order to obtain the 100 customers to be assigned to the experimental group. A total of 413 customers were contacted in order to obtain the 100 customers 
needed for the control rate. Some of the reasons for the large rejection rate were meter inaccessibility, intention of moving, and refusals.

\subsubsection{Proposed Analys is}

Descriptive Statistics and Comparative Analysis. The standard analysis, as outlined in table 3-2, will be conducted. Because of the large number of exclusions (Types I and II), unweighted sample data will be analyzed and system variables (\#21 and \#22 in table 2-2) will not be estimated.

Response Surface Analyses. Since a single TOD rate was involved, elasticities will not be estimated.

\subsection{Ok lahoma}

\subsubsection{Description}

The one-year experiment in Edmond, Oklahoma, involves six time-of-day rates (two with seasonal variations), four seasonal rates, two flat rates, and the existing rate. Electricity consumption for customers on the seasonal and flat rates were recorded on regular single dial meters. Usage for the majority of the other customers was recorded on two-dial meters which provide usage on a billing month basis for the peak (noon to $9 \mathrm{p.im.)}$ and base periods. Little base period price variation occurs among the six TOD rates. Customers are required to participate in this sludy; however, they will not be charged for electricity used during the single month after completion of the experiment. Some customers were deliberately given more information (concerning TOD rates and techniques for shifting electricity consumption) than others.

Approximately 8,511 residential customers are served by the participating utility, the Edmond Municipal Electric Company. Low income customers were excluded from the experiment. Two stages of sampling occurred in the selection of 600 sample customers. The first stage involved the selection 
of a presample of 1,472 customers. Within each meter reading route, customers were selected in clusters of from four to six customers. The monthly use of electricity per household was used as a size measure to determine the number of clusters to be selected from each route. These clusters were systematic samples of every third house beginning with the house immediately to the left of a random starting number. The presample of 1,472 customers was then stratified with respect to location, income, electric usage, and energy consumption and appliance inventory characteristics. A computer program was was used at the final selection stage to randomly select the number of sample units by strata. This resulted in 20 cells, each containing 30 households, each of which was representative of the city of. Edmond. These cells were randomily assigned to each of the 20 treatmenits inciuding the three controls.

\subsubsection{Proposed Analysis}

Descriptive Statistics and Comparative Analysis. The standard analysis, as outlined in table 3-2, will not be made for the Edmond, Oklahoma study because of the small sample sizes used.

Response Surface Analyses. Table 3-15 graphically summarizes the Edmond, $0 k 1$ ahoma rates. Since all customers face the same rate form only individual rate regressions will be completed. Thus, single regressions on average monthly consumption for peak and base periods (a total of two regressions per month) will describe the appropriate response surfaces. It is unlikely that regressions on day-of-system-peak consumption will be feasible for the 10 percent of the TOD customers whose consumption was monitored at 15 minute intervals. Excluding the flat rates, there are six unique rows for each season; estimates can be obtained for all of the price coefficients in the second order Taylor's series model. There will be 210 customers included in each seasonal regression. 
Table 3-15. Summary of Oklahoma experimental rates

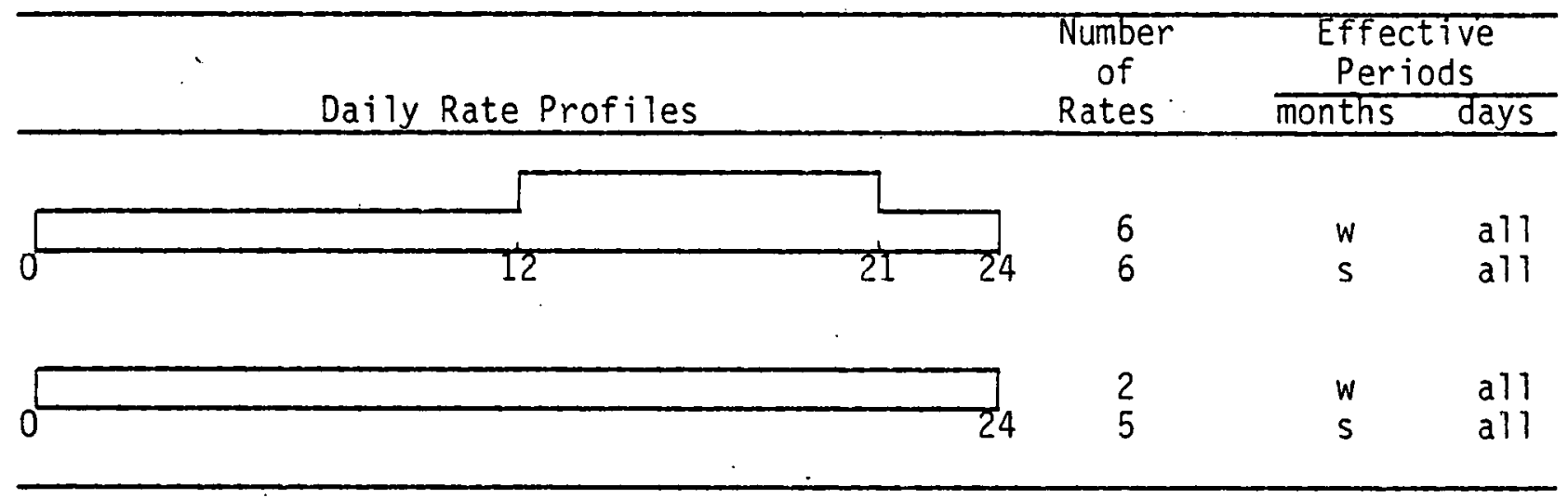




\subsection{Puerto Rico}

\subsection{1 .1 Description}

Experimental rates are scheduled to be in effect for about 2.5 years, beginning in the summer of 1978. Fifteen-minute KWH recorders will be used to monitor usage on about 350 customers who will receive experimental rates and on about 50 control-group customers. The Puerto Rico experiment will involve 22 experimental TOD rates with peak and base rating periods during weekdays; base prices are in effect on weekends and holidays. On weekdays, peak prices are in effect either for six hours or for 12 hours. There is considerable variation in both peak and base prices. A system of compensation payments is planned; however, the details are unknown.

The population of interest consists of all residential customers of the Puerto Rico Water Resources Authority. The sampled population was limited to residents of San Juan who were not living in public housing. These customers were stratified with respect to income and electricity consumption and a simple random sample selected from each stratum. The number of customers to be assigned to each treatment from each stratum was determined using a modified version of the Conlisk-Watts alloaction procedure. To implement the above sample design, a presample was selected from each energy consumption group and the customers were interviewed unti 1 the necessary number from each income level was obtained. Members of the presample were rejected because of incomplete data records, unusual consumption patterns, or when the head of the household was uncooperative or repeatedly unavailable. The procedure to be used to assign selected customers in each income/consumption stratum to each of the treatment groups (and price pairs) and to the control group is unknown. 


\subsubsection{Proposed Analysis}

Descriptive Statistics and Comparative Analysis. The standard analys is, as outlined in table 3-2 will not be conducted for the Puerto Rico study because of the small sample sizes used.

Response Surface Analyses. Table 3-15 depicts the rate design for Puerto Rico. Since there are three unique rate forms, three systems of individual rate regressions as well as a system of combined rate regressions will be estimated. Also, seasonal analyses will be completed.

Three regressions each on average monthly consumption and day-ofsystem-peak consumption for peak and base periods (a total of 12 separate regressions per month) are needed to describe all appropriate response surfaces. There are enough unique rows in each regression to estimate al1 second order terms. The number of customers in each regression vartes from 120 to 213 , including 50 customers on flat rates in each regression.

One of several possible sources of bias in the analys is of a response surface for Puerto Rico is a government subsidization of customers who use $425 \mathrm{KWH} /$ month or less. For a given month customers who consistently use less than $425 \mathrm{KWH}$ face a different price than those who use more. Therefore either separate regressions will be performed for these two groups, or the subsidized group will be dropped.

The combined rate analysis of the Puerto Rico data may be based on three independent time periods (table $3-16$ ). Since the pooled design matrix will contain 22 unique rows, all second order terms can be estimated.

\subsection{Rhode Is ] and}

\subsubsection{Description}

The Rhode Island Demonstration Project involves a single experimental rate (170 customers) and a control group (130 customers). The experimental 
Table 3-16. Summary of Puerto Rico experimental rates

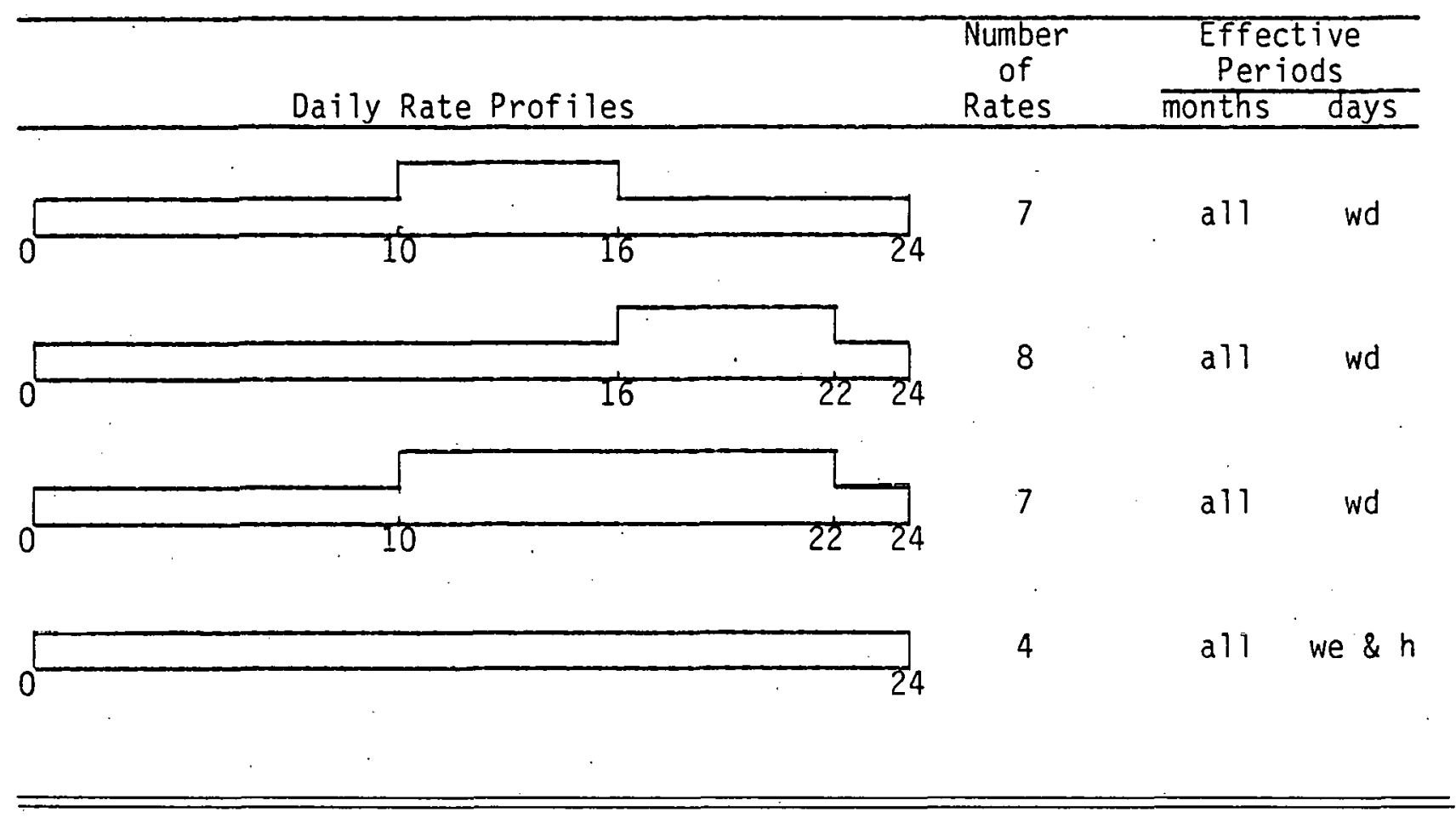

Independent Rating Periods for Combined Rate Analysis

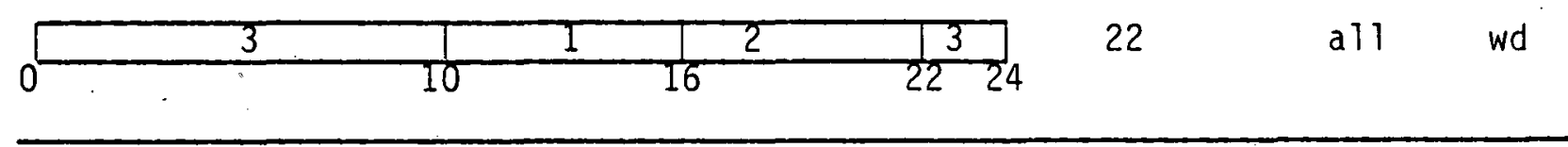


rate is a seasonal time-of-day rate with a two-part demand charge. Participation in this experiment is mandatory; it is scheduled to last 14 months (beginning in September, 1977). Fifteen-minute KWH meters are used to monitor the usage of all participants.

The population consists of the 65,700 residential customers of the Blackstone Valley Electric Company. These customers were stratified into three categories: general residential, controlled electric water heating, and electric space heating. These categories were not mutually exclusive since some customers had both controlled electric water heating and space heating. An initial sample was obtained by selecting five systematic samples from each stratum. The resulting 250 general residential, 100 controlled electric water heating, and 100 electric space heating customers were then screened, and those planning to move during the experiment or with incompatible wiring were excluded. Every other customer (a 50 percent subsample) with a billing history shorter than 12 months was deleted. When duplications occurred, one of the two selections was randomly discarded. After the screening process was completed, a random subsaniple from each stratum was selected for the experimental and control groups.

\subsubsection{Proposed Analysis}

Descriptive Statistics and Comparative Analysis. The standard analysis, as outlined in table $3-2$, will be conducted.

Response Surface Analyses. Since a single TOD rate was involved, elasticities will not be estimated.

\subsection{Washington}

\subsection{3 .1 Description}

The Washington demonstration project involves two utilities--Seattle City Light (SCL) and Puget Sound Power and Light (PSPL)--each testing one 
experimental rate on a voluntary basis. This project is unique in that the test rates are simply the new residential rates and do not reflect pricing of electricity by time-of-use. The Seattle City Light study is a one-year study involving 500 customers evenly split between test rates and control. The Puget Sound Power and Light study is a two-year study and involves 200 customers (100 on the experimental rate and 100 on a control rate).

SCL serves approximately 220,000 residential customers in the city of Seattle and the PSPL serves approximately 200,000 in suburban and rural King County. Substantive customer groups were excluded both prior and subsequest to sampling. Customers with less than one year residency at their present address and customers with poor credit ratings were purged prior to sample selection. Also, a number of customers were rejected after the sample was selected because participation was voluntary and because telephoning was relied upon for response. It is estimated that the population for which strictly defensible inferences can be obtained will be approximately 50 percent of the universe, i.e., SCL and PSPL service areas. The sampled population results from a stratified random design with proportional allocation for both SCL and PSPL. Also, the stratification for each utility consisted of ten usage-level groups.

\subsubsection{Proposed Analysis}

Descriptive Statistics and Comparative Analysis. The standard analysis, as outlined in table 3-2, will not be conducted. Because of the use of monthly KWH meters, only one variable--average KWH per customer during each billing month--will be analyzed.

Response Surface Analyses. Since TOD rates were not involved, elasticities will not be estimated. 


\subsection{Wiscons in}

\subsubsection{Description}

The Wiscons in experiment consists of twelve basic rates including the existing rate; since customer charges differ for rural and urban customers (in a similar manner across all twelve rates), twenty-four explicitlydefined rates are actually involved. One of the basic eleven experimental rates is a seasonal-flat rate, whereas the remaining ten are seasonal TOD rates with weekend-weekday variations. One of these ten rates includes a demand charge; the remaining nine TOD rates involve on-peak rating periods of 6,3 , or 12 hours and on-peak. to off-neak prire ratios of (approximately) $8: 1,4: 1$ and $2: 1$. Participation is mandatory in this three-year experiment. Fifteen-minute KWH recorders will be used to monitor the usage of roughly 700 customers.

The population consists of the 247,000 residential customers of the Wiscons in Public Service Corporation. Customers with monthly usage below $100 \mathrm{KWH}$ in 10 of the preceding 1.2 months were excluded as well as those with an average monthly consumption of less than $100 \mathrm{KWH}$. There is also some indication that renters were excluded; this is being verified. The remaining customers were separated into nine usage-level strata and a presample of 1,039 customers was selected by simple random sampling within strata. These presample members were surveyed and partitioned into homogeneous groups according to urban/rural, air conditioning, and electric water heater classifications. A sample of 700 customers was chosen from these groups. The customers from each group were randomly assigned to treatments. 


\subsubsection{Proposed Analys is}

Descriptive Statistics and Comparative Analysis. The standard analys is, as outlined in table 3-2, will be conducted.

The Wiscons in study design allows some useful additional comparative analyses which will be performed if time and funds permit. These analyses take advantage of the approximate factorial arrangement of treatment factors and would provide a first step toward developing realistic response surface models. Nine of the treatments can be used to produce an analysis of variance table involving two factors $(R=$ price ratio, $L=$ length of peak period). These two factors would be treated as qualitative factors with high, medium, and low levels. A rural/urban split (factor $A$ ) is also advocated since customer charges are different for urban and rural customers. The analysis would utilize an initial partition such as the following:

\begin{tabular}{l} 
Source of \\
variation \\
\hline Among treatments \\
$R$ \\
$L$ \\
$A$ \\
$R \times L$ \\
$R \times A$ \\
$L \times A$ \\
$R \times L \times A$ \\
Within treatments
\end{tabular}

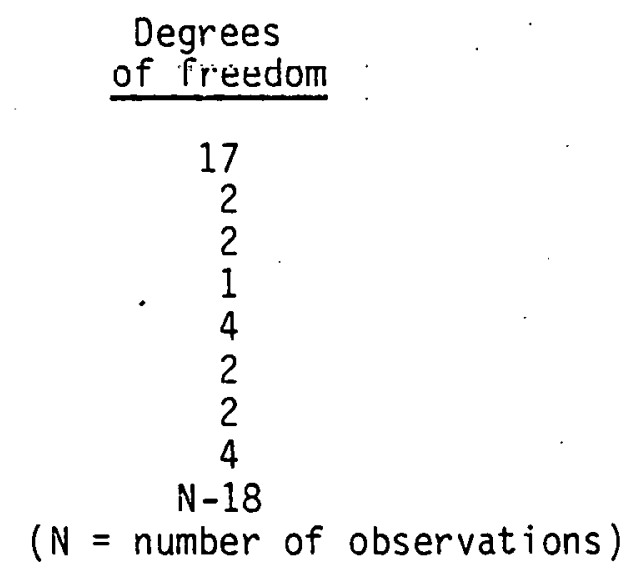

This type of analysis could be performed for various response variables that are not rate specific.

Response Surface Analyses. Table 3-17 depicts the rates in the Wisconsin experiment. Since there are three unique rate forms, systems of individual rate regressions as well as combined rate regressions will be completed (see table 3-3). Three regressions each for average monthly 
consumption and day-of-system-peak consumption for peak and base periods (a total of 12 regressions for each month) will describe all appropriate response surfaces for each rate form. Each regression will include 138 customers. The 12 regressions will initially be performed separately for rural and urban customers, and merged if it is not possible to reject the null hypothesis that there is no difference between the urban and rural parameter vectors. Typicaliy there are only four unique rows in the design matrix, allowing the estimation of only the linear terms and a single interaction term.

Combined rate regression may be based on four independent time periods in the summer and five independent periods in the winter--see table 3-17. In the summer, the ten unique rows of the design matrix will allow the. inclusion of four linear price terms and five second-order interaction terms in the regression. In the winter, there can be four second-order interaction terms in addition to the five linear terms.

Seasonal analysis will also be completed for both the individual and combined rate regressions.

\subsection{Michigan, New York, and Vermont}

\subsection{5 .1 Description}

A description of the Michigan and New York demonstration projects is not provided since it was determined that. Michigan involved only nonresidential customers and the residential component of the New York study was not funded by DOE and the data will not be made available for analysis.

Vermont tested six intermediate rates (see Appendix $N$ ) with sample sizes of 20 customers; however, only one of the six rates involved the pricing of electricity by time-of-day. 
Table 3-17. Summary of Wiscons in experimental rates*

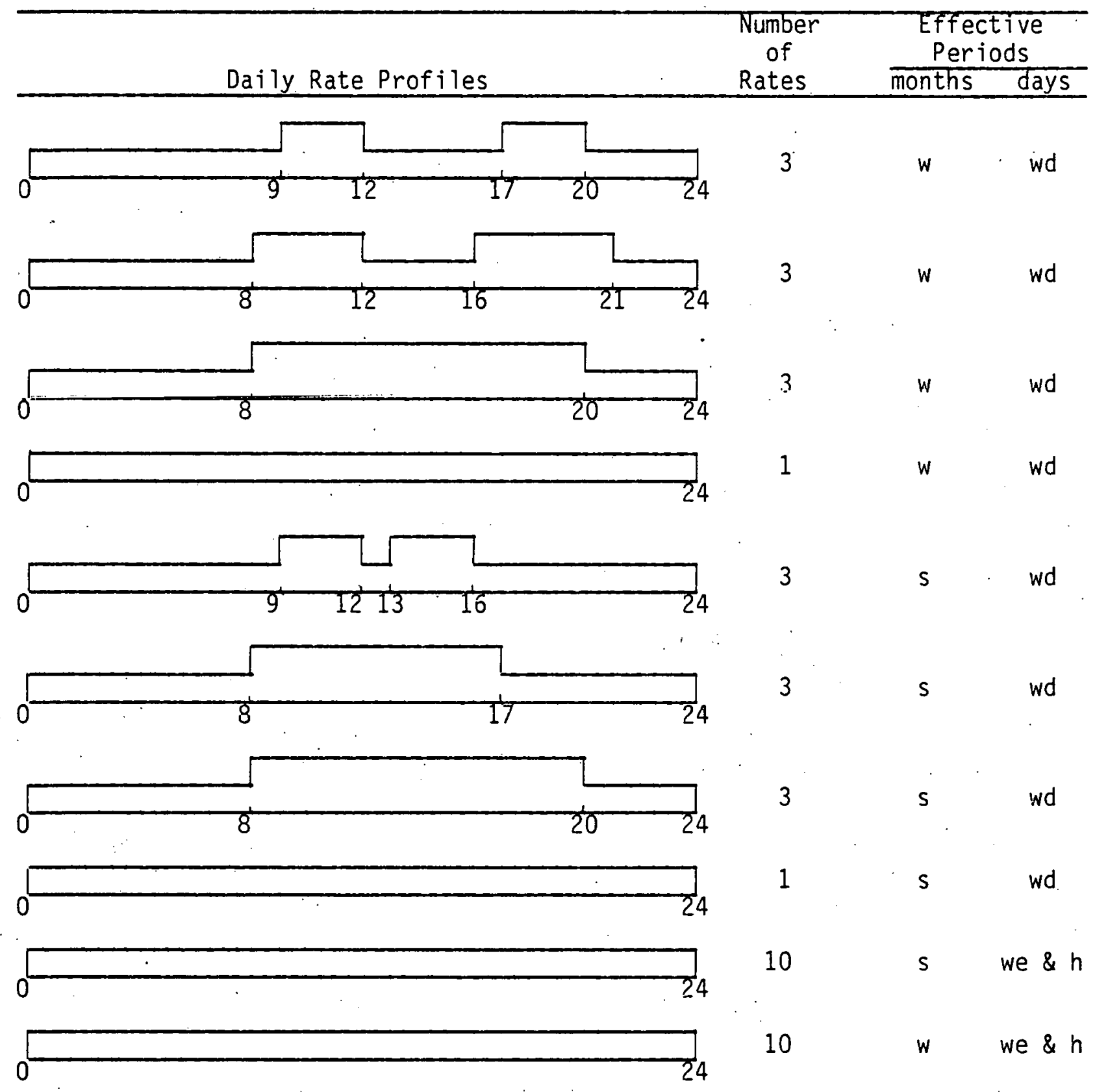

Independent Rating Periods for Combined Rate Analys is

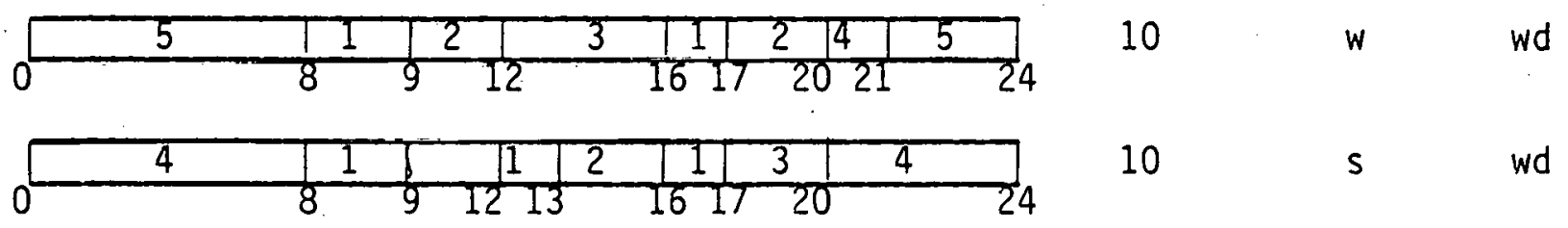

*Excludes demand charge rate. : Half the customers on each of these rates pay a customer charge of $\$ 4.94 / \mathrm{mo}$.; the other half pay $\$ 8.99 / \mathrm{mo}$. 


\subsubsection{Proposed Analysis}

Descriptive Statistics and Comparative Analysis. The standard analys is, outlined in table 3-2, is not applicable to the demonstration projects conducted in Michigan and New York since DOE funding did not support tests involving residential customers. In the case of Vermont, the very nature of the study design (see Appendix $N$ ) would suggest that an analys is as extensive as that shown in table 3-2 is unwarranted.

The following is proposed with regard to these three projects:

Michigan and New York - Analyses are not suggested for these projects. Vermont - In view of the inherent weaknesses in the Vermont study (small sample size, sample design, and lack of a valid control are three examples) and the fact that the sample results have already been summarized by the project team, we feel that very little would be gained by re-analyzing these data. As a deliverable item for this project we propose to provide a critique of this study which will draw heavily from the material presented in Appendix N. The anticipated level of effort is in the range of 10-20 man hours.

Response Surface Analyses. Elasticity estimation will nnt. he feasible for these studies. 
Pooled anaiyses (i.e., analyses conducted on a data set consisting of data from two or more projects) may permit some improvements over the project-specific analyses. The potential improvements are of two basic types:

1) increased precision in model (parameter) estimation, and

2) estimation of more general models.

The increased precision would be expected not only because of larger sample sizes but also because of a larger experimental region (i.e., greater variation in prices). Models could potentially be more general in two basic ways. First, because of the larger range in experimental prices, the same model form estimated for an individual project might be generalized to encompass a larger range in prices. Secondly, the dimensionality of the -..experimental region may he increased. That is, different--and, in general, more refined--models may be estimable from the pooled data than would have been possible from each of the component data sets. Obviously, these potential gains are made at the expense of certain assumptions concerning the uniform validity of models over the component projects and the expanded region.

Specific recommendations concerning the feasibility of pooling data from the demonstration projects should, in our opinion, be delayed until some fundamental questions involved in the project-specific analyses have been answered. For example, can one construct a project-specif ic response surface model which adequately characterizes customers' KWH usage patterns in terms of TOD prices (plus customer/dwelling characteristics, etc.)? If so, can such a model be constructed over rates with different rating 
periods? Is it reasonable, within a project, to conduct an analysis which pools data across time (e.g., August, 1977 and August, 1978 data)? Negative answers to such questions would imply that pooling across projects (or at least certain projects) would be a fruitless analytical exercise.

Although specific recommendations for pooling should be deferred, both the general scope of the pooled analyses and some of the potential criteria for pooling can be described. Pooling is considered relevant only in the context of response surface analyses since treatment comparisons across projects: a) are completely confounded with project differences, b) are not considered meaningful, and c) are (ideally) associated with the concept of drawing inferences to finite populations of residential customers. This first implies that projects not involving residential time-of-day rates be excluded from the pooled analyses. Also, construction of response (usage) variables consistently across projects requires that hourly usage data be available. Because virtually no check on the adequacy of a (project-pooled) model could be made for a project which involves a single experimental rate (because no within-project modeling could be carried out), it is recommended that these types of projects also be eliminated from consideration in any project-pooled analyses. The application of these exclusion criteria to the demonstration projects is depicted in figure $4-1$.

It is proposed that pooling of the remaining projects be considered with respect to certain potential criteria (see figure 4-1); judgments concerning the pertinence of the criteria will be inferred from the results of, and problems encountered in, the project-specific analyses. It is recognized that even though these decisions will still be largely 


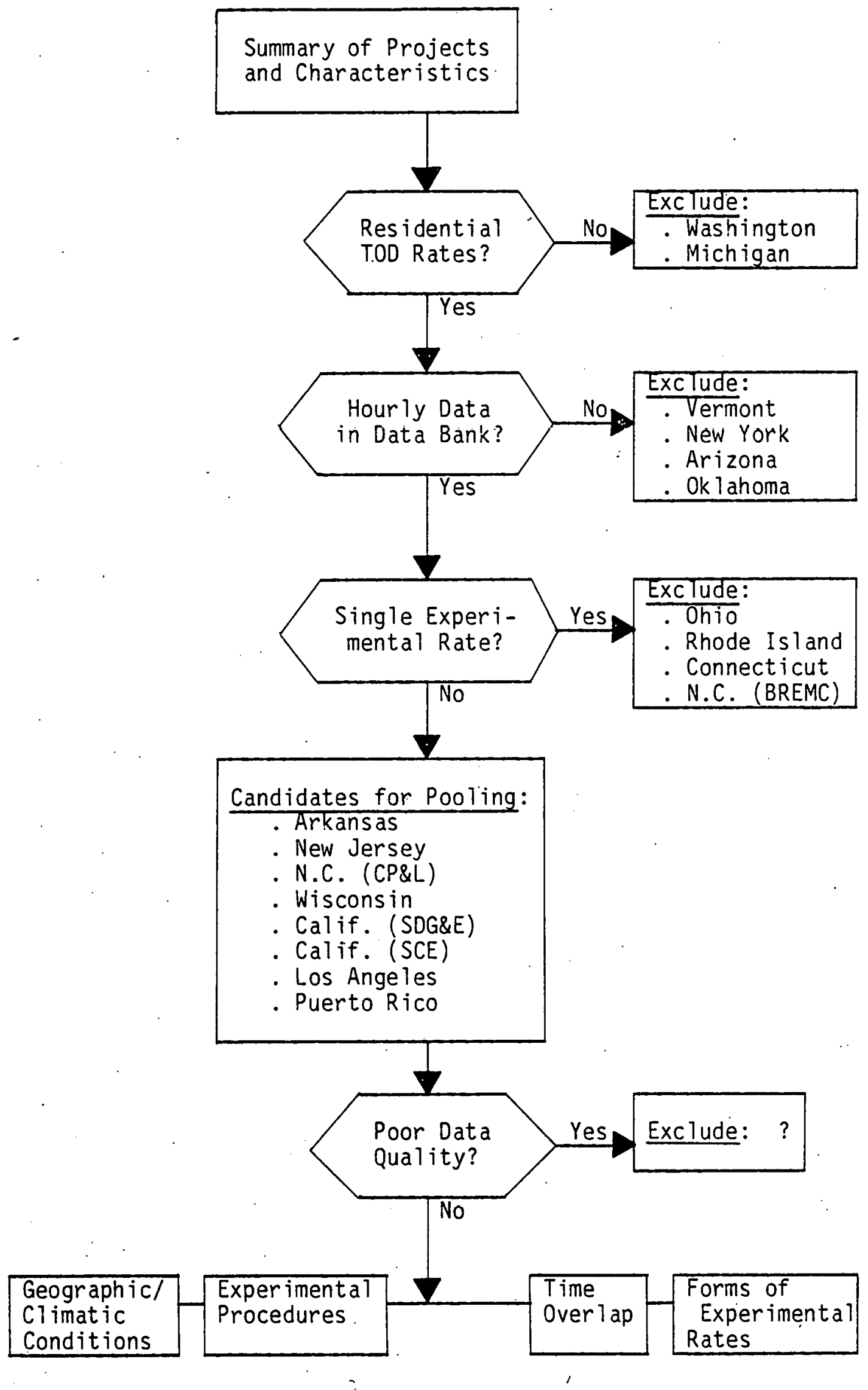

Figure 4-1. Criteria for project-pooled analyses 
subjective even after some of the project-specific analyses have been conducted, the basis for making rational decisions will be considerably strengthened by deferring these decisions. Hence, one purpose of the project-specific analyses will be to gain insight regarding the (relative) importance of :

1) differences in data quality,

2) differences in geographic/climatic conditions,

3) differences in the experimental procedures employed (e.g., type of participation, use of participation payments, etc.),

4) differences in the timing of the experiments (e.g., non-overlap of the experimental periods), and

5) differences in the experimental rates used (in particular, the use of differing seasonal, weekly, and daily rating periods).

If major analytical problems occur in the project-specific analysis of a particular project because of poor quality data (perhaps requiring a number of undesirable assumptions), then it is recommended that such a project be excluded from all pooled analyses.

Geographic/climatic conditions may be important in terms of constructing meaningful models for a specific time period. It is unlikely that California and Wisconsin customers in January, for example, would exhibit similar responses to prices, even if adjustments for weather conditions :were incorporated into the model. Restricting the pooled analyses to certain seasons may somewhat alleviate this problem. Two possible geographic/climatic groups are: a) the three studies in California and b) North Carolina (CP\&L) and Arkansas. Other groupings would be more doubtful. 
Given the exclusions mentioned above, the projects considered eligible for pooled analyses, and their status with respect to participation procedures and timing of the experiment, are shown in table 4-1.

Responses to TOD rates may or may not be different for experiments with differing participation procedures; the pooling of projects with similar procedures would avoid (at least partially) one potential source of bias in the parameter estimates.

Non-overlap of experimental periods from two (or more) projects causes considerable problems in constructing usage variables which are consistent across projects. Even when overlapping occurs, customers in the different projects may have been exposed to the experimental rates for different lengths of time and may therefore respond differently at the same point in time.

Table 4-1. Summary of relevant characteristics of projects eligible for pooled analys is

\begin{tabular}{lcccc}
\hline & Participation procedures & \multicolumn{3}{c}{ Approximate experimental period } \\
Project & Mandatory & Payments & & \\
\hline Arkansas & Yes & No & \\
New Jersey & Yes & No & \\
N.C. (CP\&L) & Yes & No & \\
Wisconsin & Yes & No & \\
Calif. (SDG\&) & $?$ & No & \\
Calif. (SCE) & Yes & Yes \\
Los Angeles & No & Yes \\
Puerto Rico & No & Yes \\
\hline
\end{tabular}


The form of the experimental rates in the component projects is a very important consideration for two primary reasons. First, it has direct bearing on the time frames for which analyses can be conducted. For example, the use of different seasonal definitions in two projects, along with the billing month problem addressed in section 2.3.2, may confine analyses to a relatively small portion of the year (since prices cannot be associated with each customer during seasonal transitions). Secondiy, the similarity (or lack thereof) of seasonal, weekly, and daily rating periods may force one either to make additional assumptions so as to be able to estimate the parameters of Inlerest or else to redcfinc these parameters. For example, if two projects each involve the same type of experimental rates except that one project defines the peak period as 1300 to 2100 and the other, from 1100 to 1900 , then pooling the data prevents one from estimating own- and cross-price elasticities for the onand off-peak periods. A new set of price-related parameters would have to be defined for such a sttuation (see section 2.2.3.1); these may or may not be more meaningful. In general, however, estimation of these new parameters cannot be made by utilizing data from only one of the component projects due to the considerable variety in the rate structures used in the various demonstration projects (see section 3.1.2.1). 


\section{Chapter 5: ORGANIZATION AND MANAGEMENT PLAN}

The analysis of the data from the electric utility rate demonstration projects, as set out in this AMP and in the contract between RTI and DOE, will be conducted by RTI staff members and by the consultants and subcontractors to RTI. The organization of the project team and the management plan for completing the study are presented in this chapter.

\subsection{Project Management}

The project leader for this study is Dr. Allen K. Miedema, Manager of the Institute's Economics Department. As project leader he has the day-to-day responsibility for the timely and professional completion of the tasks. He is also responsible for the staffing decisions. The members of the project team and their disciplinary orientation are shown in figure 5-1. For reference, the telephone numbers of the project team are also provided in the figure.

Management of the project is facilitated by: the several computerprocessed outputs that are provided routinely to the project leader by the RTI Accounting Department. These reports indicate personnel time charges reported on weekly time sheets and direct charges authorized by vouchers or purchase orders. The reports are as follow:

Personnel Report - provided for each period of time for which time sheets are submitted (approximately weekly). These reports indicate hours and costs of these hours charged by each employee for the reporting period and the cumulative for the month. This report enables the project leader to determine that all personnel charges to his project are proper; the accounting department revises any improper charges at direction of the project leader. 
Project Management

Allen K. Miedema (RTI)

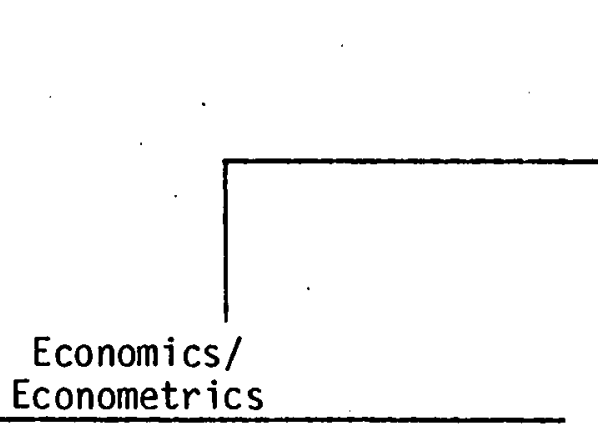

- Allen K. Miedema (RTI) (919) 541-6930

- Tayler H. Bingham (RTI) (919) 541-6932

- Jerome A. 01son (RTI) (919) 541-5947

$\vec{\sigma}$ - A. Ronald Gallant (NCSU) (919) 737-2531

- Wallace E. Hendricks (UI) (217) 333-6028

\section{Abbreviations}

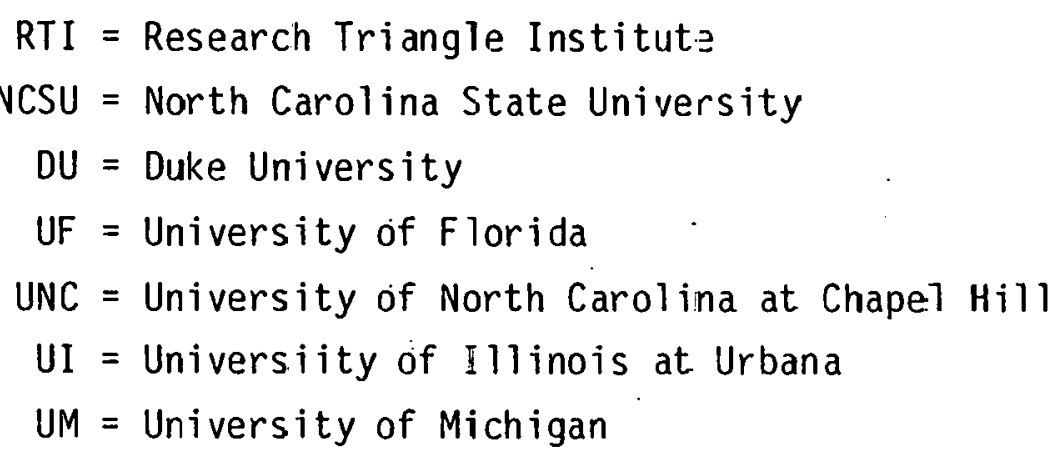

Experimental Liesign and Statistical

$$
\text { Methods }
$$

- S. B. White (FTI) (919) 541-6ङ90

- C. Andrew Clayton (RTI) (919) 541-6392

- Steven R. Wi T iams (RTI) i919) 541-6i4te

- Daniel H. Hill (UM) :313) 736-5-69

- Institute of statistics (NCSU and UNC)

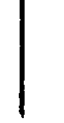

Computer

- James R. Batts (RTI) (919) 541-6:05

- Debra Duncan (RTI)

(919) 541-6108
Utility Systems

- Robert Sullivan (UF) (202) 376-4737

- John Grainger (NCSU) (919) 737-2335

- Argonne National Laboratory

Figure $5-1$. Project organization structure 
Project Cost Report - provided monthly and reports charges in dollars by line item for the current period, prior period (i.e., all previous charges), and the cumulative to date (sum of current and prior). There is also a column entitled "Proposal" which lists the amounts estimated for each line item at the time the project began. When cumulative expenditures exceed the planned or proposed amount, they are noted by three asterisks ( $\star \star \star)$. Expenditure Report - a monthly history of project charges by major line itein. At the time that approximately 55 percent of project funds have been expended, a memorandum is submitted to the project leader requesting that he summarize the status of the project. This enables contractual action to be taken if time or funds appear to be a problem.

\subsection{Data Handling Procedures .}

The primary data source for this study is the set of data provided by the 16 demonstration projects to DOE. The format is presented in table 5-1. The system for extracting the data has been developed by DOE.

RTI has had a leased line installed to the DOE computer in Rockville, Maryland. The line will be connected to computer terminals and high speed printers at RTI through the RTI telephone system.

The Statistical Analysis System (SAS) software package has been purchased by RTI and installed on the DOE computer. SAS augmented by RTI-supplied SAS procedures, is the primary analytical software package that will be used in this study.

SAS is an integrated system for data management and statistical analysis. It accepts data in virtually any form from any input device, 


\section{Electric Demonstration Data Request List}

Custoner number

I. Consumption Data (KWH)

\section{start date}

End date

Starting hour

Monthly historical consumption (KWH) 12 months

Control group consumption re-

corded at 15 minute intervals

Experimental group consurnption

recorded at 15 minute intervals

II. Electric Rates

Rate Code

Historical rate structure monthly

Control group rate structure

Experimental group rate structure

III. Utility Company Specific

Name of utility

Net system load on an hourly bas is for each experimental month

IV. Weather Information Identify weather station Hourly temperature (celcius) Hourly relative humidity

Hourly wind velocity

V. Alternative Energy Data Average price of fuel al ternatives

1. heating oil

2. natural gas

3. bottled gas

Natural gas available for appliance additions to existing natural gas customers yes or no

Natural gas available to new custoiners

$$
\text { yes or no }
$$

VI. Demographic Data (Customer

\section{Descriptivel}

Customer Specific Household

Information

Number of household members in each age bracket

$0-6 \quad 22-64$

$7-21-65+$
VI. Cont inied

Nunber of household members worling $35+$ hours a week during 6 a.m. -6 p.m. 6 p.m. -6 a.m.

Total gross family income

(all monies flowing into

the family including social

security, welf are payments. eti.)

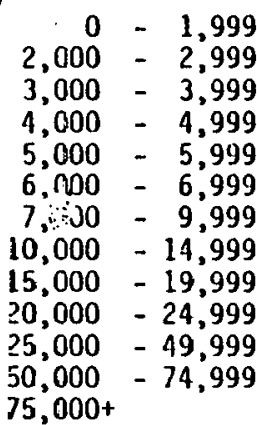

$50,000-74,999$

$75,000+$

Customer Specific Dwelling

Information

Type of dwelling

Single unattached house

Attached house

Apartinent

Mobile home

Number of rooms

Irsulation features

Staria windows

Ever where Some \& None

Irsulated glass windows

Everwhere Some \% None

Fiel to Heat Home and Home

Heating system

Fuet to heat home

nctural gas

bottled gas wood

electricity

coal

other

Type of Electric Heating Used to

Heat Home

$\begin{array}{ll}\text { radiant } & \text { heat pump } \\ \text { baseboard } & \text { other } \\ \text { forced air } & \text { don't know } \\ \text { hot water } & \text { no electric heat }\end{array}$

'II. Cont inued

Water Heating System

Capacity in gallons

Fuel

Natural gas

0 il

Electricity

Bottled gas

Other

None

VII. Appliance Inventory

Range

ype

Electricity

Botiled gas

other

No range

Air Conditioning

Type

Central

Number of window units

None

Refrigerator

Seff defrosting

Manual defrost

None

Dryer

ETectric

Gas

None

Freezer

Self defrosting

Manual defrosting

None

Dishwasher

Yes or no

Washing Machine

Yes or no 
and can be used interactively or in batch modes. In a single SAS job, one can create data sets, edit and transform them, analyze them statistically, manipulate them further, perform more analyses; store them on disk, and so forth. Variables can be transformed or deleted. It can create new variables, and create new data sets from existing ones, merge data sets, concatenate them, update them, and create subsets of them.

SAS has versatile least-squares procedures which produce a wide variety of linear and non-linear regression analyses, analyses of variance and covariance, and multivariate analyses of variance. SAS can also produce multiple and partial correlation coefficients and Spearman's and Kendall's correlation coefficients. It has several procedures for analyzing time-series data. It can produce plots and frequency and cross-tabulation tables and analyze them. It can perform discriminant analyses, factor analyses, and cluster analyses, construct and evaluate Guttman scales, perform t-tests or tests of goodness-of-fit or probit analyses and generate randomized plans for experiments:

\subsection{Project Schedule and Budget}

The required reports, their due dates, and the required number of copies are presented in table 5-2. A tentative outline of the content of the reports is outlined below. To the extent possible the content of the interim analysis reports will parallel that of the final reports. At a minimum, the interim reports will include the analysis of all data available plus the project description.

Project-Specific Analyses

Final and Interim Analys is Reports:

Introduction and Summary

Background

Summary 
Experimental Design
Purpose
Sample Selection
Experimental Rates
Customer Information and Contacts

Analys is of Experimental Data

Objectives and Limitations

Descriptive Analys is

Comparative Analys is

Response Surface Analys is

System Implications

Further Directions for Analys is

Project-Pooled Ana'lys is Reports:

Introduction

Criteria for Pooling

Analysis of Pooled Data

Objectives and Limitations

Response Surface Analys is

Further Directions for Analys is

The first of these reports will contain specific recommendations for the project-pooled analyses. Results of the analyses will be reported in the second and third reports.

\section{Summary Analytical Reports:}

These reports will summarize the major findings over the previous six months. They will describe the analytis.al effort, highlight significant findings, describe the approaches employed, problems encountered and solutions found, and identify directions for further analys is.

\section{Final Reports:}

These year-end reports will summarize our progress annually.

RTI will produce an overall (separately bound) description of the standard data processing and analys is procedures to be used in developing all project-specific reports. In the event that the procedures applied in specific project analyses are different from the standard case, the differences will be identified in an appendix to the project-specific reports. Within reason, every attempt will be made to provide a full 
reporting of the treatment of the data so that a future analyst could reconstruct the data base RTI uses, based on the provided detail. Also RTI has confirmed with the DOE computer operations group that the analysis files which are constructed by RTI can be preserved indefinitely for future access by DOE.

In preparing the various reports required in his research effort, the need for presenting results which can best benefit the user is recognized. In this regard, we will attempt to characterize the population of customers to which the results apply and identify those activities which could potentially bias the results. Issues of a highly technical nature will be included, to the extent possible, as appendices.

A tentative allocation of the project budget is presented in table 5-3. This allocation is based on a review of the demonstration projects and the alternative analysis procedures. The projects to be analyzed first have been allocated increased budget shares to reflect the initial. cost of constructing general purpose software, etc. 
Table 5-2. Project Reporting Schedule

\begin{tabular}{|c|c|c|}
\hline Due date ${ }^{\dagger}$ & Activity & $\begin{array}{l}\text { No. of } \\
\text { copies }\end{array}$ \\
\hline $1 / 31 / 78$ & Analytical Master Plan & 30 \\
\hline $3 / 31 / 78$ & $\begin{array}{l}\text { Arizona Final Analys is } \\
\text { Connecticut Final Analys is }\end{array}$ & $\begin{array}{l}20 \\
20\end{array}$ \\
\hline $4 / 30 / 78$ & First Summary Analytical Report & 30 \\
\hline $5 / 31 / 78$ & $\begin{array}{l}\text { Arkansas Final Report } \\
\text { Vermont, Michigan and New York } \\
\text { Final Analys is }\end{array}$ & $\begin{array}{l}20 \\
15\end{array}$ \\
\hline $7 / 31 / 78$ & $\begin{array}{l}\text { Los Angeles Interim Analys is } \\
\text { Wiscons in Intertm Analys is }\end{array}$ & $\begin{array}{l}20 \\
20\end{array}$ \\
\hline $8 / 31 / 78$ & $\begin{array}{l}\text { North Carolina Interim Analys is } \\
\text { California Interim Analys is }\end{array}$ & $\begin{array}{l}20 \\
20\end{array}$ \\
\hline $9 / 30 / 78$ & $\begin{array}{l}\text { First Project-Pooled Analys is* } \\
\text { Phase I Final Report } \\
\text { Edmond, Oklahoma Interim Analys is } \\
\text { New Jersey Interim Analys is }\end{array}$ & $\begin{array}{l}2.5 \\
30 \\
20 \\
20\end{array}$ \\
\hline $10 / 31 / 78$ & Second Summary Analytical Report & 30 \\
\hline $11 / 30 / 78$ & $\begin{array}{l}\text { Rhode Island Interim Analys is } \\
\text { Ohio Final Analys is } \\
\text { Washington Interim Analys is }\end{array}$ & $\begin{array}{l}20 \\
20 \\
20\end{array}$ \\
\hline $12 / 31 / 78$ & $\begin{array}{l}\text { Washington Final Analys is } \\
\text { Puerto Rico Interim Analys is }\end{array}$ & $\begin{array}{l}20 \\
20\end{array}$ \\
\hline $1 / 31 / 79$ & $\begin{array}{l}\text { Wisconsin Final Analys is } \\
\text { California Final Analys is }\end{array}$ & $\begin{array}{l}20 \\
20\end{array}$ \\
\hline $3 / 31 / 79$ & $\begin{array}{l}\text { Second Project-Pooled Analys is* } \\
\text { North Carol ina Final Analys is } \\
\text { Edmond, Oklahoma Final Analys is } \\
\text { Rhude Island Tinal Analysis }\end{array}$ & $\begin{array}{l}25 \\
20 \\
20 \\
20\end{array}$ \\
\hline $4 / 30 / 79$ & Third Summary Analytical Report & $30^{\circ}$ \\
\hline $5 / 31 / 79$ & New Jersey Final Analys is & 20 \\
\hline $7 / 31 / 79$ & $\begin{array}{l}\text { Los Angeles Final Analys is } \\
\text { Puerto Rico Final Analys is }\end{array}$ & $\begin{array}{l}20 \\
20\end{array}$ \\
\hline $9 / 30 / 79$ & $\begin{array}{l}\text { Third Project-Pooled Analys is* } \\
\text { Phase II Final Report }\end{array}$ & $\begin{array}{l}25 \\
30\end{array}$ \\
\hline
\end{tabular}

*The first project-pooled analys is report will contain specific recommendations for pooled analyses that will be conducted and reported in the second and third reports.

t Subject to delay depending on data availability. 
Table 5-3. Budget allocation

Budget share

(percent)

Analytical Master Plan

Project-Specific Analyses

Arizona

Arkansas

California (SDG\&E)

California (SCE)

Connecticut

Los Angeles

New Jersey

North Carolina (BREMC)*

North Carolina (CP\&L) *

Ohio

OkTahoma

Puerto Rico

Rhode Isl and

Vermont, Michigan, and New York

Washington

Wiscons in

5

4

5

6

4

13

4

1

1

1

3

6

. 2

1

1

10

Project-Pooled Analyses

First. Report

Second Report

Third Report

Summary Analytical Reports

First Report

Second Report

Third Report

1
1
1

Final Reports

Phase I Final Report

Phase II Final Report

*Primary analyses to be conducted by RTI under N.C. Demonstration Project Study. 
THIS PAGE

\section{WAS INTENTIONALLY \\ LEFT BLANK}




\section{BIBLIOGRAPHY}

Acton, Jan, Bridger Mitchell and Ragnhild Mowill; "Residential demand for electricity in Los Angeles: an econometric study of disaggregated data." The Rand Corporation, R-1899-NSF, September, 1976.

Atkinson, Scott E., "Responsiveness to time-of-day electricity pricing: first empirical results." Unpublished manuscript, May, 1977:"

Benus, J., J. Kmenta and H. Shapiro, "The dynamics of household budget allocation to food expenditures." Review of Economics and Statistics, (LVIII) May, 1976, 129-138.

Bieri, J. and A. de Janury, "Empirical analys is of demand under consumer budgeting." Giannini Foundation Monograph No. 30, September, 1972.

Boggis, J. G., "Domestic tariffs experiment." Load and Market Research Report No. 121, The Electricity Council, London, n.d..

Boyd, James W. (ed.), "Proceedings on forecasting methodology for time-ofday and seasonal electric utility loads." Electric Power Research Institute Special Report 31, March, 1976.

Bridge, J., Applied Econometrics. Amsterdam: North-Holl and Publishing Company, 1971 .

Christensen, L., D. Jorgensen and L. Lau, "Transcendental logarithmic utility functions." American Economic Review (LXV) June, 1975, 367-383.

Christensen, Laurits R. and Marilyn E. Manser, "Est imating U.S. consumer preferences for meat with a flexible utility function." Journal of Econometrics 5(1977): 37-53.

Clarkson, G., The Theory of Consumer Demand: A Critical Appraisal. New York: Prentice Hall, Inc., 1963.

Deaton, A., Models and Projections of Demand in Post-War Britain. New York: Wiley, 1975.

Diewert, W. E., "An application of the Shepard Duality Theorem: A generalized Leontief production function." Journal of Political Economy. (79) May/June, 1977: 481-507.

. "Functional forms for utility and expenditure functions." Report 6932, Center for Mathematical Studies in Business and Economics, Department of Economics and Graduate School of Business, University of Chicago, August, 1969. 
Forecasting and Modeling Time-of-Day and Seasonal Electricity Demands. Electric Power Research Institute Special Report, Uecember, 1977.

Frisch, Ragnar, "A complete scheme for computing all direct and cross demand elasticities in a model with many sectors." Econometrica, 1959, 27(2): $177-96$.

Geary, R., "A note on 'A constant-utility index of the cost of living." " Revi.ew of Economic Studies, 1949-1950, 18(45): 65-66.

Goldberger, A., "Functional forms of utility: a review of consumer demand theory." University of Wiscons in Systems Formulation, Methodology, and Policy Workshop Paper 6703, 1967.

Gorman, W: M., "Separable utility and aggregation." Econometrica, 1959, 27(3): $469-31$.

Hendricks, Wallace, Roger Koenker and Robert Podlasek, "Consumption patterns for electricity." Journal of Econometrics 5(1977): 1-19.

Hendricks, Wallace, Roger Koenker and Dale J. Poirier, "The residential demand for electricity by time of day: an econometric approach."

Electric Power Research Institute Research Project 882-1: Final Report, October; 1977.

- :Stochastic parameter models for panel data: an application to the Connecticut peak load pricing experiment." Bell Laboratories economic discussion paper no. 117, January, 1978.

Hieronymus, William H., "Long-range Forecasting Properties of State-of-theArt Models of Demand for Electric Energy." Volume 1: Final Report. Electric Power Research Institute, December, 1976.

Koenker, R., "Optimal peak-load pricing with time additive consumer préferences.". Bell Laboratories, May 27, 1977:

Lau, Lawrence J.,. Wuu-Long Lin and Pan A. Yotopoulos, "The linear logarithmic expenditure system: an application to consumption-leisure choice of agricultural households in the Province of Taiwan. "Food Research Institute Discussion Paper No. 1975-1, Center for Research in Economic Growth, Apri1, 1975.

Lawrence, A., and:S. Braithwait, "The residential demand for electricity with time-of-day: pricing." Unpublished manuscript, November, 1977.

Manning, Willard G., Bridger M. Mitchell and Jan Paul Acton, "Design of the Los Angeles peak load pricing experiment for electricity." The Rand Corporation, R-1955-FEA, Draft Report, March, 1976.

Mishan, E. J., "Theories of consumer's behaviour: a cynical review." Econometrica, 1961, 28(109): 1-11.

Mitchell, Bridger M., with Jan. Paul Acton and Ragnhild S. Mowi11, "Selected econometric studies of the demand for electricity: review and discussion." The Rand Corporation, November, 1975. 
Parks, Richard W., "Systems of demand equations: an empirical comparison of alternative functional forms." Econometrica, 1969, 37(4): 629-50.

Phlips, L., "A dynamic version of the linear expenditure model." Review of Economics and Statistics, 1954, 450-58.

- Applied Demand Analysis. Amsterdam: North-Holland Publishing Company, 1974.

Pollak, Robert A., and Terence J. Wales, "Estimation of complete demand systems from household budget data." University of Pennsylvania Department of Economics Discussion Paper No. 345, April, 1976.

Powe 11, Alan A., Empirical Analytics of Demand Systems. London: D.C. Heath and Company, 1974.

Stone, J. R. N., The Measurement of Consumers' Expenditure and Behaviour in the United Kingdom, 1920-1938, Volume I. Cambridge University Press, 1954 .

Stone, R., "Linear expenditure systems and demand analysis: an application to the British pattern of demand." Economic Journal, 1954, 64(255): 511-27.

Strotz, Robert H., "The empirical implications of a utility tree." Econometrica, $1957,25(2): 269-80$.

. "The utility tree." Econometrica, 1959, 27(3): 482-88.

Taylor, Lester D., Gail R. Blattenberger, Philip K. Verleger, Jr., and Data Resources, "The Residential Demand for Energy." Volume 1. Electric Power Research Institute Final Report, January, 1977.

Taylor, Lester D., and John T. Wenders, "Analys is of data from first six months of time-of-use electricity pricing experiment." Memorandum to Arizona Public Service Company, n.d..

Theil, Henri, The Theory and Measurement of Consumer Demand. Volume I. Studies in Mathematical and Managerial Economics, Henri Thei 1 (ed.). New York: North-Holland Publishing Company, 1975.

Wenders, J. T., and L. D. Taylor, "Experiments in seasonal-time-of-day pricing of electricity to residential users." Bell Journal of Economics $7(7): 536-537$ : 


\section{THIS PAGE}

\section{WAS INTENTIONALLY \\ LEFT BLANK}


ECONOMETRIC MODELS OF ELECTRICITY--AN OUTLINE

An addendum to Volume I of the AMP

by

Wallace Hendricks 
Electricity is not demanded as an end use itself, but rather it is demanded to be used in combination with other goods to produce some output such as air conditioning or fried eggs. The demand for electricity is therefore derived from the demand for the output processes in question. Since electricity is typically combined with durable goods, it is important to distinguish between the short run demand for electricity and the long run demand. In the short run, the consumer must choose a utilization rate for an existing stock of appliances. In the long run, the dellanl rur electricity is tantamount to the demand for the capital stock itself.

The experiments which have generated electricity consumption data have typically been very short run. Customers would not be expected to change their appliance stock in response to changes in the price of electricity. However, the data are gathered from cross-sectional units which have different appliance stocks (and other characteristics). Thus, price responses whlch dre estimated from this data might be viewed as "shnrt-run equilibrium" responses.

The models which are outlined below focus on the short-run utilization of these given stocks of appliances. In the actual estimation of price effects it is necessary to control for these different stocks as well as other demographic characteristics of the consumers.

\section{A Demand Model for Ellectricity in Continuous Time*}

We posit a model of the general form

$$
w(x, q \mid s)=w(v(x), u(q \mid s))
$$

*The following sections rely heavily on the work of Roger Koenker and Wallace Hendricks. 
Utility for a given stock of appliances ( $s$ ) is a function of utility derived from other goods $(v(x))$ and utility derived from consumption of electricity $(u(q \mid s))$ for the given stock. We assume that there is competition between $x$ and $q$ for shares of the consumer's budget, but intertemporal substitution within the $u$ branch is independent of spending within the $v$ branch.

The consumer maximizes (1) subject to a budget constraint for horizon of length $T$ of

$$
m=p x+\phi x(q)+\int_{0}^{T} r(t) q(t) d t
$$

where $m$ denotes income allocated to expenditure during the period, $p$ is a price vector for other commodities $(X)$ and it is assumed that the price of electricity is the sum of a fixed charge $\phi X(q)$ and a charge that varies over time $r(t)$.

As is well known the problem of maximizing (1) subject to (2) may be accomplished in two stages by first maximizing $u(q)$ and $v(x)$ for a given expenditure for electricity $\theta \mathrm{m}, \theta \varepsilon[0,1]$ and then finding a global optimum by selecting a $\theta$ to maximize

$$
w^{\star}(\theta)=w\left(v^{\star}(\theta), u^{\star}(\theta)\right)
$$

where $v^{*}(\theta)$ and $u^{*}(\theta)$ were found in the first stage for all $\theta$.

At this point it is convenient to focus our attention on the conditionally optimal demand path $q(t \mid \theta)$. In general, we may not be in a position to analyze the consumer's behavior with respect to all goods, but only with respect to electricity. A solution is to impose separability between the v-branch and the u-branch of the consumer's utility tree. The 
problem of maximizing (1) subject to (2) is therefore reduced to

$$
\begin{gathered}
\operatorname{Max} u(q \mid s, \theta) \\
\text { s.t. } \theta m \geq \phi X(q)+\int_{0}^{T} r(t) q(t) d t
\end{gathered}
$$

The conditionally optimum demand path $\hat{q}(t \mid \theta)$ can then be found by specifying a functional form for $u$.

\section{Specifying the Form for the U}

Traditional econometric studies of consumer demand for electricity have typically ignored the spectflcalion of the form of the utility function and posited a demand function $q(t)=g(R, m ; s)$ where $R$ is a vector of prices. This function has usually been approximated by either a simple linear or log-linear equation which does not incorporate the restrictions implied by neoclassical demand theory. On the other hand, most studies which have used functional forms that satisfy the criterion of utility maximization have used forlls which are rather restrictive and hence somewhat inflexible. Typically such forms have employed the properties of homotheticity and additivity. The problems associated with these assumptions are discussed in more detail in the body of the text. For now, we will put forward two possible functional forms for $u$. However, we must emphasize the trade-off between specifying a functional form and making restrictive assumptions.

\section{1 "Stone-Geary" Utility Function}

The continuous time analogue to the Stone-Geary utility function is given by

$$
u(q)=\int 0_{0}^{T} \beta(t) \ln (q(t)-\alpha(t)) d t
$$


Maximizing this function subject to the budget constraint* generates the periodic demand paths

$$
q(t)=\alpha(t)+\frac{\beta(t)}{r(t)}\left[\theta m-\iint_{0}^{T} r(s) \alpha(s) d s\right]
$$

In terms of expenditure this implies the linear expenditure system

$$
e(t)=r(t) \alpha(t)+\beta(t)\left[\theta m-\int_{0}^{T} r(s) \alpha(s) d s\right]
$$

where $\alpha(t)$ is committed demand and $\beta(t)$ is the marginal budget share function.

\subsection{Trans log Utility Function}

The time additive Stone-Geary function imposes rather severe restrictions on the structure of intertemporal preferences. The translog function is considerably more general.

The continuous time analogue to the indirect utility function in the translog case is given by

$$
\begin{aligned}
& \text { en } v(p)=\int T^{T} a(t) \ln p(t) d t \\
& +1 / 2 \int_{0}^{T} \int_{0}^{T} \beta(t, s) \ln p(t) \ln p(s) d t d s \\
& \text { where } p(t) \equiv r(t) / \theta m \text { and } \\
& \beta(t, s)=\beta(s, t) \text { for } a 11 \text { t and } s
\end{aligned}
$$

This generates the consumer demand policy.

$$
\frac{q(t)=\frac{\theta m}{r(t)}\left[\alpha(t)+\int_{0}^{T} \beta(t, s)(\ln r(s)-\ell n \theta m) d s\right]}{\int_{0}^{T} \alpha(t) d t+\int_{0}^{T} \int_{0}^{T} \beta(t, s)(\ln r(s)-\ln \theta m) d t d s}
$$

*This formulation assumes that there is no fixed charge for electricity. Since the fixed charge has an income effect, but no price there is no loss in generality. 
The demand paths in the models above are continuous. Data from peak load pricing experiments will yield a time-series on $q$ and $r$ for a cross section of individuals $i=1, \ldots, N$. There is clearly a problem of estimating these continuous time models using discrete data. We cannot hope to identify a continuum of parameters (for example $\alpha(t)$ and $\beta(t)$ in the L.E.S. formulation) from this necessarily discrete sample without further assumptions. One possibility is to restrict the parameters of the utility function to be smooth and periodic. The cubic spline approach of Hendricks, et al., is an example of this approach for the "arbitrary demand function." Koenker and Hendricks are presently working on incorporating the smoothness restrictions in the L.F.S. and translog models. The second possibility which is almost universally used is to formulate the model in discrete time. Rather than estimating a demand path $q(t)$, electricity is viewed as different commodities which are indexed by the time of day that they are consumed. Demand over some arbitrary time interval is typically integrated to form these commodities (e.g., peak and off-peak hours).

Given the state of the art in estimaling continuous time models of electricity demand, it seems appropriate to carry out the analys is of the demonstration project data within the standard discrete time formulations.* There are some important lessons to be learned from the continuous time formulation which must be carried over to any discrete time analysis. Some of these are outlined below:

(1) How the "commodities" are defined may have a substantial impact on the results. In principle, they should be defined as narrowly as possible, i.e., integration over long periods of the day might be inappropriate. In particular, hours from non-adjacent pricing periods must tried.

*If time and resources permit, the cubic spline approach might be 
be treated as different commodities. Thus, when some experiments have more than one peak period during the day, consumption during each peak period must be treated separately.

(2) Consumption in any period depends on prices during a 11 other periods. If the unit of analys is is to be consumption during a particular rating period, consumption during that period will not only depend on prices during the other periods, but also the timing and length of the periods. In the discrete time framework, this means incorporating the concept of a "rate family," i.e., a series of prices with the same timing and length of periods during the day. Results obtained for one "rate. family" may not carry over to others.

\section{Discrete Time Models}

By far the most common approach to the analys is of electricity demand has been to choose an arbitrary form for the short run demand function for electricity without imposing the restrictions of neo-classical demand theory (see, e.g., Taylor). A typical formulation for the case when there are two rating periods (Peak and Off-peak) is

$$
\begin{aligned}
& Q_{\text {Peak }}=a+b_{1} P_{\text {Peak }}+b_{2} P_{\text {off-Peak }}+b_{3} \text { Income }+\sum_{i=4}^{J} b_{j} Z_{j} \\
& Q_{\text {Off-Peak }}=c+d_{1} P_{\text {Peak }}+d_{2} P_{0 f f-P e a k}+d_{3} \text { Income }+\sum_{j=4}^{J} d_{j} Z_{j}
\end{aligned}
$$

where $Z$ is a vector of stocks of appliances and other demographic characteristics. Sometimes the quantities are measured as expenditure shares and sometimes the equation is log-linear. The major advantage of this formulation is the ease of calculation.

A more general form for approximating this arbitrary demand function is to use a Taylor's series expansion. Ignoring any third order (or higher) effects this would mean incorporating interaction variables (i.e., between peak and off-peak prices) into the model given above. The problems involved in incorporating these second order effects are 
discussed in detail in the body of the text. It should be noted, however, that the "Taylor's series" approach is in fact more general than most of the work which has been done on electricity demand in the past.

Recently several researchers have attempted to analyze electricity consumption within the context of the discrete time L.E.S. and transiog models. These models have the advantage of incorporating some of the restrictions implied by neoclassical demand theory. They carry the disadvantage of difficulty in estimation. The models themselves and a discussion of each is given in the body of the text. 
Research Triangle Institute

P.O. Box 12194

Research Triangle Park, N.C. 27709 